\title{
Assessment of Materials Needs for Fusion Reactors
}

\author{
Compiled by
}

G. S. Allison

July 1976

Prepared for the Energy Research and Development Administration under Contract E(45-1):1830 
NOTICE

This report was prepared as an account of work sponsored by the United States Government. Neither the United States nor the Energy Research and Development Administration, nor any of their employees, nor any of their contractors, subcontractors, or their employees, makes any warranty, express or implied, or assumes any legal líability or responsibility for the accuracy, completeness or usefulness of any imformation, apparatus, product or process disclosed, or represents that its use would not infringe privately owned rights.

PACIFIC NORTHWEST LABORATORY

operated by

BATTELLE

for the

ENERGY RESEARCH AND DEVELOPMENT ADMINISTRATION

Under Contract E(45-1)-1830

Printed in the Unuted States of America Available from

National Technical Information Service

U.S. Department of Commerce

5285 Port Royal Road

Springfield, Virginia 22151

Price: Printed Copy \$7.75; Microfiche $\$ 2.25$ 
BNWL-1933

UC-20

ASSESSMENT OF MATERIALS NEEDS

FOR FUSION REACTORS

Compiled by

G. S. Allison

Major contributions by

E. S. Bartlett

July 1976

Battelle

Pacific Northwest Laboratories

Richland, Washington 99352 


\section{CONTENTS}

LIST OF FIGURES •

LIST OF TABLES

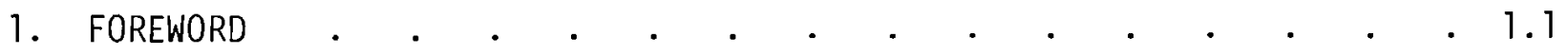

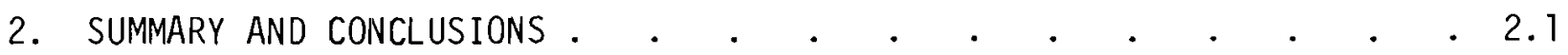

2.1 Status of Manufacturing . . . . . . . . . . . 2.3

2.1.1 Stainless Steel and Nickel Base Alloys . . . . . 2.4

2.1.2 SAP (Sintered A7uminum Product) . . . . . . . 2.5

2.1 .3 Refractory Metals . . . . . . . . . . . 2.5

2.2 Status of Resources . . . . . . . . . . . . . . . 2.7

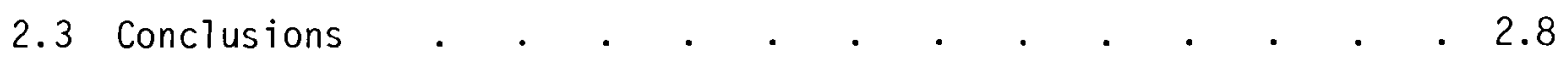

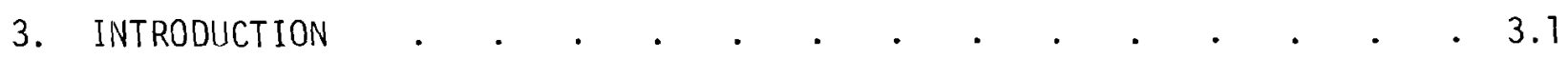

3.1 Status of Controlled Thermonuclear Power Technology . . . 3.1

3.2 Projected Power Base . . . . . . . . . . . . . 3.1

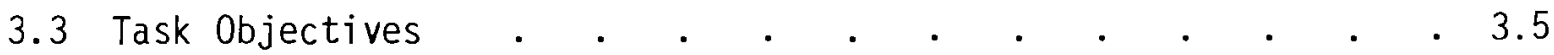

References for Section 3 .

4. CTR CONCEPT DESCRIPTIONS AND DEVELOPMENT OF MATERIAL
REQUIREMENTS..
..

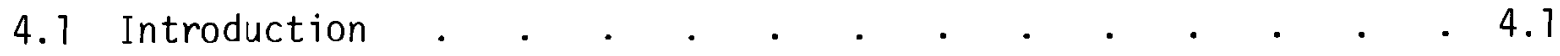

4.2 Generalized Systems Description . . . . . . . . 4.2

4.3 Fuels. . . . . . . . . . . . . . . . . . 4.5

4.4 Plasma Confinement . . . . . . . . . . . . . . 4.7

4.5 Conceptual Power Plant Designs . . . . . . . . . . . 4.7

4.5.1 Magnetic Confinement Designs . . . . . . . 4.10

4.5.2 Inertial Confinement Designs . . . . . . . 4.20

4.6 Construction Material Requirements . . . . . . . . 4.23

References for Section 4 . . . . . . . . . . . 4.44

5. PROJECTED MATERIAL/COMMODITY AVAILABILITY . • . • • • . 5.1

5.1 Introduction . . . . . . . . . . . . . . . . 5.1

5.2 Projected Domestic Demand: 2000-2020 A.D. . . . . . . 5.2

5.2.1 Domestic Demand Analysis . . . . . . . . 5.4

5.2.2 Capacity for Structural Material Manufacture • • . 5.9

5.2.3 Foreign Supply of Selected Commodities . . . . . 5.15 
5.3 Reserves/Resources . . . . . . . . . . . . . . . 5.21

5.4 Sintered Aluminum Product . . . . . . . . . . . 5.25

5.5 Resume of Forecast Material/Commodity Status . . . . . 5.26

References for Section 5 5 .

6. DETAILED EVALUATION OF SELECTED MATERIALS/COMMODITIES . • • • . 6.1

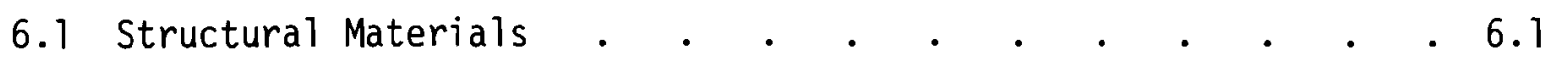

6.1 .1 Stainless Steel and Nickel Alloy . . . . . . . 6.1

6.1 .2 Refractory Metals . . . . . . . . . . . 6.10

6.2 Other Blanket and Shield Materials . . . . . . . . . . 6.22

6.2 .1 Boron . . . . . . . . . . . . . 6.22

6.2 .2 Beryllium . . . . . . . . . . . . . 6.23

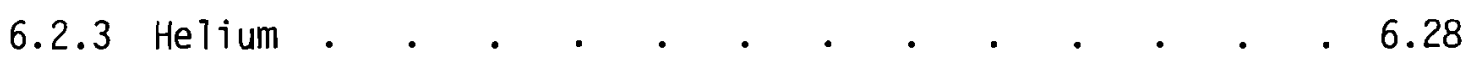

6.2 .4 Lithium . . . . . . . . . . . . . . . 6.30

6.2 .5 Lead . . . . . . . . . . . . 6.33

6.2 .6 Yttrium . . . . . . . . . . . . . . 6.34

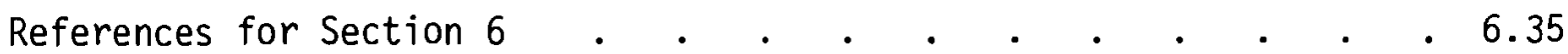




\section{LIST OF FIGURES}

3.1 United States Electricity Use, Historical and Forecasts 3.2

3.2 CTR Capacity Forecast $\quad 3.4$

4.1 Functional Relations of CTR Power Plant Systems 4.4

4.2 Thermally Averaged Reaction Rates for Various Fusion Fuels $\quad 4.6$

4.3 Cross Section View of UWMAK-I Fusion Reactor 4.11

$\begin{array}{lll}4.4 & \text { Section View of the PPPL Tokamak } & 4.15\end{array}$

4.5 Cross Section and Flow Schematic of the Wetted Wall 4.22

4.6 Cross Section of the Blascon Pressure Vessel and Lithium Vortex 4.22

4.7 Potential Fusion Power in the Period 2010-2030 4.35

\section{LIST OF TABLES}

2.1 CTR Nuclear Island Materials Summary 2.2

3.1 Installed Capacity $\left(G_{e}\right)$ at Beginning of Year 3.3

4.1 Material Requirements for CTR and LMFBR Power Plants 4.3

4.2 Major ERDA Fusion Research Efforts 4.8

4.3 Originators of Conceptual and Reference CTR Power Plant Design 4.9

4.4 CTR Power Plant Material Requirements - Construction 4.24

4.5 CTR Power Plant Material Requirements - Average Annual Replacement Quantities $\quad 4.26$

4.6 Normalized CTR Power Plant Material Requirements - Construction 4.27

4.7 Normalized CTR Power Plant Material Requirements - Average 4.28 Annual Replacement Quantities $\quad 4.28$

4.8 Materials Requirements - UWMAK-I Nuclear Island 4.30

4.9 Materials Requirements for Balance of Plant-UWMAK-I 4.31

4.10 Summary of Elemental Requirements for UWMAK-I $\quad 4.32$

4.11 Source of the Need for Critical Elements in the UWMAK-I
Reactor Facility

4.12 Materials Required for Construction of PPPL Tokamak Fusion
Reactor and Reactor Building 
4.13 Elemental Requirements for a CTR-Based Electrical Industry of $10^{6} \mathrm{MW}_{\mathrm{e}}$ Capacity

4.14 Elemental Requirements for UWMAK-I Tokamak 4.36

4.15 Elemental Requirements for Princeton Tokamak 4.37

4.16 Elemental Requirements for Oak Ridge Tokamak 4.38

4.17 Elemental Requirements for Los Alamos Theta Pinch 4.38

4.18 Elemental Requirements for Brookhaven Tokamak Blarket and Shield, Integrated to UWMAK-I Plant 4.39

4.19 Elementa? Requirements for Equal Contributions from Five Designs 4.40

4.20 Annual El emental Requirements for a Model CTR Industry Comprising Five Designs for Total Nominal Capacity of $1 \times 10^{6} \mathrm{MW}_{\mathrm{e}} \quad 4.41$

4.21 Annual Elemental Requirements for a Model CTR Industry Comprising Five Designs for Total Nominal Capacity of $1 \times 10^{6} \mathrm{MW}_{\mathrm{e}} \quad 4.42$

4.22 Annual Elemental Requirements for a Model CTR Industry Comprising Five Designs for Total Nominal Capacity of $1 \times 10^{6} \mathrm{MW}$

5.1 Demand for Elements Projected to the Year 2000 A.D. 5.5

5.2 CTR Demand Related to Industrial Supply Potential 5.7

5.3 Approximate Maximum Annual CTR Requirements (Year 2030) for Selected Materials of Manufacture, Model Industry, Equal Participation by Five Designs, $10^{6} \mathrm{MW}_{\mathrm{e}}$ Capacity

5.4 Adequacy of Reserves for Elements by "Model" CTR 5.22

5.5 Summary of Material Supply Capability in Response to Probable CTR Requirements 
4.13 Elemental Requirements for a CTR-Based Electrical Industry of $10^{6} \mathrm{MW}$ e Capacity

4.14 Elemental Requirements for UWMAK-I Tokamak

4.15 Elemental Requirements for Princeton Tokamak 4.37

4.16 Elemental Requirements for Oak Ridge Tokamak 4.38

4.17 Elemental Requirements for Los Alamos Theta Pinch 4.38

4.18 Elemental Requirements for Brookhaven Tokamak Blanket and Shield, Integrated to UWMAK-I Plant

4.19 Elemental Requirements for Equal Contributions from Five Designs 4.40

4.20 Annual Elemental Requirements for a Model CTR Industry Comprising Five Designs for Total Nominal Capacity of $1 \times 10^{6} \mathrm{MW}_{\mathrm{e}} \quad 4.41$

4.21 Annual Elemental Requirements for a Model CTR Industry Comprising Five Designs for Total Nominal Capacity of $1 \times 10^{6} \mathrm{MW}_{\mathrm{e}} 4.42$

4.22 Annual Elemental Requirements for a Model CTR Industry Comprising Five Designs for Total Nominal Capacity of $1 \times 10^{6} \mathrm{MW}_{\mathrm{e}} \quad 4.43$

5.1 Demand for Elements Projected to the Year 2000 A.D. 5.5

5.2 CTR Demand Related to Industrial Supply Potential 5.7

5.3 Approximate Maximum Annual CTR Requirements (Year 2030) for Selected Materials of Manufacture, Model Industry, Equal Participation by Five Designs, $10^{6} \mathrm{MW}_{\mathrm{e}}$ Capacity

5.4 Adequacy of Reserves for Elements by "Model" CTR

5.5 Summary of Material Supply Capability in Response to Probable CTR Requi rements 


\section{FOREWORD}

Controlled thermonuclear reactors (CTR) are expected to supply a significant portion of the power demand in the United States starting about the year 2010. CTR technology is currently in the conceptual design stage with no single design selected for development. It is the purpose of this study to evaluate current information on probable CTR structural material needs with an emphasis on identifying potentially critical problem areas which may limit fusion reactor construction. The main area of concern for this study is materials supply. This initial effort draws on current expertise within Battelle Memorial Institute, and ongoing industrial research by leading manufacturers involved in CTR development.

This study was conducted by Battelle, Pacific Northwest Laboratories, commoniy called Battelle-Northwest (BNW) for the United States Energy Research and Development Administration under Contract No. E(45-1)-1830, with the principal investigator G. S. Allison, Fuels and Materials Department.

Major contributions were made by E. S. Bartlett, Battelle Columbus Laboratories, in the area of materials manufacturing. Contributions by Dr. E. T. Hayes as a consultant are also gratefully acknowledged. 


\section{SUMMARY AND CONCLUSIONS}

This report has the goal of presenting for the CTR designer and material supplier potentially significant problem areas in materials manufacturing and in structural material resources projected for potential application in fusion power reactor construction. The projected material requirements are based on presently available bills-of-materials for conceptual CTR designs used for

constructing a hypothetical fusion power generating capacity of $10^{6} \mathrm{MW}_{\mathrm{e}}$ maturing exponentially over a 20 -year period. This generating capacity buildup was selected from the family of forecast curves shown in Section 3.

Table 2.1 is a summary of the projected elemental requirements, the ratio of these requirements to the projected total U.S. demand, and the salient problems currently identified with the CTR use of these elements. The projected requirements shown in this table are based upon a "model" industry, which is described in Section 4, and the estimated potential use of molybdenum, niobium, vanadium, and tantalum as blanket structural materials. These refractory structurals are included, even though not used in currently published conceptual designs, because there is a possibility that their use may be desirable at some point in the evolution of the CTR industry.

The highly developed state-of-the-art for conventional materials has prompted their almost exclusive use in current CTR conceptual designs, because this would create a minimum of component fabrication or material manufacturing problems. Along with the potential use of the refractory metal structurals come the probable major problems in their component fabrication technology and/or manufacturing capacity, which will occur because of their lesser degree of development and limited production. The initial efforts in assessing CTR component fabrication problems were, therefore, concentrated on assessing the state-of-the-art for Mo, Nb, V, and Ta. This was accomplished by means of the study conducted by McDonnell Douglas Astronautics CompanyEast under contract to Battelle-Northwest, which is reported in Refractory Metals Fabrication Technology as Applied to Fusion Reactors, BNWL-2053, July 1976. 
TABLE 2.1. CTR Nuclear Island Materials Summary

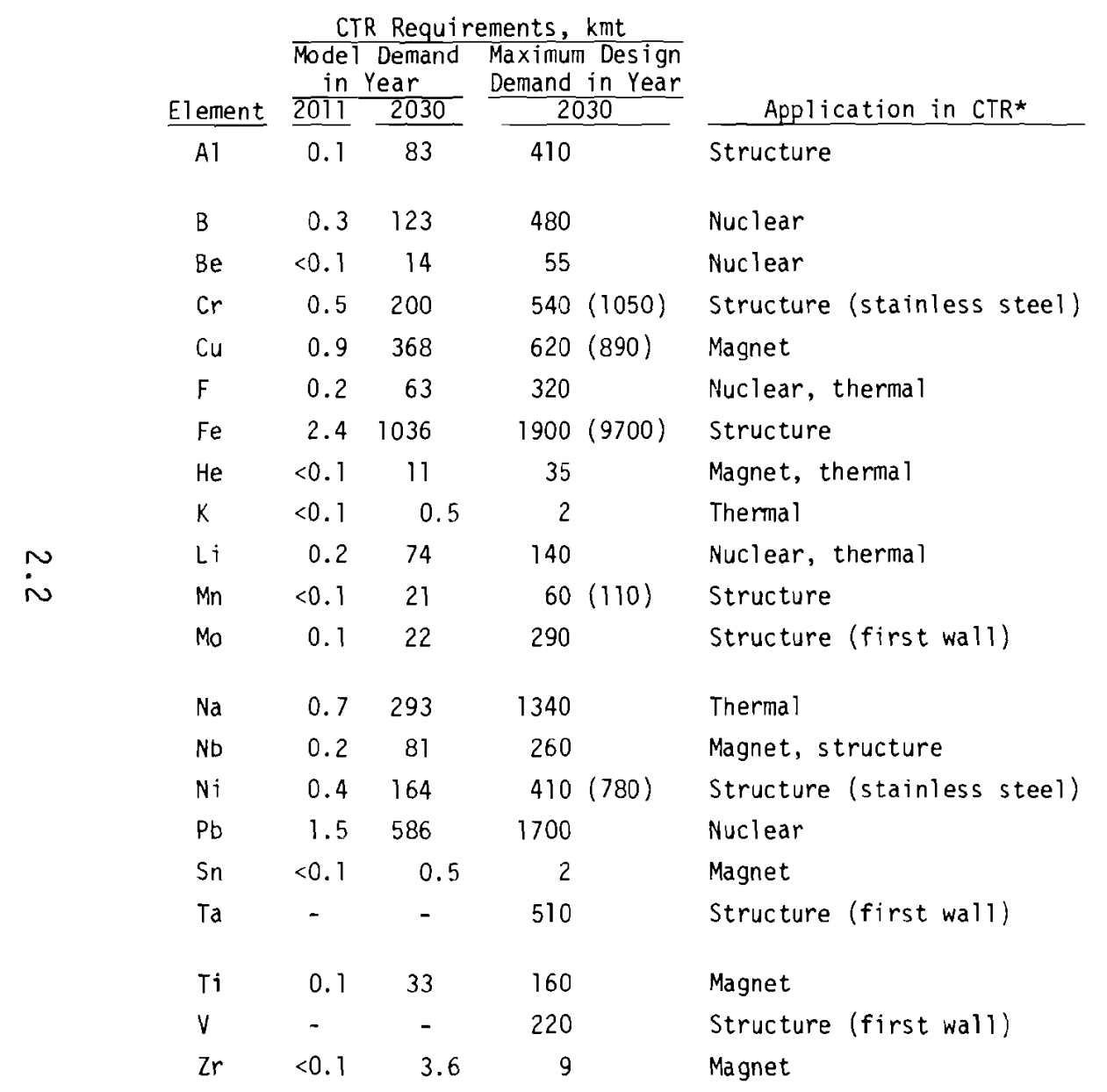

\begin{tabular}{|c|c|c|c|}
\hline \multirow[b]{2}{*}{$\begin{array}{l}\text { Potential Problems } \\
\text { in Manufacturing or Fabrication }\end{array}$} & \multicolumn{3}{|c|}{$\begin{array}{l}\text { Ratio of CTR Demand } \\
\text { to Total Domestic Demand }\end{array}$} \\
\hline & $\begin{array}{l}\text { Model } \\
2011 \\
\end{array}$ & $\frac{\text { in Year }}{2030}$ & $\begin{array}{c}\text { Maximum Design } \\
\text { in Year } \\
2030 \\
\end{array}$ \\
\hline \multirow{11}{*}{$\begin{array}{l}\text { SAP would require mfg. lead } \\
\text { time - joining must improve }\end{array}$} & $<<0.01$ & $<0.01$ & $<0.01$ \\
\hline & $<<0.01$ & 0.14 & 0.53 \\
\hline & $<0.04$ & 2.2 & 8.5 \\
\hline & $<<0.01$ & 0.08 & $0.21 \quad(0.42)$ \\
\hline & $<<0.01$ & $<0.01$ & $0.01 \quad(0.02)$ \\
\hline & $<<0.01$ & $<0.01$ & 0.04 \\
\hline & $<<0.01$ & $<0.01$ & $<0.01 \quad(0.05)$ \\
\hline & $<0.01$ & 0.32 & 1.0 \\
\hline & $<<0.01$ & $<<0.01$ & $<<0.01$ \\
\hline & 0.01 & 1.9 & 3.7 \\
\hline & $<<0.01$ & $<0.01$ & $0.02(0.03)$ \\
\hline \multirow{2}{*}{$\begin{array}{l}\text { Mfg. needs lead time - small } \\
\text { plate size - joining problem }\end{array}$} & $<<0.01$ & 0.09 & 1.2 \\
\hline & $<<0.01$ & $<<0.01$ & $<0.01$ \\
\hline \multirow[t]{4}{*}{ Mfg. needs lead time } & 0.01 & 2.3 & 7.2 \\
\hline & $<<0.01$ & 0.12 & $0.30(0.57)$ \\
\hline & $<<0.01$ & 0.09 & 0.26 \\
\hline & $<<0.01$ & $<0.01$ & 0.01 \\
\hline \multirow[t]{2}{*}{$\begin{array}{l}\text { Probably not enough Ta to } \\
\text { consider }\end{array}$} & - & - & 127 \\
\hline & $<<0.01$ & 0.01 & 0.06 \\
\hline \multirow[t]{2}{*}{ Whole industry must be built } & - & - & 1.6 \\
\hline & $<<0.01$ & 0.02 & 0.05 \\
\hline
\end{tabular}

NOTES: * Structure - Reactor Structure

Nuclear - Fuel, breeding, neutron multiplier, shielding, poison

Thermal - Cooling, thermal insulation, heat transfer

Magnet - Magnet winding, cooling 
The status of manufacturing, which for this report includes mining, refining, melting, and production of mill shapes, was studied primarily through personal contact with the affected industry. As with the component fabricability study, only the obvious and potentially major manufacturing problems were addressed in any great detai1. As the CTR industry matures the more obscure, less serious problems will be identified and dealt with.

A document of this type which is intended to be informative to both the fusion reactor designer and the materials supply industry snould include a minimum statement of the current and projected status of the resources for the materials of concern. To this end a cursory study of existing data was made to identify potential problems of CTR materials supply. Potentially major problems which were identified in this study are discussed.

\subsection{STATUS OF MANUFACTURING}

Materials and elements for which there is question regarding projected industrial capacity sufficient to meet possible CTR requirements include stainless steels, nickel base alloys, $S A F$, and the refractory metals Mo, Nb, $V$, and Ta. The nature of the potential impact of the CTR requirements for structural materials upon specific segments of the supplying industry varies according to the size and according to the technological and business aspects of the impacted industrial segments. Thus, at one end of the spectrum, CTR demands for stainless steel, although quite significant in terms of projected stainless steel production capacity, would be small--almost insignificant--in terms of the business aspects of the steel industry of which stainless and specialty steels are a part. In the other extreme, possible CTR demands for refractory metals would impact quite small and specialized industrial segments, possibly to the extent that the continued welfare of these industrial segments would be at the mercy of the CTR demands. In essence, CTR demands for structural refractory metals might require major restructuring of this industry's business operations, or even the creation of an industry where none currently exist. In the first case, industrial expansions to accommodate CTR demand would probably be routine and without a requirement for a guarantee premium 
by the CTR activity. In the later case, the CTR activity could well be required to assume a major portion of the business risk involved in terms of guaranteed long-term markets, capital risk insurance, or another equitable means of assurance.

Although the potential requirements for CTR materials will result in some pragmatic business decisions by industry in most cases, and may require some form of fiscal assurance in others, there appear to be no insurmountable barriers to sufficient production capacity to supply the demand for materials by a maturing CTR-based power industry. In most instances, it will probably be necessary for industry to preplan capacity growth rates to include CTR demands. Such preplanning will ordinarily require up to about 5 years' lead time, based upon discussions with industry representatives and experts versed in specific industrial economics.

\subsubsection{Stainless Steel and Nickel Base Alloys}

The maximum annual CTR demand for 304 and 316 stainless steels is estimated to be 1 Mmt* for the nuclear island alone, but about 3.5 Mmt for total plant requirement. Thus, nuclear island needs in years of maximum growth would be 25 to $30 \%$ of the projected stainless steel industry capacity, or would require a 25 to $30 \%$ increase in their capacity. As the necessity for this expansion would become apparent within the first few years of maturation, management of the growth should be routine. CTR balance-of-plant, and probably non-CTR based plant, requirements for austenitic stainless steels would approach the total industry output. However, even at a $2 X$ output requirement, adequate time for planning and expansion would be available. The model CTR demand for nickel-base alloys appears to be about one-tenth of the projected industry capacity. Thus, the domestic aspects of supply of stainless steel and nickel base alloy to meet CTR requirements in years of maximum demand is viewed as a problem that would be overcome with normal planning, and probably would not comprise a major CTR growth restraint.

\footnotetext{
* Mega Metric Tons
} 


\subsubsection{SAP (Sintered Aluminum Product)}

Recent improvements in technology based on exploratory production of high strength powder metallurgy alloys and upon developments in pigment production indicated that improved SAP in larger size ingots (such as might be required by the Brookhaven National Laboratory CTR design) could now be made in quantity with about 2 years lead time. The quantities required should pose no problems, presuming adequate commercial incentive and not too stringent purity requirements.

\subsubsection{Refractory Metals}

Niobium manufacturing technology is well established and indications are that the industry could easily meet the demands of a CTR industry for structural forms (including $\mathrm{Nb}-\mathrm{Ti}$ wire or $\mathrm{Nb}_{3} \mathrm{Sn}$ - containing product).

Molybdenum manufacturing technology is geared to the supply of relatively thin-gage products in limited size ranges (e.g., maximum sheet dimension is about $60 \mathrm{~cm}$ ) as required to meet present and at least near-future markets. Large-dimension plate manufacture is not in the scene. It may be that a selected mode? (UWMink III) will require plates in thicknesses up to $1.3 \mathrm{~cm}$, and in widths exceeding the approximate $60 \mathrm{~cm}$ limitations of present mi11 equipment for Mo-TZM. Presuming that this model becomes established as technically and economically viable, the scale-up of Mo alloy mill capability could run to tens of millions of dollars for capitalization requirements that would have to be justified in terms of market guarantee. This requirement would be amplified if larger melting and extrusion facilities were needed to provide, say $1.3 \mathrm{~cm}$-thick plate with mechanical properties similar to those presently obtained on 0.1 to $0.2 \mathrm{~cm}$-thick sheet. In comparison with plant and equipment costs required to gear up to large, thick plate production, the cost of optimizing the manufacturing technology would be relatively minor.

To meet the model CTR demand, an annual rate of growth in the Mo industry capacity of about $10 \%$ (rather than a presumed $6.5 \%$ ) rate would be required for the first 10 years, and about $8 \%$ for the "final" 10 years of 
CTR maturation. The less probable case of single CTR design requirements would mandate annual growth rates of about $20 \%$ for the first 8 years of CTR buildup, tapering off to about $8 \%$ after 17 to 18 years. Presuming longrange accuracy of relatively short-range industry forecasts of Mo metal product demand (i.e., assuming that industrial capacity for Mo mill products attains roughly $10 \mathrm{kmt}$ by the year 2000 to meet ex-CTR demand) a planned increase in the rate of growth to meet "model" CTR requirements would probably be readily accommodated by industry. The higher rates of growth required for several years for the less-likely, single "Mo machine" CTR base would involve appreciably greater capital risk which might be difficult for industry to justify, as the Mo mil1 product industry would become dominated by the market for CTR demand after about 5 years. In all probability some type of market guarantee would be necessary to induce the industry to accept a capitalization program needed to expand mill product facilities.

Vanadium has not yet been considered for structural application in CTR nuclear islands to the extent necessary to define potential material requirements. Vanadium alloys are not capable of the higher operating temperature potential of either Nb or Mo but their potential exceeds those of austenitic stainless steels, and probably at least some of the readily-fabricated nickel-base materials. Vanadium is especially attractive from the standpoint of low activation in the CTR environment.

For want of quantitative definition, amounts of $V$ required in a hypothetical CTR design are assumed to be one-half of the quantities assumed for Mo, based on lower density for $V$. Thus, "model" requirements for $V$ alloys, as hypothetical designs comprising one-fifth of a developing CTR industry, are:

\begin{tabular}{cc} 
Year & $\begin{array}{c}\text { Vanadium Alloy } \\
\text { Requirement, } \\
\text { kmt/year }\end{array}$ \\
\hline 2011 & 0.15 \\
2015 & 1.2 \\
2020 & 3.9 \\
2025 & 6.9 \\
2030 & 10.8 \\
Cumulative & 90
\end{tabular}


Limited studies to develop $V$ alloys for potential aerospace and fission reactor use were carried out in the 1960s. Westinghouse developed and produced pilot quantities (principally tubing), of "Vanstar" alloys, which was the closest approach to the development of a $V$ alloy mill product industry. This work, along with studies at Illinois Institute of Technology Research Institute (IITRI--then Armour Research Foundation), was important in demonstrating that the establishment of a $V$ alloy industry is technically viable.

Because there is no present market for $V$ alloy mill products, there is no $V$ alloy mill product industry as such. However, the technology exists and plant facilities used in the production of Ta and Nb alloys are probably amenable also to the fabrication of $V$ alloys. Should markets develop to warrant the establishing of a $V$ alloy mill product industry, such an industry would certainly come into existence.

A deterring technological aspect might be the relatively limited state of knowledge relating to $V$ alloy behavior as a function of alloy content and over a broad spectrum of environmental conditions. Most $V$ alloy development studies were directed towards specific targets, and comprehension of alloy behavior is considerably more restricted for $V$ than for $\mathrm{Nb}$, Mo, or Ta, for example. If $V$ alloys are to be seriously considered as an important CTR material of construction, specific alloy and manufacturing process development efforts directed towards specific CTR needs should be initiated within the next few years to ensure the optimum use of $V$ alloys in CTR machines. Tantalum is not considered for structural purposes because of resource limitations.

\subsection{STATUS OF RESOURCES}

Currently available data on CTR materials resources were briefly surveyed to expose any glaring gaps between potential demand and probable resources. This is not, nor was it intended to be, a resource assessment, but rather an attempt to flag potentially serious problems of supply for the designer. 
Among the most critical shortfall materials recognized in this study are beryllium and helium. These must certainly be carefully managed to preserve a viable CTR industry operating at a reasonable cost. Tantalum is also a short resource material with certain characteristics which suggest its attractiveness as a structural material for CTR nuclear islands. However, current reserves of $50 \mathrm{kmt}$ are about sufficient to meet projected cumulative world demand to the year 2000, and are totally inadequate to supply any significant (e.g., one-fifth of CTR industry based on Ta structures) CTR structural usage. Although the discovery of new types of Ta deposits as extensive as the pyrochlor deposits of Nb would possibly permit consideration of Ta for CTR structural use, there is no indication that such discoveries will occur. For this reason, it is improbable that the application of Ta as a CTR structural material will ever be realistic.

Materials which have limited United States controlled resources must be carefully applied because of the political nature of their supply. Chromium and $\mathrm{Nb}$ are two outstanding examples of resources with potential political shortages.

\subsection{CONCLUSIONS}

Most material requirements to meet the demands of a maturing CTRbased power industry are forecast to be available within a routine framework of planning for expansion by the supplying industries. There are, however, some projected material manufacturing and supply constraints that will deserve more detailed consideration as the design and material scenarios of a developing fusion reactor power industry become better defined. The principal conclusions resulting from this materials overview are as follows:

- For carbon, alloy, and stainless steels, nickel base alloys, boron, copper, fluorine, mercury, potassium, sodium, niobium, lead, tin, titanium, yttrium, and zirconium, no serious material constraints to the potential growth of a CTR-based power industry are foreseen. Where notable increases in industrial capacity would be required as CTR demand is projected to grow, these increases could readily be accommodated by more or less routine planning within the respective industries. 
(The following conclusions reflect findings relative to potentially serious manufacturing technology constraints.)

- Recent information suggests that Mo alloy flat rolled products in thicknesses up to about $1.3 \mathrm{~cm}$ may be required. Present technology has not demonstrated that the properties of such thick sections can be made to match those of thin-gage sheet. If designers cannot accommodate currently available plate properties in Mo-TZM (for which data are sparse), then manufacturing process development studies will be required.

- A "minimum-activation" approach using aluminum as the primary blanket structural may require special high purity aluminum, which, with current technology, would be expensive. One producer is known to be conducting research on less expensive, high-purity aluminum. Depending upon the success of this, additional research may be required. A7so, if designs using 5000 or 6000 series aluminum alloys are promising, a potential problem with strength (which in part accrues to "impurities") will require alloy development studies.

- In comparison with other structural materials considered in present conceptual CTR technology, experience in the manufacturing of $V$ alloys with mechanical property ranges available is rather modest. Present technology is sufficient to indicate that this 7 imited experience will not be a major constraint, but research and development will be required to establish $\mathrm{V}$ alloy technology for the shapes and forms required for potential CTR service.

(The following conclusions relate to possible constraints as reflected in limits of manufacturing capacity.)

- The inclusion in a CTR design scenario of a significant fraction of the growing industry calling for substantial amounts of beryllium (e.g., as in the PPPL or UWMAK II concepts) over an extended period of time would require major expansion of beryllium-producing facilities. Although the projected maturation period (20 years) would be sufficient for the industry to accommodate the required expansion (assuming the 
development of sufficient ore reserves and the availability of capital), CTR requirements would dominate the market for beryllium. Firm assurance of a continuing market would be a necessary ingredient in the required industrial expansion. In the more likely case that beryllium demand would peak for a short period during growth of a CTR industry, this demand might best be accommodated by stockpiling for several years prior to the years of peak demand. A detailed technical economic analysis geared to the most probable need for beryllium in a maturing CTR-based industry should be an item for study as the CTR growth scenario becomes more firm.

- The demand for 1 ithium in the breeding blankets of DT-fueled CTR machines would dominate the lithium market as it is projected to grow during the considered maturation period. As in the case of beryllium, major industrial expansion would be required and could be accommodated within the presently considered growth scenario. This could only be justified with firm assurance of continued market support by the CTR industry. A further complication concerns the mix of natural and enriched 1 ithium that would be required. Major requirements for ${ }^{6} L_{i}$ in a developing CTR industry could result in a glut of ${ }^{7} \mathrm{Li}$. To moderate this potential problem, it has been suggested that the separation of ${ }^{6} \mathrm{Li}$ from all lithium production be initiated as soon as possible to build an inventory of this valuable isotope against the time when it will be needed by a maturing DT-based fusion industry.

- Industrial capacity for the manufacture of Mo metal would only be a problem in the event that a Mo-alloy-intensive design, such as UWMAK III, were to provide a large fraction of a CTR growth scenario. UWMAK III data were not available for inclusion in the modeling conducted in this study. In the extreme case of a CTR industry based on the UWMAK III design, a lead period on the order of 10 to 20 years (e.g., starting in about the year 2000) would be required to meet the CTR demand, according to industry representatives. Mine development costs running to hundreds of millions of dollars and mi11-product manufacturing expansion 
(if wide plate is required) in the tens of millions of dollars would be necessary. These capital expenditures would have to be justified by the promise of market return.

- Material forms or amounts required by a maturing CTR industry for boron, potassium, sodium, niobium, and yttrium appreciably exceed the projected ex-CTR demands for the specific material requirements. However, discussions with various industry representatives and commodity specialists indicated that any constraints to the supply of these materials in the forms required would be minor, and could readily be accommodated by industry on a quick turnaround basis ( 1 or 2 years) when the CTR demands become apparent and firm.

(The following conclusions reflect findings relative to material/commodity resources and reserves.)

- A probable CTR demand for beryllium exceeds the best estimate for current world reserves. The prospects for discovery of additional beryllium reserves to meet this demand are quite uncertain. Additional detailed consideration of the realistic level of need for beryllium in a maturing CTR industry is warranted to determine whether the true need is compatible with known reserves and/or possible additional resources.

- Because no conceptual design has specified the structural use of Ta, this material was not considered in detail. However, it is clear that world Ta reserves are very small in comparison with hypothetical CTR demand if a significant fraction of the maturing industry were to require major use of structural Ta (e.g., approaching the use of Mo in UWMAK III).

- The apparent demand for lithium by the developing CTR industry seems well within the potential supply from reserves. However, if this demand were to include a major requirement for ${ }^{6} \mathrm{Li}$, current reserves could prove inadequate. Additional definition of requirements for enriched lithium should be undertaken. 
- The demand for helium presents a special case. In terms of currently known reserves and probable additional resources, potential CTR demand for helium is modest. However, reserves contained in natural gas are being wasted, and by the time helium may be needed to support a CTR industry, the problem will be acute. The recovery of helium from the atmosphere will be expensive and energy consumptive. Three possible events could reduce the severity of this pressing problem:

(1) Reinstitution of the helium conservancy act

(2) The development of superconductors that would operate in liquid hydrogen

(3) The unexpected discovery of additional helium reserves of significance.

- For several other materials, projected rates of ex-CTR consumption would exhaust current reserves. In each case, however, continued development of reserves is expected to keep pace with consumption. In some cases, added reserves will be of different grades, and technology modification and/or adjusted market prices will be required, but material supply will be maintained.

- Reliance of the United States upon foreign supply is a factor for several commodities that would be in demand by a growing CTR industry. These include aluminum, chromium, fluorine, manganese, niobium, nickel, tin, tantalum and others to greater or lesser extents. Of these, chromium is presently considered the most precarious in terms of potential political instabilities. There is little current concern in regard to the near-term supply of other foreign material resources, although cartelization poses somewhat of an economic threat in the case of some commodities. In the long range, the vicissitudes of international politics are difficult to predict, and one can only expect that future equitable global allocations of resources and wealth will not seriously impair the growth of a major segment of any one nation's economy. 


\section{INTRODUCTION}

\subsection{STATUS OF CONTROLLED THERMONUCLEAR POWER TECHNOLOGY}

The physics involved in the generation of power by a controlled thermonuclear reaction have been demonstrated in several large experiments both in the United States and abroad. The United States Energy Research and Development Agency has supported fusion research and development programs at various Universities, National Laboratories and contract research and development laboratories throughout the country. Some of these programs have been devoted to conceptual engineering designs for Tokamak, theta-pinch, mirror, and laser fusion power reactors. These designs, which are described in general terms in Section 4 of this report, are used as one of the bases for projecting the construction materials required for generating fusion power. There are several of these conceptual design studies and each calls for a slightly different set of materials of construction. Therefore, since no single design can be selected as a base, they loosely define a rather broad spectrum of materials which might be employed.

\subsection{PROJECTED POWER BASE}

The second parameter, or base, required to project the construction materials needed to support a fusion power generating capacity is a forecast of the amount of power to be generated by fusion reactors. There have been many electricity consumption forecasts made in the past. A11 were based in some way on historical experience. A study of these forecasts was made for presentation in an environmental study by Hartley. (1) The four forecasts shown in Figure 3.1 were selected and projected to the year 2040 to be used for projecting CTR generating capacity. An analysis of how the CTR would fit into this power use pattern was performed and presented as the six cases shown in Table 3.1, and plotted in Figure 3.2. The portion of Case 5 between 2010 and 2030 was selected as the base used in this report for projecting materials. This case calls for a build-up exponentially from 0 to $10^{6}$ Mwe over the 20 -year period. 


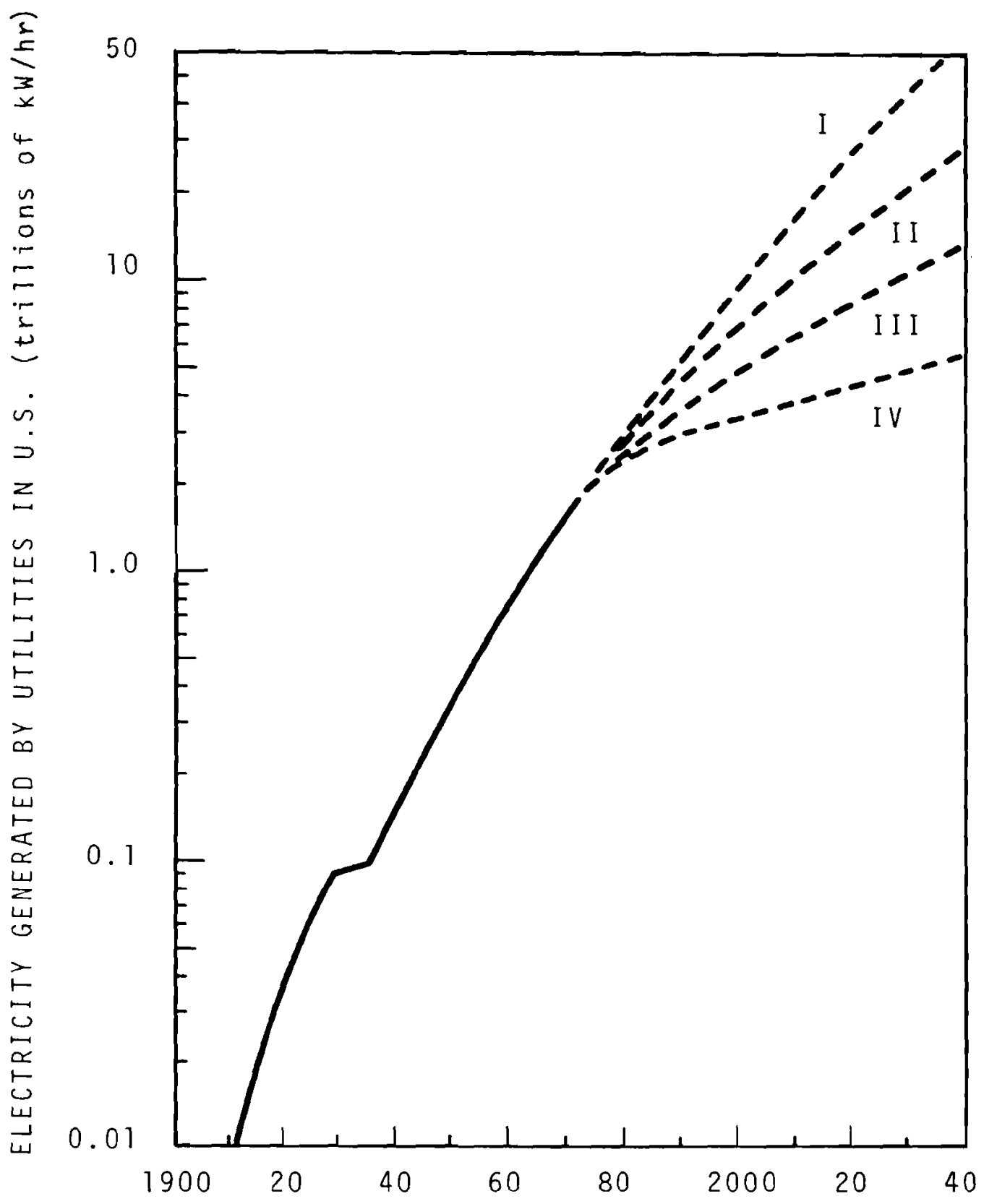

FIGURE 3.1. United States Electricity Use, Historical and Forecasts 
TABLE 3.1. Installed Capacity $\left(\mathrm{GW}_{\mathrm{e}}\right)$ at Beginning of Year

\begin{tabular}{|c|c|c|c|c|c|c|}
\hline Year & $\begin{array}{l}\text { Light } \\
\text { Water } \\
\text { Reactor } \\
\text { (LWR) } \\
\end{array}$ & $\begin{array}{l}\text { High } \\
\text { Temperature } \\
\text { Gas Reactor } \\
\text { (HTGR) }\end{array}$ & $\begin{array}{c}\text { Liquid Metal } \\
\text { Fast Breeder } \\
\text { Reactor } \\
\text { (LMFBR) } \\
\end{array}$ & $\begin{array}{l}\text { Controlled } \\
\text { Thermonuclear } \\
\text { Reactor } \\
\text { (CTR) } \\
\end{array}$ & Fossil & Total \\
\hline $\begin{array}{l}1980 \\
1990 \\
2000 \\
2010 \\
2020 \\
2030 \\
2040\end{array}$ & $\begin{array}{r}74 \\
426 \\
929 \\
1195 \\
1104 \\
860 \\
784\end{array}$ & $\begin{array}{c}0.33 \\
33 \\
123 \\
185 \\
648 \\
1397 \\
1473\end{array}$ & $\begin{array}{c}0.4 \\
30 \\
692 \\
1709 \\
1920 \\
1306\end{array}$ & $\begin{array}{r}62 \\
2331 \\
8277\end{array}$ & $\begin{array}{r}387 \\
454 \\
636 \\
1004 \\
1725 \\
2090 \\
2119\end{array}$ & $\begin{array}{c}461.3 \\
913.4 \\
1718 \\
3076 \\
5247 \\
8598 \\
13959\end{array}$ \\
\hline $\begin{array}{l}1980 \\
1990 \\
2000 \\
2010 \\
2020 \\
2030 \\
2040\end{array}$ & $\begin{array}{r}74 \\
354 \\
727 \\
903 \\
823 \\
648 \\
601\end{array}$ & $\begin{array}{l}0.33 \\
32 \\
83 \\
183 \\
424 \\
678 \\
654\end{array}$ & $\begin{array}{c}0.4 \\
31 \\
406 \\
899 \\
1038 \\
710\end{array}$ & $\begin{array}{r}62 \\
897 \\
2807\end{array}$ & $\begin{array}{l}345 \\
355 \\
418 \\
448 \\
620 \\
743 \\
738\end{array}$ & $\begin{array}{l}419.3 \\
741.4 \\
1259 \\
1940 \\
2828 \\
4004 \\
5510\end{array}$ \\
\hline $\begin{array}{l}1980 \\
1990 \\
2000 \\
2010 \\
2020 \\
2030 \\
2040\end{array}$ & $\begin{array}{r}66 \\
214 \\
430 \\
488 \\
446 \\
335 \\
320\end{array}$ & $\begin{array}{l}0.33 \\
21 \\
64 \\
219 \\
334 \\
343 \\
226\end{array}$ & $\begin{array}{l}0.4 \\
30 \\
174 \\
373 \\
425 \\
330\end{array}$ & $\begin{array}{r}62 \\
547 \\
1300\end{array}$ & $\begin{array}{l}296 \\
282 \\
283 \\
241 \\
277 \\
290 \\
286\end{array}$ & $\begin{array}{l}362.3 \\
517.4 \\
807 \\
1122 \\
1492 \\
1940 \\
2462\end{array}$ \\
\hline $\begin{array}{l}1980 \\
1990 \\
2000 \\
2010 \\
2020 \\
2030 \\
2040\end{array}$ & $\begin{array}{r}66 \\
191 \\
336 \\
369 \\
328 \\
265 \\
252\end{array}$ & $\begin{array}{l}0.33 \\
14 \\
39 \\
130 \\
125 \\
105 \\
24\end{array}$ & $\begin{array}{l}0.4 \\
6 \\
24 \\
107 \\
142 \\
135\end{array}$ & $\begin{array}{r}37 \\
172 \\
392\end{array}$ & $\begin{array}{r}265 \\
205 \\
174 \\
99 \\
106 \\
107 \\
93\end{array}$ & $\begin{array}{l}331 \\
411 \\
555 \\
622 \\
703 \\
791 \\
896\end{array}$ \\
\hline $\begin{array}{l}1980 \\
1990 \\
2000 \\
2010 \\
2020 \\
2030 \\
2040\end{array}$ & $\begin{array}{r}74 \\
356 \\
729 \\
910 \\
828 \\
653 \\
601\end{array}$ & $\begin{array}{l}0.33 \\
32 \\
83 \\
181 \\
418 \\
677 \\
630\end{array}$ & $\begin{array}{c}0.4 \\
31 \\
407 \\
900 \\
1033 \\
704\end{array}$ & $\begin{array}{r}62 \\
897 \\
2907\end{array}$ & $\begin{array}{l}345 \\
353 \\
416 \\
443 \\
619 \\
743 \\
668\end{array}$ & $\begin{array}{l}419.3 \\
741.4 \\
1259 \\
1940 \\
2828 \\
4003 \\
5510\end{array}$ \\
\hline $\begin{array}{l}1980 \\
1990 \\
2000 \\
2010 \\
2020 \\
2030 \\
2040\end{array}$ & $\begin{array}{r}74 \\
356 \\
730 \\
913 \\
833 \\
658 \\
606\end{array}$ & $\begin{array}{l}0.33 \\
32 \\
83 \\
138 \\
151 \\
417 \\
658\end{array}$ & $\begin{array}{c}0.4 \\
30 \\
448 \\
1235 \\
2128 \\
3337\end{array}$ & & $\begin{array}{l}345 \\
353 \\
415 \\
441 \\
609 \\
800 \\
909\end{array}$ & $\begin{array}{l}419.3 \\
741.4 \\
1258 \\
1940 \\
2828 \\
4003 \\
5510\end{array}$ \\
\hline
\end{tabular}




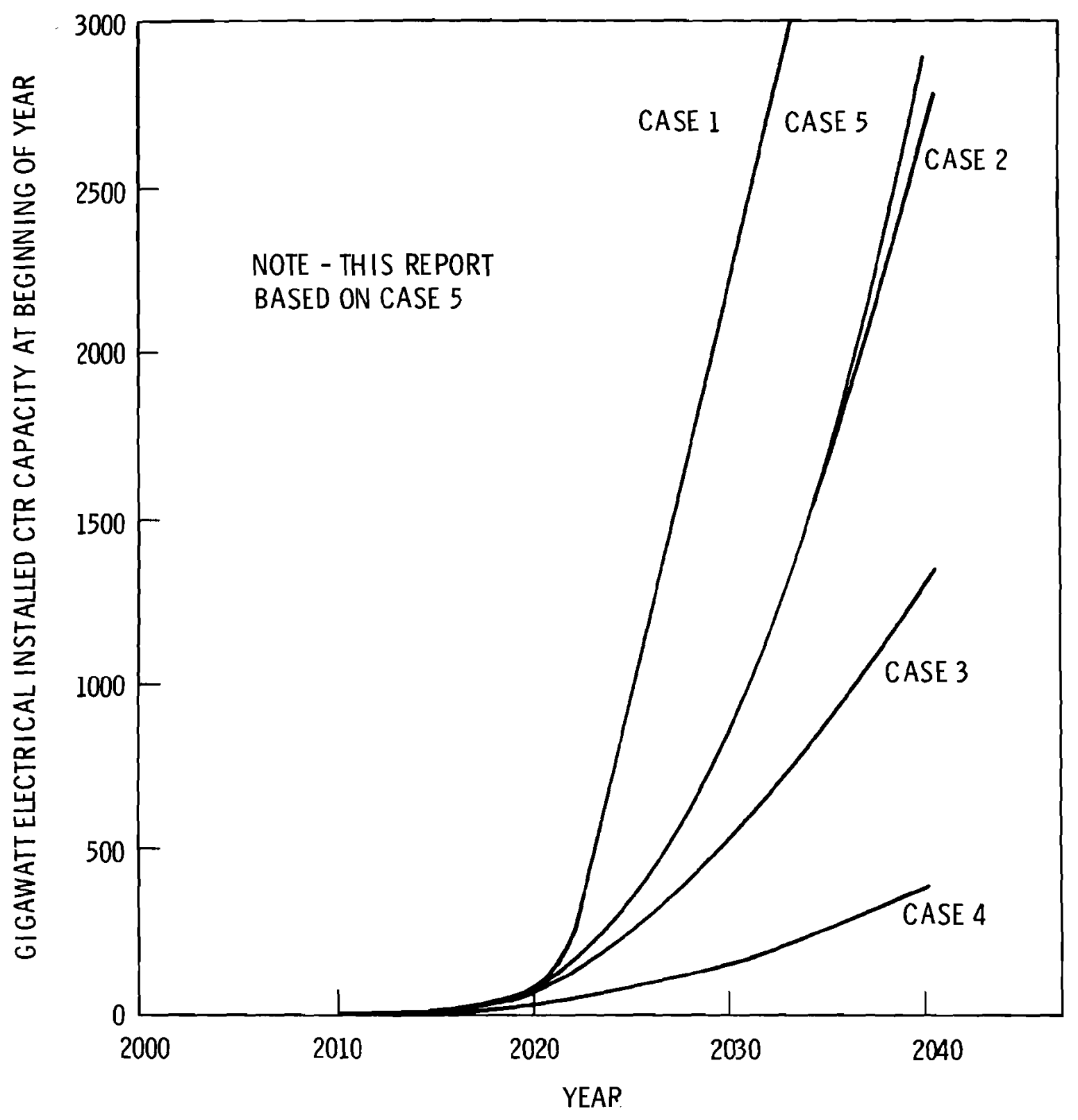

FIGURE 3.2. CTR Capacity Forecast 
Only those materials which are peculiar to the nuclear portion of the plant which delivers the thermal energy to the conventional electrical generation plant are considered in this projection. It is assumed that the devices used to convert the thermal energy to electrical energy will be conventional steam plants and common to all fusion power generation devices, and therefore will not be considered.

This study makes no attempt to predict the mix of the designs used to build up the projected fusion power generation capacity, but undertakes only to identify and emphasize potentialiy critical problem areas, which will require more intensive study to identify limits to fusion reactor construction.

\subsection{TASK OBJECTIVES}

The objectives of this study are:

- Collect potential material requirements from all conceptual designs into single source.

- Project the material quantities required for CiR electrical generating plants to meet a forecasted CTR electrical power demand.

- Study the potential problems in material manufacturing and supply to add to the data basis used in selecting materials for piloting in intermediate fusion devices such as FERF, EPRs, and DEMO.

\section{REFERENCES FOR SECTION 3}

1. J. N. Hartley, L. E. Erickson, R. L. Engel, and T. J. Foley, Materials "Availability" for Fusion Reactor Construction, BNWL-2016, BattelleNorthwest, Richland, WA, July 1976. 


\section{CTR CONCEPT DESCRIPTIONS AND DEVELOPMENT OF MATERIAL REQUIREMENTS}

\subsection{INTRODUCTION}

This section considers the fabrication and supply aspects for the materials required to construct the nuclear islands of fusion power plants. There are, of course, several concepts for fusion power generation in varying degrees of advancement of design details. Only those concepts which have advanced to the point of having a somewhat firmed-up bill-of-materials published are considered here. Others will be added as they become available. It is felt that the designs used herein as a basis for CTR materials fabrication and supply studies cover a broad enough range to present most if not all the problems to be faced by CTR construction in the future.

It must be recognized that the materials requirements presented herein are of a preliminary nature and, therefore, subject to change at a rate depending upon the degree of advancement of the design concept from which they were taken. The older and firmer the design concept is, the firmer and more detailed the material requirements are.

Several material and design problems that will be encountered will be unique to the considered CTR industry. In general, these relate to: 1) harnessing the power contained in $14 \mathrm{MeV}$ neutrons in structural systems designed to survive the expected fluences for significant periods, 2) the containment and control of the plasma fuel core, which in the more advanced torroidal designs is accomplished by very large magnet structures, and 3) the extraction of heat and continuous processing of the transfer media to recover fuel values that will be bred in the blanket. Major requirements for materials will be: 1) in the construction of piants and 2) in periodic replacement of first wall and at least portions of the blanket structures. Several CTR machine designs have been conceived to the point where bills-of-materials have been drawn up. The power plants derived from these machine concepts are large, ranging from about 500 to $5000 \mathrm{MWe}$ per plant. The material requirements are varied according to design specifics, but run to tens of metric tons per $\mathrm{MW}_{\mathrm{e}}$. For typical plants, large tonnages of structural and 
breeding-blanket materials will be needed. The projected abilities of industry to provide the CTR materials demand is one of the aspects examined in this study.

CTR power plants are expected to be capital and material intensive when compared with fission reactor power plants, due to complex structure and low power density. In Table 4.1 the material requirements for various CTR designs are compared with those of a liquid metal fast breeder reactor power plant. It should be noted that several of the CTR designs have evolved considerably since tabulations were prepared; all will doubtless change in the future. This table is based on preliminary information and is presented for comparison of magnitudes of materials only. More complete and up-to-date materials data where available are presented in later discussions.

Brief descriptions of some of the more complete reactor conceptual designs are presented to give the reader some idea of the wide variation in the type and degree of the problems of fabrication and supply.

\subsection{GENERALIZED SYSTEMS DESCRIPTION}

Reactions which occur between light nuclei and liberate energy as a result of rearrangement of the nuclei are commonly called fusion reactions. In order for such reactions to occur, the interacting nuclei must collide with sufficient energy to overcome the repulsive forces between them. When the energy of collision is the energy of random thermal motions of the nuclei, the reaction is called thermonuclear. A controlled thermonuclear reactor, then, is a device for achieving the release of energy by thermonuclear fusion in a controlled manner.

The energy released in fusion reactions comes from a conversion of mass to energy--the mass of the products of the reaction is smaller than the mass of the colliding nuclei, and $\Delta E=(\Delta m) c^{2}$ as shown by Einstein. This energy is carried off primarily as the kinetic energy of the reaction product particles. The release, collection, and conversion of this energy to electricity is the function of a CTR power plant. 


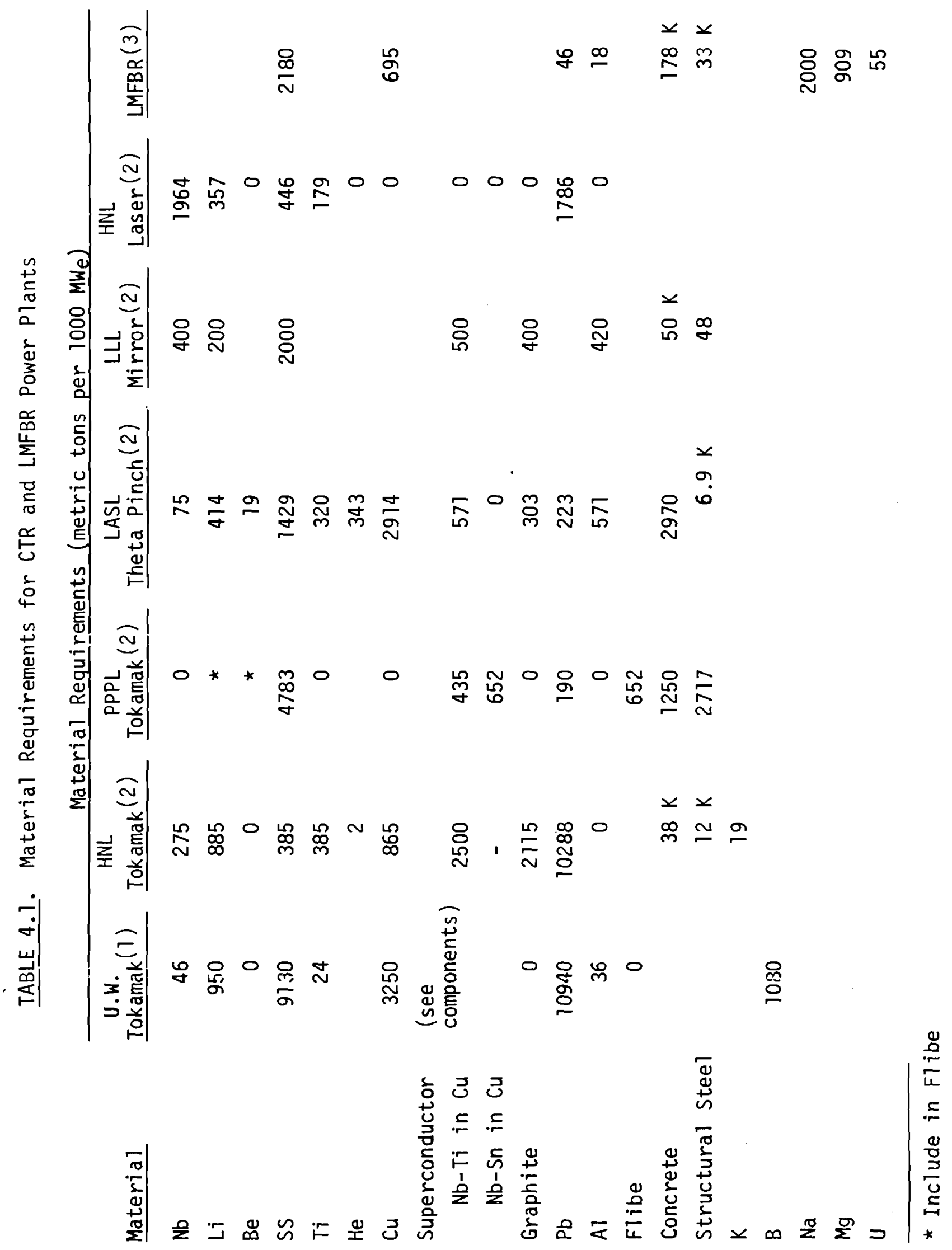


Both charged particles (atomic nuclei) and uncharged particles (neutrons) can be produced in fusion reactions. Electric and magnetic fields can be used to direct the motions of charged particles and to extract electrical energy from them (direct conversion). Neutron kinetic energy, however, usually can only be collected as heat generated by collisions of the neutrons with material placed in a blanket around the chamber in which the neutrons are released. Conversion of heat energy to useful work (electricity) requires a heat engine operating in a thermodynamic cycle such as conventional steam turbine plants.

For the purpose of this general description, a CTR power plant may be considered to consist of two complementary sets of systems--one set that produces, confines and maintains the fusioning plasma, and one set that captures the reaction products, extracts their kinetic energy and ultimately produces electricity. In addition, two feedback mechanisms probably will be necessary to reduce fuel cycle costs and radionuclide releases. First, unburned plasma will be collected, along with reaction products, for return to the plasma fuel system. Second, for deuterium-tritium, the fuel with the greatest likelihood of use in first generation CTRs, it is necessary to produce tritium via a nuclear reaction induced by neutrons from the fusion reaction. This tritium must also be returned to the fuel system. A diagram indicating the functional relations of the primary CiR power plant systems is shown in Figure 4.1.

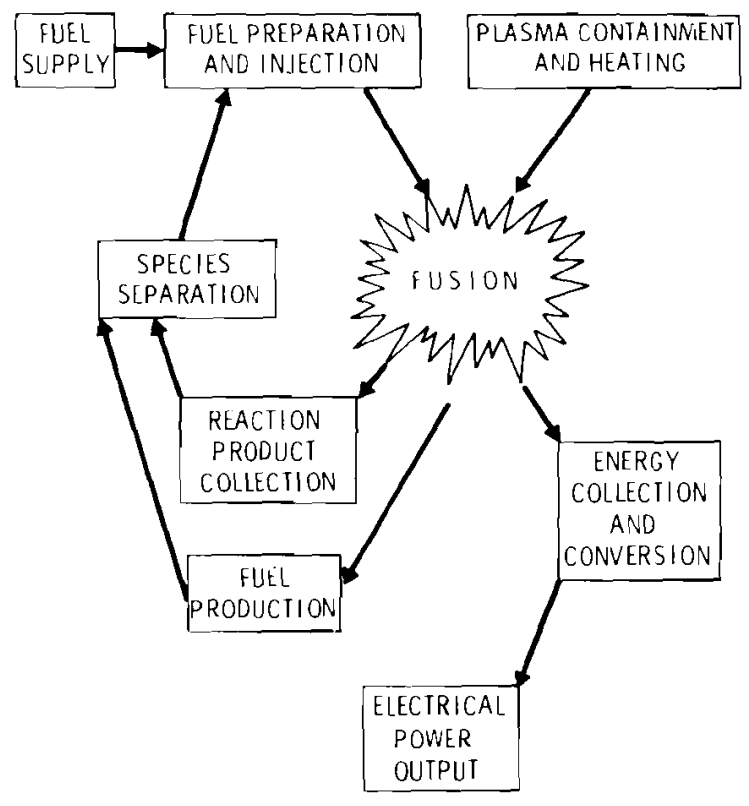

FIGURE 4.1. Functional Relations of CTR Power Plant Systems 


\section{$4.3 \quad$ FUELS}

In order for the rate of fusion energy production in a plasma to equal the rate of energy input to the plasma (breakeven), high values of plasma density and temperature are required. Due to the extreme difficulty of achieving adequate plasma conditions, it is quite likely that the fuel used in the first commercial reactors will be that with the least stringent plasma requirements--deuterium and tritium. The reaction and its products are

$$
D+T \rightarrow{ }^{4} \mathrm{He}+n+17.6 \mathrm{MeV} .
$$

Fuels considered for power plant use must be obtainable in large quantities at a relatively low cost per unit of electricity produced. While natural supplies of tritium which satisfy this criterion do not exist, it is possible to produce tritium from lithium via the reactions

$$
\begin{aligned}
& { }^{6} \mathrm{Li}+n \rightarrow T+{ }^{4} \mathrm{He}+4.8 \mathrm{MeV} \\
& { }^{7} \mathrm{Li}+n \rightarrow T+n+{ }^{4} \mathrm{He}-2.5 \mathrm{MeV} .
\end{aligned}
$$

Because the $14 \mathrm{MeV}$ neutrons produced in D-T fusion exceed the $2.5 \mathrm{MeV}$ threshold for the ${ }^{7} \mathrm{Li}$ reaction, it is possible for a fusion neutron to produce two tritons in 1 ithium--by inducing the ${ }^{7} \mathrm{Li}$ reaction, which emits a secondary neutron, which induces the ${ }^{6} \mathrm{Li}$ reaction. Studies indicate that blankets can be designed for D-T fusion reactors which will breed tritium, producing more than enough tritium to fuel the fusion reaction.

The presence of deuterium in water with an isotopic abundance of $0.015 \%$ ensures its availability, and large reserves of 1 ithium exist in the United States. Production costs for deuterium and lithium are very low in relation to the worth of the power which can be generated from them. Thus, in addition to being the fuel in which fusion may be the easiest to achieve, deuterim and tritium bred from $1 i$ thium satisfy the requirements for fuel for a large scale power industry. 
In Figure 4.2, the thermally averaged reaction rates for several fusion fuels are plotted as a function of ion kinetic temperature. ${ }^{(4)}$ A range is indicated for the $\mathrm{p}-{ }^{11} \mathrm{~B}$ reaction due to uncertainties in cross sections and other effects. The significant increases in plasma temperature necessary for achieving fusion in fuels other than deuterium-tritium are displayed in this figure. The appeal of the alternative fuels lies in the long-term availability of fuel, reducing neutron production and eliminating the necessity to breed fuel through transmutation reactions. Advanced fuels show promise of decreasing the induced activation of blanket and structural materials, of reducing inventories and effluents of radioactive tritium gas, and of decreasing waste heat per unit of electrical power by allowing more efficient electrical generation via direct conversion.

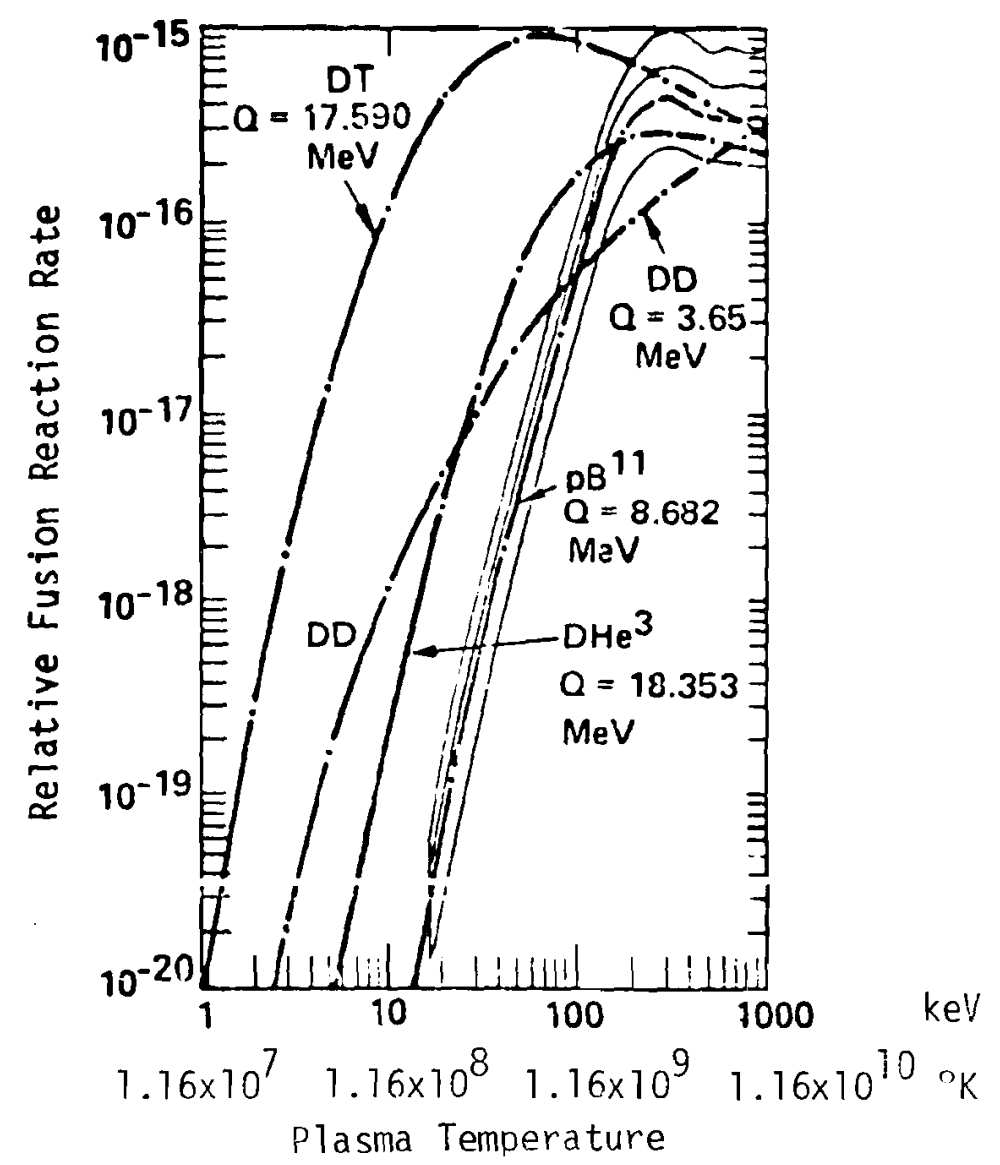

FIGURE 4.2. Thermally Averaged Reaction Rates for Various Fusion Fuels (4) 


\subsection{PLASMA CONFINEMENT}

Magnetic and inertial confinement schemes have been proposed to isolate plasmas with kinetic temperatures exceeding $10^{8} \mathrm{~K}$ from surrounding physical systems. In the various magnetic confinement schemes proposed, helical charged particle motion along magnetic field lines is used to inhibit charged particle diffusion out of the reaction region. This is necessary to hold the plasma together during the period in which fusion reactions take place.

Magnetic field lines form closed loops. Consequently, unless a CTR plasma chamber is constructed to contain entire field line loops--as in toroidal machines--charged particles spiraling along field lines may escape confinement where the field lines exit the plasma chamber. However, a remedy for this problem exists in the form of magnetic "mirrors" which tend to reflect charged particles. Plasma confinement in both toroidal magnetic geometries and between magnetic mirrors is under study.

Inertial plasma confinement is actually nonconfinement. The thermonuclear plasma disassembles on a time scale determined by plasma particle velocities and collision rates--fractions of a nanosecond. (The release of large amounts of fusion energy during this brief period requires that considerable attention be paid to the containment of blast effects.) In this system the plasma creation, compression, and heating is accomplished by laser irradiation of a solid fuel pellet. Laser energy is coupled to the fuel via electromagnetic interactions. In fact, this coupling must be strong enough to cause plasma implosion to densities many hundreds of times that of the solid fuel pellet. Thus, the action-at-a-distance property of the electromagnetic interaction is of fundamental importance to both fusion confinement methods.

\subsection{CONCEPTUAL POWER PLANT DESIGNS}

The Federal Government is the primary sponsor of fusion research in the United States, with about $90 \%$ of the total effort managed by the ERDA. ${ }^{(5)}$ of this, slightiy more than half is managed by the Division of Controlled Thermonuclear Research, which supports a broadly based program of research, development, reactor technology, and the magnetic containment programs. Most of the 
remainder of the government fusion program is managed by the Division of Military Application, in support of laser fusion research.

Most of the ERDA support is allocated to a few major laboratories. Research laboratories and the confinement schemes which are studied there are 1 isted in Table 4.2. In addition, smaller programs are supported at other ERDA laboratories, universities, and industrial sites.

\section{TABLE 4.2. Major ERDA Fusion Research Efforts}

$\begin{array}{lll}\text { Lawrence Livermore Laboratory } & & \text { Confinement Schemes Studied } \\ \text { Los Alamos Scientific Laboratory } & & \text { Inertial; Magnetic (mirror) } \\ \text { Oakridge National Laboratory } & \text { Magnetic (Tokamak) } \\ \text { Princeton Plasma Physics Laboratory } & \text { Magnetic (Tokamak) } \\ \text { Sandia } & \text { Inertial }\end{array}$

In a 1973 report prepared for the Chairman of the USAEC ${ }^{(5)}$ the following objectives were identified for the fusion program.

Research

To conduct theoretical, computational, and experimental studies seeking the body of knowledge that predicts the behavior of thermonuclear fusion experiments and the operating characteristics of fusion reactors. Development

To develop the technology necessary to perform fusion research.

\section{Confinement Systems}

To investigate, develop and establish the feasibility of low density closed (Tokamak), high density closed (theta pinch), and open (mirror) magnetic confinement systems as a basis for practical fusion power generation. Laser-Fusion

To investigate, develop, and establish the feasibility of laser-fusion as a basis for practical fusion power generation. 
Fusion Reactor Technology

To develop the engineering base, qualify materials, develop components and conduct engineering studies necessary for the design, construction and operation of prototype, demonstration, and commercial fusion power reactors.

In support of the Fusion Reactor Technology objectives, conceptual and reference designs for CTR power plants have been prepared by various study groups, as identified in Table 4.3. Major systems have been identified, their functions described, and systems diagrams have been prepared for each of the designs.

It should be noted that these designs are generally the result of ongoing efforts. Some of the design documents lack complete descriptions of certain facets of the design, assuming the existence of the necessary systems or assuming the feasibility of a process. In such cases this is simply noted in the following descriptions. No attempt has been made to review the completeness of preceding efforts to justify or support such assumptions.

The expected duration of the thermonuclear burn, during which fusion reactions take place varies widely between the several magnetic confinement concepts. The mirror reactor burn is not expected to be time limited due to

TABLE 4.3. Originators of Conceptual and Reference CTR Power Plant Design

Magnetic Confinement CTR

Tokamak

University of Wisconsin

Oakridge National Laboratory

Princeton Plasma Physics Laboratory

Theta Pinch

Los Alamos Scientific Laboratory

Mirror

Lawrence Livermore Laboratory

Inertial Confinement CTR Wetted Wall

Los Alamos Scientific Laboratory

Blascon

Oakridge National Laboratory

Suppressed Ablation

Lawrence Livermore Laboratory 
continuous plasma replenishment. Impurity buildup during the Tokamak burn is expected to require refueling after burn times of many hundreds of seconds, or less. Plasma expansion will require termination of the theta-pinch burn after many tens of milliseconds, and pellet disassembly limits inertially confined thermonuclear burn to fractions of a nanosecond. Thus, significant differences are found in the systems supporting the fusion plasma among the various magnetic and inertial confinement schemes.

A11 of the designs are based upon the use of D-T fuel. Hence, each must handle the same reaction products and breed tritium from lithium. Nevertheless, properties of blanket systems are determined in part by thermonuclear burn duration and frequency and by space 7 imitations, and significant differences do exist.

\subsubsection{Magnetic Confinement Designs}

The three magnetic confinement concepts are: Tokamak, theta pinch, and mirror. Each is discussed here, and the power plant designs based upon each concept are described.

Tokamak. A Tokamak is a toroidal machine which contains entire magnetic field loops within its plasma chamber. While charged plasma particles spiraling about magnetic field lines are individually confined by a simple toroidal field, plasma instabilities (including gross motion of the plasma as a whole) require a more complex magnetic field structure for containment. Plasma stabilization requires that the circular field loops be distorted into helices. This is achieved by inducing a current in the plasma ring which creates its own magnetic field. The field lines produced by the combined effects are a nested set of helices whose pitch angles vary with radial position within the torus cross section.

An additional vertical field, perpendicular to the plane of the torus, is required to stabilize the radius of the plasma ring and to provide vertical stability, thus keeping the plasma centered in the toroidal plasma chamber. Consequently, Tokamaks require magnetic circuits to produce toroidal and vertical magnetic fields, and to induce a high current (megamperes) in the plasma. 
Three power plant conceptual designs based upon the Tokamak principle of magnetic confinement have been produced. The University of Wisconsin has devoted extensive efforts to a design starting with basic plasma requirements. ${ }^{(6)}$ A design has been developed at Oakridge National Laboratory starting from assumed plasma conditions, ${ }^{(7)}$ and Princeton Plasma Physics Laboratory has developed the third design. ${ }^{(8)}$ Descriptions of each of these energy systems follow.

University of Wisconsin Tokamak. The design philosophy of UWMAK-I ${ }^{(6)}$ requires use of present-day technology capabilities invoking as little extrapolation as possible. (Thus stainless steel structural material is specified.) Reasoning from plasma scaling laws, cost optimization fixes the power output at $5000 \mathrm{MW}_{\mathrm{t}}$ and the plasma chamber size as follows: torus major radius, $13 \mathrm{~m}$; minor radius, $5.5 \mathrm{~m}$. Figure 4.3 shows the reactor in cross section. (6)

The coils producing the UWMAK-I magnetic fields are of superconducting Nb-titanium. Included are the toroidal field coils, the air-core ohmic heating transformer coils, and the poloidal divertor coils.

An initial charge of D-T fuel gas is ionized and a plasma current established by the ohmic heating transformer coils. It is not expected that ohmic heating alone will lead to ignition. Further plasma heating (to ignition) by

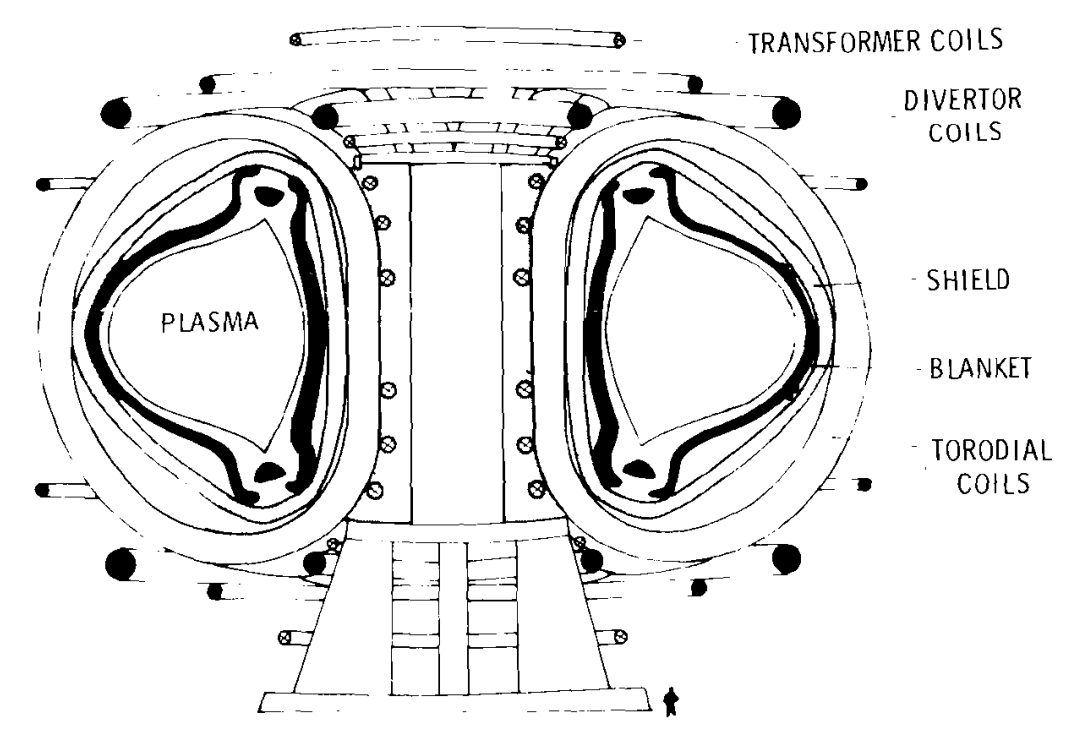

FIGURE 4.3. Cross Section View of UWMAK-I Fusion Reactor 
the injection of energetic beams of neutral atoms is to be employed. This is accomplished in a few seconds, after which the neutral beam injectors are shut down and plasma energy is maintained by alpha particle heating from the fusion reactions.

The average confinement time of plasma particles is about $15 \mathrm{sec}$, followed by escape and then collection by a double null magnetic divertor. Plasma density is maintained by fuel injection in the form of solid pellets of D-T. The fuel feed rate will be $8.4 \mathrm{~kg} \mathrm{~T}$ and $5.6 \mathrm{~kg} \mathrm{D}$ per day.

Energy collection and tritium production take place in a blanket located inside the magnet coils, adjacent to the plasma. Neutron moderation and capture are accomplished by liquid lithium metal contained in the Type 316 stainless steel structure and reflector.

Lithium is also the primary coolant for the blanket. It is circulated out of the blanket to exchange heat to an external sodium system. From this intermediate cooling system heat is exchanged to a steam turbine system.

Tritium bred in the blanket lithium and trapped in flowing lithium in the divertors is removed by passing a portion of the lithium stream exiting from the heat exchangers through an yttrium extraction bed. Thermal regeneration of the extraction beds releases the tritium, which is then sent to the fuel system via the cryogenic purification system.

Particles and radiation which penetrate the blanket are to be attenuated by a shield protecting the superconducting magnets. A heterogeneous mixture of lead and boron carbide with stainless steel structure is specified. A heat removal system employing helium gas is specified for the shield.

Oakridge National Laboratory Tokamak. An ORNL study (7) addresses design of the blanket and magnet shield portions of a $1000 \mathrm{MW}_{t}$ CTR, including related systems. Design of systems associated with the production of the fusion reaction is not addressed. Sizes, field strengths, and other critical parameters relating to plasma confinement are assumed using representative values based upon other ORNL studies. The dimensions chosen for the toroidal plasma chamber are: major radius $10.5 \mathrm{~m}$; minor radius $3.5 \mathrm{~m}$. 
The plasma is to be confined by a toroidal magnetic field produced by superconducting magnets. Vertical magnetic fields are to be produced by copper coils. An iron core is provided in the center of the solenoid. Subsequent studies show that extending the iron core to make a complete iron magnetic circuit is favored. (9)

Plasma fueling and heating is to be accomplished by neutral beam injection. The fuel feed rate is $0.6 \mathrm{~kg}$ of $T$ and $0.4 \mathrm{~kg}$ of $D$ per day. The thermonuclear burn lasts almost 3 min. It is terminated by impurity build-up when the helium content of the plasma reaches $10 \%$. It is assumed that plasma losses will be sma 11 and that it will not be necessary to protect the blanket vacuum wa11 from escaping plasma particles by means of a magnetic divertor.

At the termination of the burn the spent plasma is cooled and neutralized. It blows down from the toroidal plasma chamber into the vacuum duct-plenum region, where it is cooled to near room temperature. It is then pumped out and sent to a distillation system for reclamation of the unburned fuel which is purified and recycled to the injection system. External deuterium supply and tritium supp?y from b?anket systems are planned.

Energy collection and tritium production take place in a blanket located inside the magnet coils, adjacent to the plasma. Neutron moderation and capture is accomplished by lithium and graphite contained in the $\mathrm{Nb}$ blanket structure.

Lithium is the primary coolant and is circulated within the blanket by MHD pumping. Heat exchange to an intermediate potassium binary system takes place within the outer blanket region. The potassium vapor is piped out of the reactor to a topping turbine, and is then condensed in a steam generator. The steam thus produced drives a curíine-generator.

Tritium bred in the blanket lithium is allowed to diffuse through the tubes of the heat exchanger into the potassium system. A small amount of lithium is dissolved in the potassium system's condensate tank. A sidestream of about one-fifth of the potassium system flow is sent through cold traps where condensed LiT is filtered out. Tritium released during regeneration of the lithium getter is sent to the fuel system. 
Particles and radiation which penetrate the blanket are to be attenuated by a shield to protect the superconducting magnets. Graphite followed by lead is specified, with inclusion of $\mathrm{LiOH}$ suggested.

Princeton Tokamak. The Princeton design philosophy is based upon the use of present technology and materials as far as possible. Power output is $5300 \mathrm{MW}_{\mathrm{t}}$, and $\mathrm{plasma}$ chamber dimensions are: major radius $11 \mathrm{~m}$; minor radius $3.6 \mathrm{~m}$. Figure 4.4 shows a section view of the reactor. ${ }^{(8)}$

Al1 magnet coils are of Nb-tin superconductor cooled by liquid helium. Included are coils which produce the toroidal, vertical, and poloidal divertor fields, and the transformer coils which produce and maintain the plasma current.

An initial charge of D-T gas is ionized by an $r f$ discharge, and heated by plasma current induced by the vertical field coils. Plasma density and energy are then increased by injection of beams of neutral atoms of fuel gas, and ignition occurs. It is expected that plasma and "ash" will escape from the plasma following an average residence time of $3.9 \mathrm{sec}$, during which a burnup of $8.7 \%$ is achieved. The single nu11 poloidal divertor guides the escaping particles into an exhaust chamber for collection.

Plasma fuel replenishment is by the injection of pellets of solid D-T which ablate in the plasma. The fuel feed rate is $6.0 \mathrm{~kg}$ of $T$ and $4.0 \mathrm{~kg}$ of $D$ per day. A fundamental design assumption is that impurity buildup is controlled by plasma losses so as not to limit the duration of the thermonuclear burn.

Maintaining the plasma current is expected to require continuous change of the flux in the transformer coil. Consequently, the duration of the thermonuclear burn is limited by the capacity of the transformer coil to about $11 / 2 \mathrm{hr}$. This is followed by a $30 \mathrm{sec}$ pumpout, refilling with fresh fuel gas, and initiation of another cycle.

Escaping plasma ions collected by the magnetic field of the divertor are neutralized in collection chambers, and the neutral gas atoms are pumped from the divertor channel by vacuum pumps. Impurity removal is accomplished by 


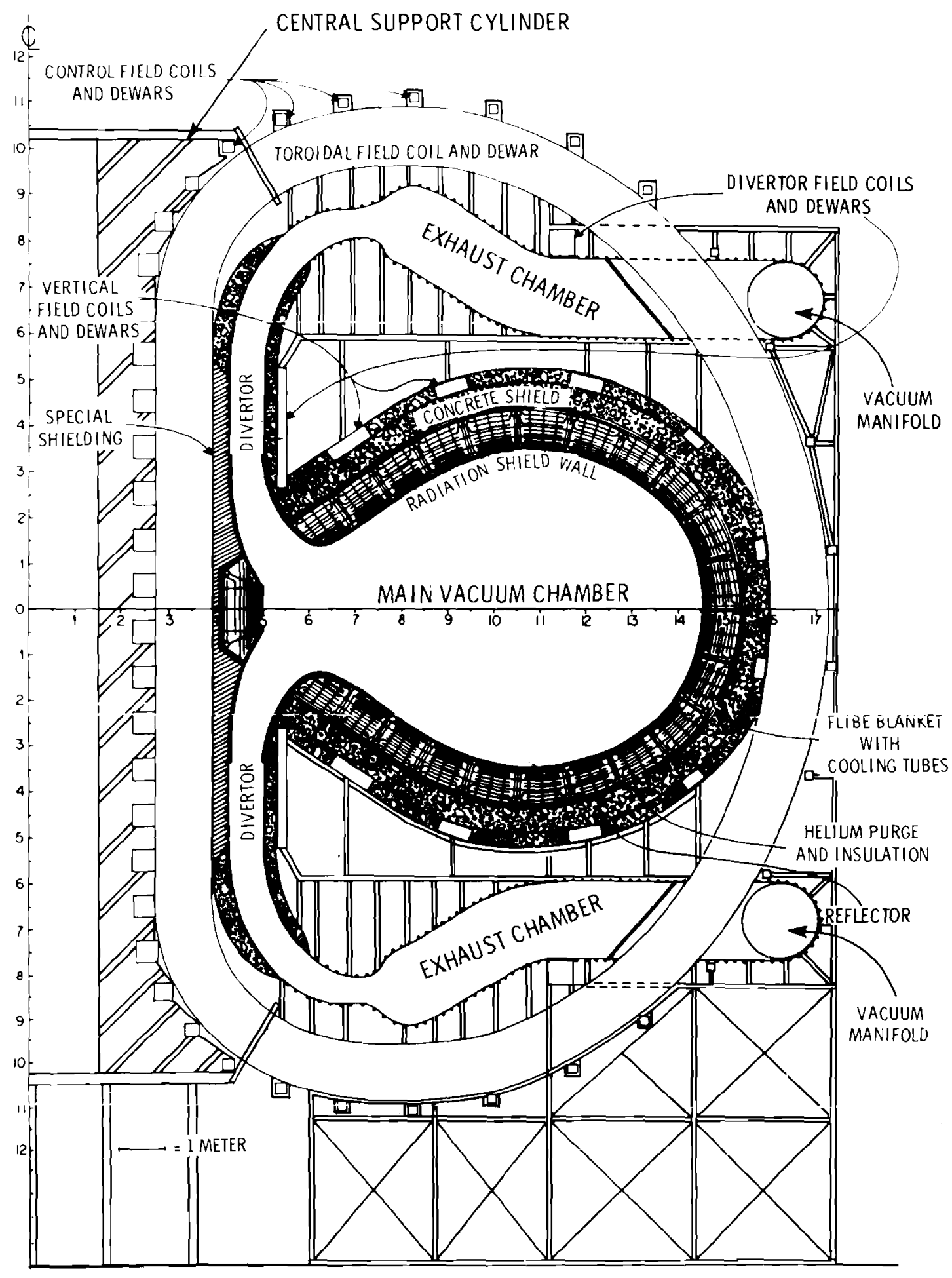

FIGURE 4.4. Section View of the PPPL Tokamak 
cryogenic distillation, and the purified fuel is recycled. External deuterium supply and tritium supply from blanket systems are planned.

Energy collection and tritium production take place in a blanket located inside the magnet coils. Neutron moderation and capture is accomplished in molten flibe (fluorine, lithium, beryllium, a eutectic mixture of the salts LiF and BeF $)$ and in structural material of the Nimonic alloy PE-16 (43\% $\mathrm{Ni}$, $35 \% \mathrm{Fe}, 17 \% \mathrm{Cr}, 3 \% \mathrm{Mo}, 1 \% \mathrm{Ti}$ and $1 \% \mathrm{Al})$.

Heat is removed from the blanket by helium gas coolant, with heat transfer taking place throughout the blanket. The inner blanket wall is separated from the plasma by a radiation shield of tubes also cooled by helium. Heat is exchanged from the helium systems to a steam turbine system.

Molten flibe is continuously circulated from the blanket through a desorber where bred tritium, entrained as TF gas, is removed by helium gas sparging. Circulation of the gas through potassium fluoride beds yields $\mathrm{KTF}_{2}$ from which tritium is chemically recovered and sent to the fuel system.

Particles and radiation penetrating the blanket are attenuated by a shield consisting of half a meter of concrete and iron. This shield protects the superconducting magnets during operation and limits radiation affecting maintenance personnel when the reactor is shut down.

\section{Theta Pinch}

In a theta pinch device, a fast-rising magnetic field is used to heat and compress plasma to thermonuclear ignition conditions. The applied magnetic field induces currents in the plasma by transformer action which flow in the "theta" direction encircling the coil axis. Interaction of these currents with the rising magnetic field heats and compresses the plasma - hence, the "theta pinch."

Plasma shock heating and compression in theta pinch experiments have been accomplished simultaneously, using a single, one-turn magnet coil. However, it is believed that by use of separate, concentric coils, the functions of plasma implosion heating and compression can be separated and staged. This is expected to reduce the necessary plasma compression, improving plasma stability 
and lowering costs. (10) The physics and technology of theta pinch staging are presently under investigation at Los Alamos Scientific Laboratory. Separation and staging of plasma shock heating and compression are assumed in the design described below.

Los Alamos Theta Pinch. The Los Alamos Reference Theta Pinch Reactor (RTPR) (11) is a toroidal machine, thus eliminating end losses. It operates in a pulsed mode, with a $0.1 \mathrm{sec}$ thermonuclear burn every $10 \mathrm{sec}$. This yields a power cutput of $3600 \mathrm{MW}_{t}$. The major radius of the $\mathrm{p}$ ? asma chamber is $56 \mathrm{~m}$; its minor radius is $0.5 \mathrm{~m}$. With an aspect ratio exceeding 100 , the plasma chamber shape may be likened to that of a bicycle tire, in contrast to doughnut-shaped Tokamaks having aspect ratios near 3 .

The pulsed operation of the RTPR is as follows. D-T gas contained within the plasma chamber is ionized, shock heated and compressed to fusion ignition by the application of strong, fast-rising magnetic fields. Following ignition, the deposition of alpha particle energy in the plasma causes plasma expansion. To prevent plasma-wall contact the burn is terminated by relaxing the magnetic containment field, ailowing the plasma to expand into a layer of neutral D-T gas introduced along the wall. The plasma radius is then maintained constant by slowly relaxing the magnetic field, while the plasma is quenched and neutralized. Plasma energy is then transferred through the gas to the plasma chamber wal1. Options available for refueling range from constant-pressure dilution of the gases remaining in the plasma chamber, to chamber evacuation followed by the introduction of fresh fuel.

Recycle of unburned D-T gas is achieved by removing impurities and ash from the exhaust gas by cryogenic distillation. External deuterium suppiy, and tritium supply from blanket systems are planned.

Energy collection and tritium production take place in a blanket located inside the magnet coils, adjacent to the plasma. The blanket receives $14 \mathrm{MeV}$ neutrons and plasma radiation during the thermonuclear burn. In addition, it receives plasma kinetic energy transmitted from the quenched plasma through the neutral gas blanket following each burn. Direct conversion of charged 
particle energy is accomplished during the thermonuclear burn as the plasma, heated by the deposition of alpha particle energy, expands against a constant inagnetic field.

Neutron moderation and capture in the blanket is accomplished by lithium, beryllium and graphite, with neutron multiplication by Be $(n, 2 n)$ reactions. Neutrons are parasitically captured by Nb structural material and alumina $\left(\mathrm{Ai}_{2} \mathrm{O}_{3}\right)$ insulation, and they escape to the surrounding magnet coils. Incorporation of beryllium in the blanket for the purpose of neutron multiplication allows tritium breeding with a thinner blanket and a consequent reduction in the amount of energy which must be transferred to and from the magnet coils.

Thermal energy removal from the blanket is accomplished by pumping the (molten) lithium out of the blanket and through a heat exchanger. Heat exchange can be to an intermediate sodium system or to a potassium binary system in which potassium vapor drives a topping turbine. From either intermediate system, heat is exchanged to a conventional steam turbine system.

Extraction of tritium bred in the blanket lithium is accomplished by diverting a small portion of the lithium stream exiting from the primary heat exchanger through a molten salt contractor systen. The greater solubility of LiT in the molten salt than in the lithium causes it to move preferentially with the salt when the liquids are separated by centrifugation. Either electrochemical or gas sparging techniques will then be used for liberation of the tritium from the molten salt. The molten salt contactor will also serve to remove a wide range of impurities from the lithium, including corrosion products and impurities which might react with structural materials.

Some neutron and gamma ray leakage from the blanket to and through the magnet coils is tolerated to minimize magnet coil size. An external concrete biological shield is provided to reduce radiation levels in areas adjacent to the reactor.

Mirror

A charged particle in helical motion about a magnetic field line experiences a retarding force as it moves into a region of increasing magnetic field. 
If this force is strong enough, the particle's motion along the field line will be stopped and the particle will be pushed back toward its source (the rotation about the field line remaining unchanged). This effect may be likened to reflection by a mirror - hence, a localized high-field region of a magnetic field may be termed a magnetic mirror. Charged particle confinement by trapping between two magnetic mirrors is called mirror confinement.

A charged particle whose direction of motion is close enough to the direction of the magnetic field line around which it spirals will penetrate a magnetic mirror. Consequently, for each magnetic mirror there exists a "loss cone" through which particles can escape. Because plasma particles are continually scattered into the loss cone by collisions, mirror confinement is inherently leaky.

Livermore Mirror. The Livermore Mirror CTR design ${ }^{(12)}$ envisions plasma creation and continuous replenishment of leaking plasma by the injection of energetic beams of neutral fuel atoms. These are ionized and trapped in the plasma. Plasma impurities, including helium "ash" are maintained at a low level by the dilution effect of continuous plasma replenishment combined with plasma loss through the mirrors. Consequently, the operating cycle for this mirror confinement CTR is not expected to be limited by the necessity for plasma refreshment, and continuous operation is projected.

The kinetic energy of leaking plasma particles represents a sizable power loss from the plasma, which must be made up by the neutral beam injectors. This power loss is sufficiently great that direct conversion to electrical energy of the kinetic energy of leaking plasma is required. Furthermore, the maintenance of plasma energy content by neutral beam injection requires that a sizable fraction of the electrical power generated be returned to the injectors. The reactor produces $1130 \mathrm{MW}_{t}$, and generates $750 \mathrm{MW}_{e}$, of which $430 \mathrm{MW}$ is generated by direct conversion and $320 \mathrm{MW}$ by the thermal cycle. The net plant output is $170 \mathrm{MW}_{\mathrm{e}}$.

Stability of plasma confined between magnetic mirrors requires a magnetic well - that is, a magnetic field having minimum strength in the plasma center. 
Such a field is achieved in the Livermore design by a "Yin-Yang" coil configuration in which the radius of the magnet coils is $10 \mathrm{~m}$. (12) The plasma is confined in the central region between the superconducting coils, and leakage is selectively directed through one of the mirrors into an expander-collector structure which directs it to the direct convertor.

Recycle of unburned fuel is necessary, requiring collection of the leaked plasma. Plasma ions escaping through the magnetic mirrors are decelerated by an electric field in a direct convertor and neutralized on charge collector elements. The neutral gas atoms thus produced are then collected by the vacuum system. The system for purification of this unburned fuel is not defined. External deuterium supply and tritium supply from blanket systems are planned.

Neutron energy collection and tritium production take place in a blanket located adjacent to the plasma, which consists of overlapping layers of stainless steel tubes containing lithium, and graphite. The lithium is the primary coolant. It is pumped through the tubes, which are directed along magnetic field lines to minimize MHD pumping losses. Heat exchange to a nonconducting intermediate coolant (immune to MHD pumping losses) takes place in the blanket. The intermediate coolant (helium is a likely choice) conveys the heat to a steam generating system.

Tritium is removed from the lithium by diffusion through the stainlesssteel tubes to the vacuum system. Consequently, tritium must diffuse through the lithium, as well as through the tube walls. Lack of data on attainable rates for this process is noted, as is the need for further design study to minimize tritium holdup in the lithium.

Particles and radiation which penetrate the blanket are to be attenuated by a shield which protects the superconducting magnets. Preliminary studies assume a composition of one-half lead and one-half kerosene.

\subsubsection{Inertial Confinement Designs}

Central to power plant design based upon the inertial confinement concept is the assumption that ignition of a pellet of D-T fuel can be achieved by 
imploding and heating it with focused laser beams. According to a recent report, some previously classified details of pellet design have been released. (13) Among the pellets of interest are glass microsperes about $50 \mu \mathrm{m}$ in diameter, containing D-T gas at 50 to 100 atmospheres pressure.

The production of electrical power requires that the energy released in the pellet explosions be captured. Proposed power plant designs employ repeated pellet explosions, ignited in a central cavity in a containment vessel. The cavity is surrounded by a bianket to moderate the fusion neutrons and to breed tritium by capture in Li.

The fusion neutrons deliver roughly three quarters of the energy of the fusion pulses to the blanket, distributing it over a volume of material. The remainder of the energy is delivered to the containment surface as the kinetic energy of pellet debris and helium "ash," and as x rays. Several concepts have been proposed to protect this surface from the effects of very high rates of energy deposition. In the Wetted Wall concept, (14) Figure 4.5 , a layer of liquid lithium coating the blanket wall is ablated by the blast energy and the vapor is blown down to a diffuser/condensor. In the Blascon concept, ${ }^{(15)}$ Figure 4.6 , the cavity is a vortex in a swirling pool of molten $\mathrm{Li}$, and no surface structure exists. In the Suppressed Ablation ${ }^{(16)}$ concept a liquid Li layer coats and protects the blanket wal1, but is not ablated because energy fluxes are held sufficiently low. Other concepts which have been proposed, but not developed to the power plant stage, include a drywall concept having an ablative inner blanket wall of carbon, (17) and a cavity having bare walls which are protected from the ionized plasma debris and helium ash by magnetic fields. (18) An outline of some of the engineering aspects of an inertial confinement CTR dubbed the Saturn reactor has been presented. (19)

In describing the energy released in the fusion of a pellet, one may note that the energy release of chemical high explosive is about $2 \mathrm{MJ}$ per pound of TNT. However, the blast effect of a fusion pulse will be much smaller than that of a TNT explosion for two reasons. First, the mass of fusion pellet debris carrying the blast is a million times smaller than the mass of 


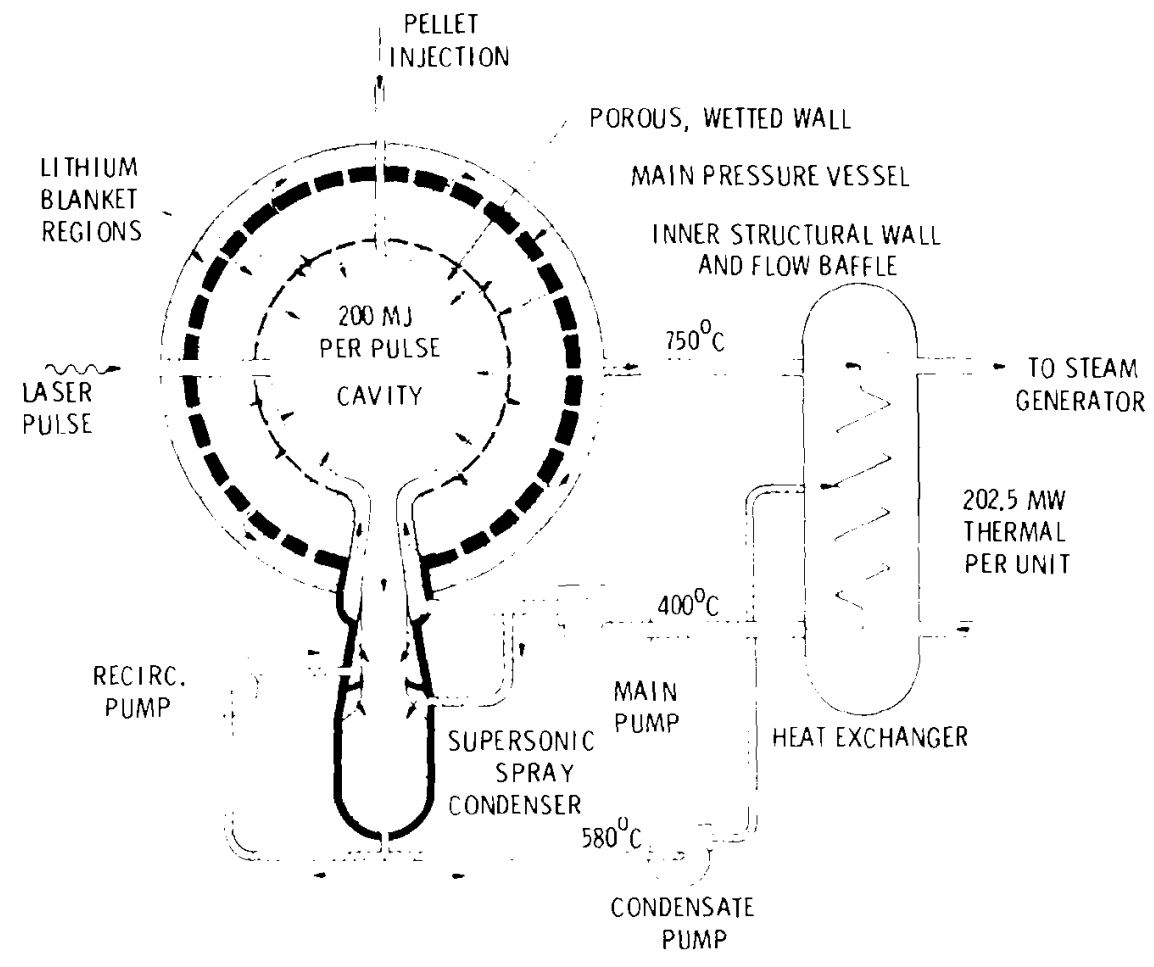

FIGURE 4.5. Cross Section and Flow Schematic of the Wetted Wall Laser-Pellet CTR

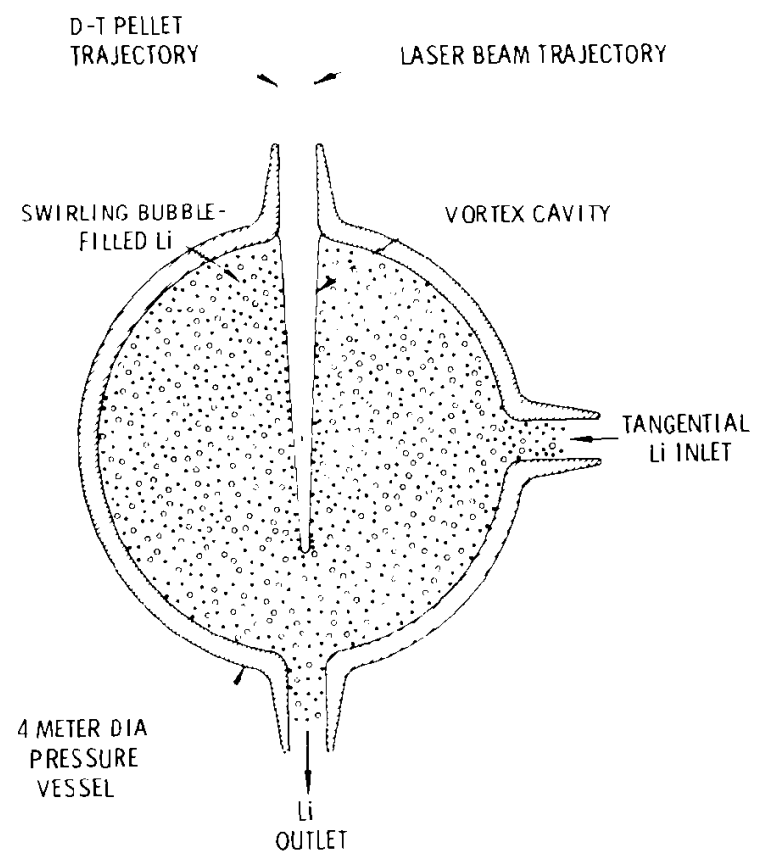

FIGURE 4.6. Cross Section of the Blascon Pressure Vessel and Lithium Vortex 
debris from an equivalent TNT explosion; and second, most of the energy is carried by neutrons which penetrate material surfaces and interact with a distributed volume of material. Consequently, blast effects of fusion pulses will be more than 1000 times weaker than blast effects of TNT explosions of equivalent energy. However, the complexity of confinement analys is may be indicated by noting that ablative blowoff from confinement surfaces can cause shock waves which amplify blast effects by orders of magnitude.

\subsection{CONSTRUICTION MATERIAL REQUIREMENTS}

The material quantities used in this document for projecting the materials demands of a maturing CTR generating capacity are presented in summary form in the following tables (Tables 4.4 through 4.7 ):

- CTR Power Plant Material Requirements - Construction

- CTR Power Plant Materials Average Annual Replacement Quantities

- Normalized CTR Power Plant Material Requirements - Construction

- Normalized CTR Power Plant Material Requirements - Average Annual Replaacement Quantities.

These tables, prepared and updated by Bryan Gore for CTR Environmental Assessment, represent the best data available on construction material requirements.

It is felt that refractory metals may be used in the first wall and blanket construction to a larger extent than is indicated by current conceptual designs. As the technology advances and temperatures go up the strength limitations of stainless steels will be exceeded which will damand the higher temperature properties of the refractory metals. To form a base for estimating the quantities of refractory metals required for a projected generating capacity the first wall of UWMAK-II was assumed to be constructed of Mo, $V, N b, T a$ alloys. This assumption establishes an order of magnitude of the potential use of one or more of these refractories in first wall construction, and form the basis for projecting the demand, supply, and fabrication problems. 


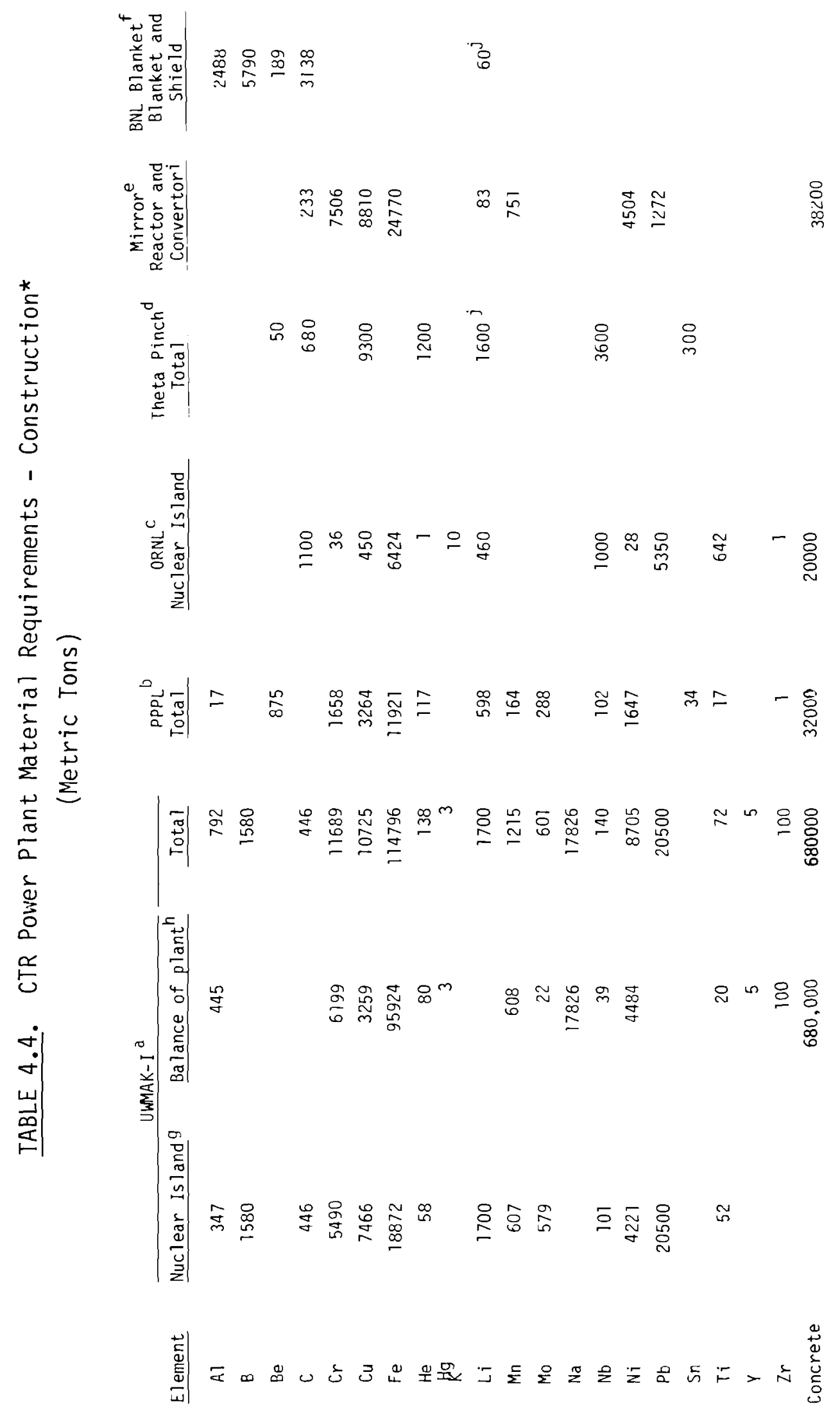




\section{TABLE 4.4. Footnotes}

*In addition to the sources indicated in footnotes a, b, c, d, e, and $f$, the following powerplant designs were consulted but did not include information on material requirements:

J. Williams, T. Merson, F. Finch, F. Schilling, and T. Frank, "A Conceptual Laser Controlled Thermonuclear Reactor Power Plant," CONF-740402-P1, Proceedings of the First Topical Meeting on the Technology of Controlled Nuclear Fusion, San Diego, CA, April 16-18, 1974. (The "Wetted Wal1" concept.)

A. P. Fraas, "Conceptual Designs of a Series of Laser-Fusion Power Plants of 100 to $300 \mathrm{MW}(\mathrm{e})$," presented at the 9 th Intersociety Energy Conversion Engineering Conference, San Francisco, CA, August 26-30, 1974. (The

$\rightarrow \quad$ "Blascon" concept.)

G J. Hovingh, J. Maniscalco, M. Peterson, and R. W. Werner, "The Preliminary Design of a Suppressed Ablation Laser-Induced Fusion Reactor," CONF-740402-PI, Proceedings of the First Topical Meeting on the Technology of Controlled Thermonuclear Fusion, San Diego, CA, Apri1 16-18, 1974. (The "Suppressed

a. B. Badger et al. (22 authors), ULMAlí-I, A Hisconsin Toroidal Fusion Reactor Design, Volume II, UWFDM-68, University of

A Fusion Power Plant, R. G. Mills, Ed., MATT-1050, Princeton Plasma Physics Laboratory, 1974. Does not include requirements for 5 mall Physics Laboratory, 1974 . Does not include requirements for smaall Output is 2030 MWe.

C. A. P. Fraas, Conceptual Design of the Blanket and Shield Region and Related Systems for a Full Scale Toroidal Fusion Reactor, ORNL-TM-3096. Related Systems for a Full Scale Toroidal Fusion Reactor, ORNL- d. J. E. Draley, R. A. Krakowski, T. A. Coultas, and V. A. Maroni, An Engineering Design Study of a Reference Theta-Pinch Reactor (RTPR): March, 1975. llajor elements only. iket plant output is 4700 ille.

e. R. W. Werner, G. A. Carlson, J. Hovingh, J. D. Lee, and M. A. Peterson, Progress Report \#2 on the Design Considerations for a Low Power As emphasized by the title, this design is for an experimental device of low power. Optimization for power production would be expected to introduce economics of scale reducing some of the material requirements per MWe. Covers blanket and shield, Cu for coils, 304 SS coil support structure and direct convertor structure. Superconductor for coils not included. Net plant output is 170 MWe.

f. J. R. Powell, Ed., "Preliminary Reference Design of a Fusion Reactor Exhibiting very Low Residual Radioactivity." BNL-19565, Brookhaven Nat'1 Lab, December 1974. Net Plant Output is 1605 MWe.

g. Only construction materials included here (differs from tabulation in source). Tabulation includes all material within toroidal magnets, plus
divertor and vertical field coils, injectors, and entire primary coolants

$h$. Not including turbine, reheaters, control room, cooling towers and electrical switch gear. Not including tritium extraction equipment except yttrium.

i. These requirements were not developed in the design document. Blanket and shield requirements were calculated from the spherical shell neutronics molel; coil requirements and materials for coil support and for the direct convertor structure were calculated from description and dimensions, by G. A. Carlson.

j. Feedstock for ${ }^{6} \mathrm{Li}$ enrichment included. 
TABLE 4.5. CTR Power Plant Material Requirements - Average Annual Replacement Quantities*

(Metric Tons)

\begin{tabular}{|c|c|c|c|c|c|c|}
\hline Element & UWMAK-I ${ }^{a}$ & $\underline{\mathrm{PPPL}^{\mathrm{b}}}$ & $\underline{O R N L^{C}}$ & Theta Pinch ${ }^{d}$ & Mirrore & BNL Blanket ${ }^{f}$ \\
\hline Al & 7.2 & & & & & 252 \\
\hline $\mathrm{Be}$ & & & & 10 & & 1 \\
\hline C & & & 110 & 140 & 11. & 174 \\
\hline $\mathrm{Cr}$ & 129. & 39 & & & 6.3 & \\
\hline $\mathrm{Cu}$ & 7.2 & & & 2 & & \\
\hline $\mathrm{Fe}$ & 445. & 85 & & & 20. & \\
\hline $\mathrm{He}$ & & & & 1 & & \\
\hline Li & & & & 16 & & 5 \\
\hline $\mathrm{Mn}$ & 14. & & & & 0.6 & \\
\hline Mo & 14. & & & & & \\
\hline $\mathrm{Nb}$ & & & 14 & 77 & & \\
\hline $\mathrm{Ni}$ & 100 & 94 & & & 3.8 & \\
\hline $\mathrm{Zr}$ & & & 0.1 & & & \\
\hline
\end{tabular}

* See Footnotes to Table 4.4

a. Due to 316 SS replacement. $32 \%$ due to biannual replacement of inner blanket; $68 \%$ due to rep 7 acement of remainder of blanket every 10 years.

b. Due to Pe-16 replacement; one-fifth of blanket each year.

c. Replace blanket every 10 years.

d. Replace one-fifth of blanket modules each year.

e. Blanket life is not estimated in the design. 304 SS structure and first wall loading are similar to UWMAK-I. Table is based upon replacement schedule postulated by rough analogy to ULMAK-I. Replacement of inner $30 \mathrm{~cm}$ of blanket every 2 years; replacement of outer $70 \mathrm{~cm}$ of blanket every 10 years; 30 year plant life.

f. Replace one-third of blanket modules each year. 


\section{TABLE 4.6. Normalized CTR Power Plant Material Requirements - Construction*}

\begin{tabular}{|c|c|c|c|c|c|c|c|}
\hline Element & $\begin{array}{l}\text { ULMAK-1 } \\
\text { Total } \\
\end{array}$ & $\begin{array}{l}\text { PpPL }^{\mathrm{b}} \\
\text { Iotal }\end{array}$ & $\begin{array}{c}\text { ORNL }{ }^{\mathrm{C}} \\
\text { Nuclear Is land } \\
\end{array}$ & $\begin{array}{l}\text { Theta Pinch } \\
\text { Total }\end{array}$ & $\begin{array}{l}\text { Mirrore } \\
\text { Reactor and } \\
\text { Convertor }\end{array}$ & $\begin{array}{c}\text { BNL Blanket } f \\
\text { Blanket and Shield }\end{array}$ & $\begin{array}{l}\text { Reference Envel ape } \\
\text { Maximum }\end{array}$ \\
\hline A] & 0.54 & 0.008 & & & & 1.55 & $1.6^{f}$ \\
\hline B & 1.07 & & & & & 3.61 & $3.6^{f}$ \\
\hline $\mathrm{Be}$ & & 0.43 & & 0.012 & & 0.12 & $0.4^{\mathrm{b}}$ \\
\hline c & 0.30 & & 2.12 & 0.17 & 1.4 & 1.26 & $2.7^{c}$ \\
\hline $\mathrm{Cr}$ & 7.92 & 0.82 & 0.07 & & 44. & & 44. $\mathrm{e}$ \\
\hline $\mathrm{Cu}$ & 7.27 & 1.61 & 0.87 & 2.27 & 52. & & b3. $\epsilon$ \\
\hline $\mathrm{Fe}$ & 77.8 & 5.87 & 12.4 & & 146. & & 146. $\mathrm{e}$ \\
\hline $\mathrm{He}$ & 0.09 & 0.06 & 0.002 & 0.29 & & & $0.3^{\mathrm{d}}$ \\
\hline $\mathrm{Hg}$ & 0.002 & & & & & & $0.002^{\mathrm{a}}$ \\
\hline$k$ & & & 0.02 & & & & $0.02^{\mathrm{c}}$ \\
\hline Li & 1.15 & 0.29 & 0.89 & 0.39 & 0.49 & 0.04 & $1.2^{\mathrm{a}}$ \\
\hline$M n$ & 0.82 & 0.08 & & & 4.4 & & $4.4^{e}$ \\
\hline Mo & 0.47 & 0.14 & & & & & $0.4^{\mathrm{a}}$ \\
\hline $\mathrm{Na}$ & 12.1 & & & & & & $12.1^{\mathrm{a}}$ \\
\hline $\mathrm{Nb}$ & 0.09 & 0.05 & 1.93 & 0.88 & & & $1.9^{\mathrm{c}}$ \\
\hline $\mathrm{Ni}$ & 5.90 & 081 & 0.05 & & 27. & & 27. $e$ \\
\hline $\mathrm{Pb}$ & 13.9 & & 10.3 & & 7.5 & & $13.9^{\mathrm{a}}$ \\
\hline $5 n$ & & 0.02 & & 0.07 & & & $0.07^{d}$ \\
\hline$T i$ & 0.05 & 0.008 & 1.24 & & & & $1.24^{\mathrm{C}}$ \\
\hline Y & 0.003 & & & & & & $0.003^{\mathrm{a}}$ \\
\hline$z r$ & 0.07 & 0.0005 & 0.002 & & & & $0.97^{\mathrm{a}}$ \\
\hline Concrete & 461. & 15.8 & 38.6 & & 225. & & 461. a \\
\hline
\end{tabular}

* See Footnotes to Table 4.4

Maximum quantities are from designs correspondingly labeled 


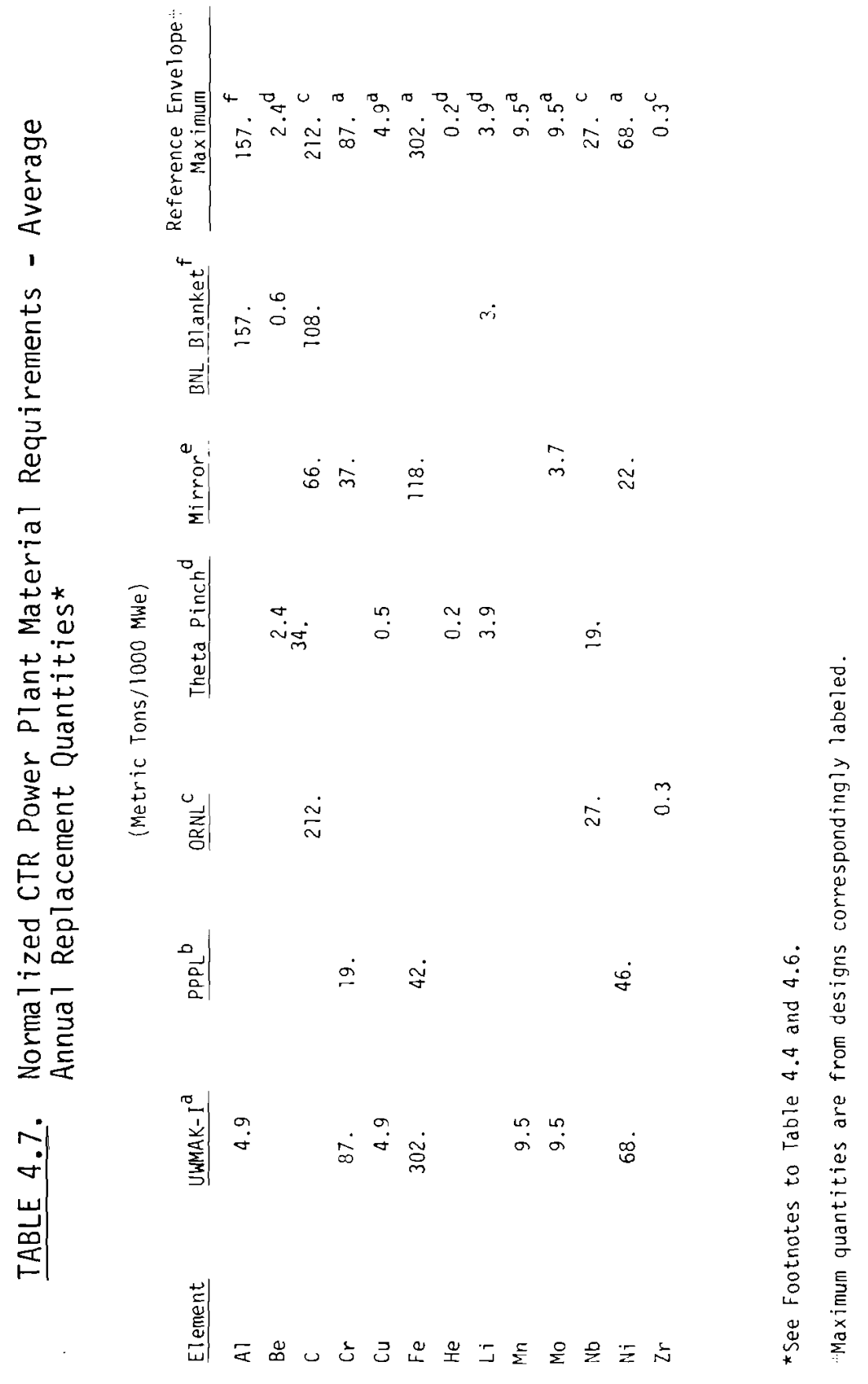


These four refractory metals, and their alloys, were selected as the primary potential refractory candidates for first wall construction. As such it was felt that their potential for fabrication and supply problems is much greater than in the more commonly used steels. McDonnell-Douglas AstronauticsEast, with extensive experience in this area, was selected to perform the state-of-the-art study of fabrication on these four metals. The results of this study are reported in BNWL-2053 entitled Refractory Metals Fabrication Technology as Applied to Fusion Reactors.

Very little in detail design of the components of the first wall is available. Most of the component fabrication studies have been of a generic nature based on the available details of the UWMAKS and PPL and HNL Tokamaks. This problem will receive increasing attention as the conceptual designs progress, and as fabrication problems crop up during construction of interim and experimental devices. In the design of EPRs and DEMOS it is hoped that fabricability of components will be a definite input affecting the designs.

The currently available details of material requirements (bill of materials) are included in Tables 4.8 through 4.12. These are included to inform the reader of the types and locations of the materials in the nuclear islands of the reactors. Tables such as these and personal communications were used to establish the range of materials usage for the projected CTR economy.

As a basis for comparing elemental requirements for a CTR-based electrical industry of $10^{6} \mathrm{MW}_{e}$, Table 4.13 summarizes the CTR nuclear island elemental requirement. The range of annual construction requirements shown allows for the possibility that some fusion reactors would not require some of the elements listed, and indicates likely variations in individual requirements among designs.

This range is simply $1 / 20$ of the tota 1 requirements, assuming a 20-year maturation period for a $10^{6} \mathrm{MW}$ industry based on fusion power. According to the projected rate of maturation as reproduced in Figure 4.7 , annual requirements would start very modestly, and would grow to on the order of $10 \%$ of total requirements towards the end of maturation. By this scheme, annual requirements during the last 3 or 4 years of maturation would be about double the "average" requirement ranges shown in Table 4.13 . 


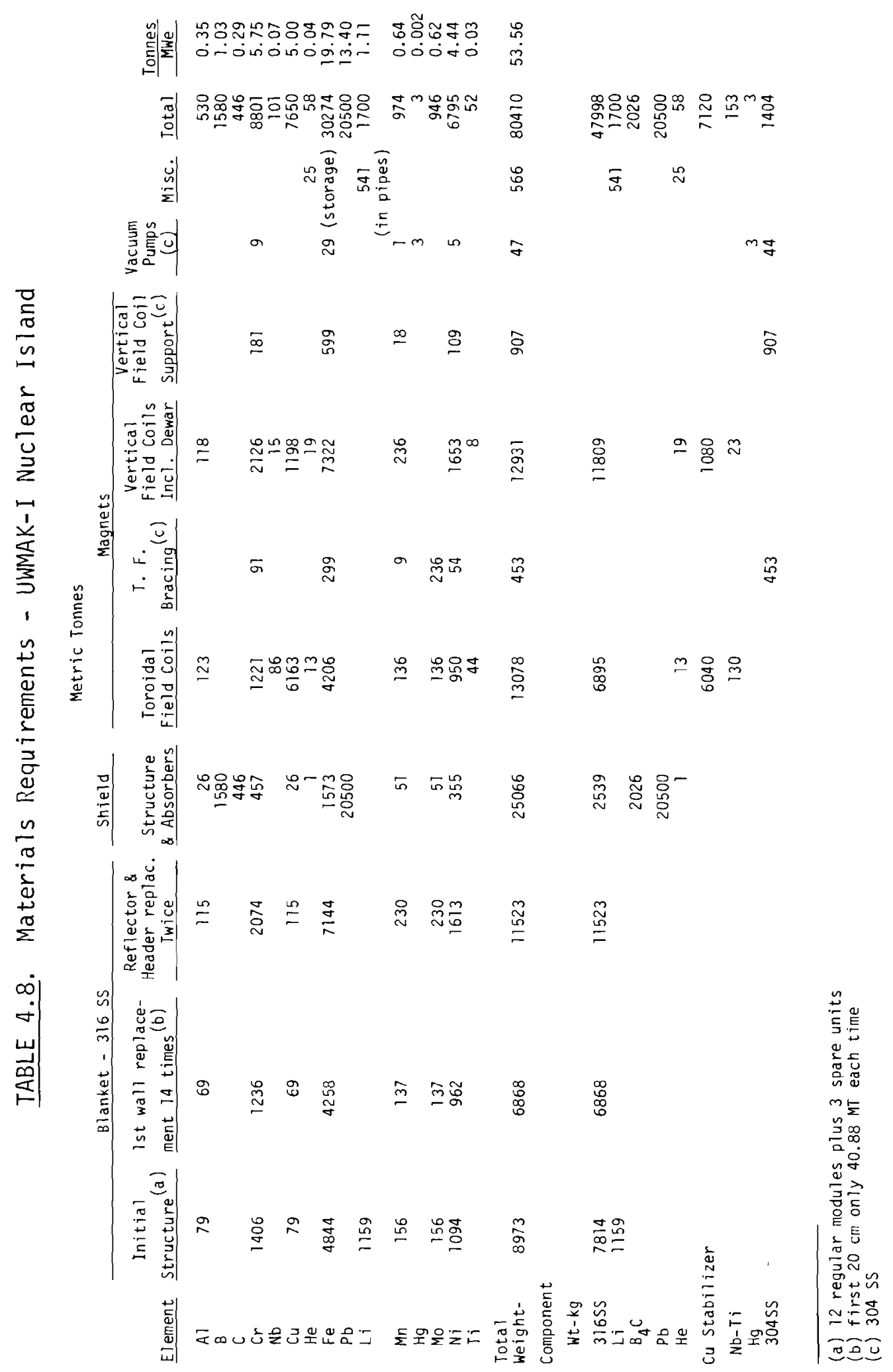




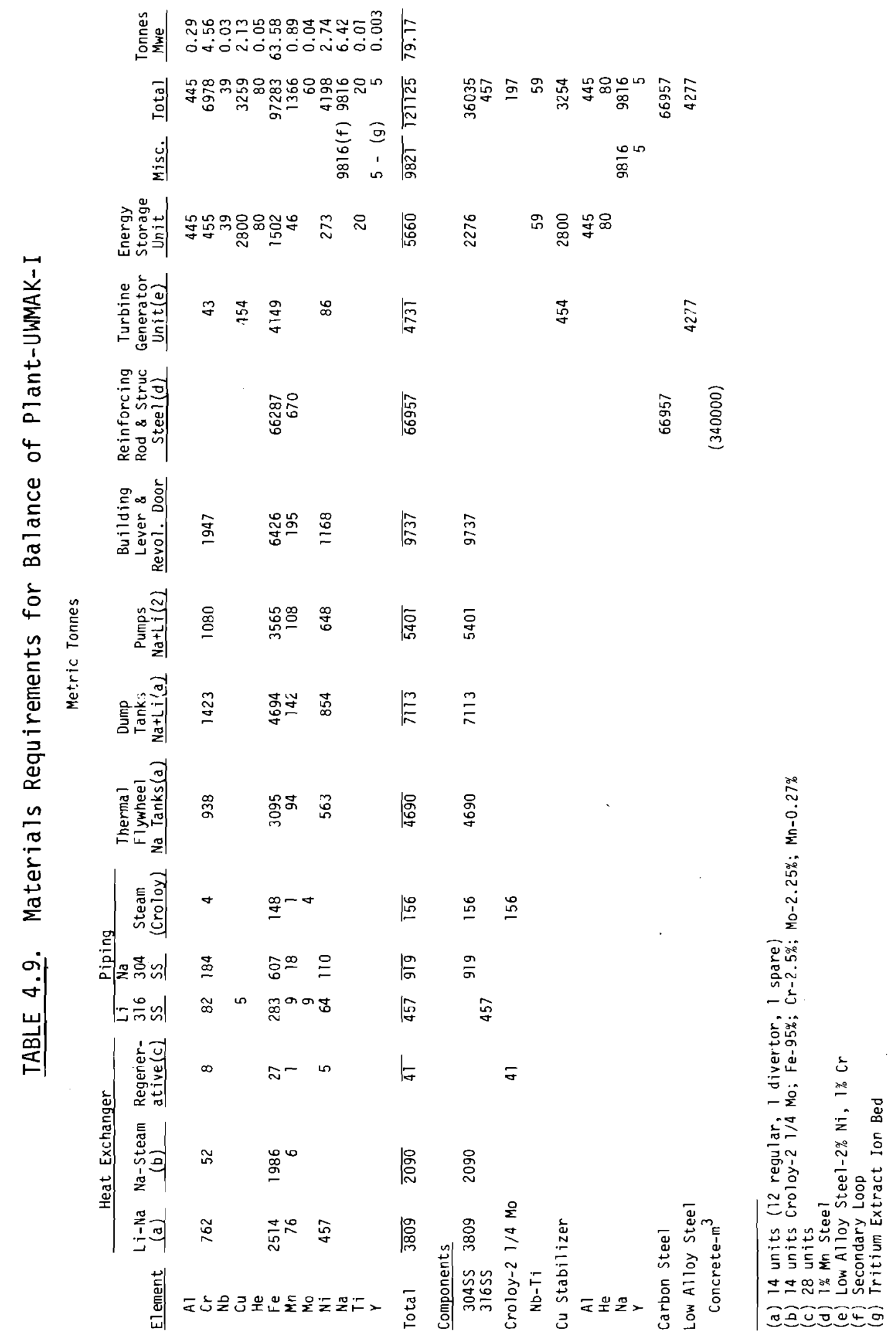


TABLE 4.10. Summary of Elemental Requirements for UWMAK-I

\begin{tabular}{|c|c|c|c|c|}
\hline \multicolumn{5}{|c|}{ Metric Tonnes } \\
\hline Element & $\begin{array}{l}\text { Nuclear } \\
\text { Island } \\
\end{array}$ & $\begin{array}{l}\text { Balance } \\
\text { of Plant }\end{array}$ & Total & $\begin{array}{l}\text { Tonnes } \\
\text { MWe }\end{array}$ \\
\hline A1 & 530 & 445 & 975 & 0.64 \\
\hline B & 1,580 & - & 1,580 & 1.03 \\
\hline C & 446 & - & 446 & 0.29 \\
\hline $\mathrm{Cr}$ & 8,801 & 6,978 & 15,779 & 10.31 \\
\hline $\mathrm{Nb}$ & 101 & 39 & 140 & 0.09 \\
\hline $\mathrm{Cu}$ & 7,650 & 3,259 & 10,909 & 7.13 \\
\hline $\mathrm{He}$ & 58 & 80 & 138 & 0.09 \\
\hline $\mathrm{Fe}$ & 30,274 & 97,283 & 127,557 & 83.37 \\
\hline $\mathrm{Pb}$ & 20,500 & - & 20,500 & 13.40 \\
\hline $\mathrm{Li}$ & 1,700 & - & 1,700 & 1.11 \\
\hline$M n$ & 974 & 1,366 & 2,340 & 1.53 \\
\hline $\mathrm{Hg}$ & - & 3 & 3 & 0.002 \\
\hline Mo & 946 & 60 & 1,006 & 0.66 \\
\hline $\mathrm{Ni}$ & 6,795 & 4,198 & 10,993 & 7.18 \\
\hline $\mathrm{Na}$ & - & 9,816 & 9,816 & 6.42 \\
\hline $\mathrm{Ti}$ & 52 & 20 & 72 & 0.05 \\
\hline$Y$ & - & 5 & 5 & 0.003 \\
\hline & 80,410 & 121,125 & 201,535 & 131.72 \\
\hline
\end{tabular}

TABLE 4.11. Source of the Need for Critical Elements in the UWMAK-I Reactor Facility*

Percent of Total Requirements

\begin{tabular}{|c|c|c|c|c|c|c|c|c|c|}
\hline \multicolumn{6}{|c|}{ Nuclear Island } & \multicolumn{3}{|c|}{$\begin{array}{c}\text { Components Peculiar } \\
\text { to UWMAK-I }\end{array}$} & \multirow[b]{2}{*}{$\begin{array}{c}\text { Balance } \\
\text { of } \\
\text { Plant } \\
\end{array}$} \\
\hline $\begin{array}{l}\text { Ele- } \\
\text { ment }\end{array}$ & $\begin{array}{l}\text { Initial } \\
\text { Struc- } \\
\text { ture }\end{array}$ & $\begin{array}{l}\text { First } \\
\text { Wal1 } \\
\text { Repl. }\end{array}$ & $\begin{array}{c}\text { Balance } \\
\text { of } \\
\text { Blanket } \\
\text { Repl. }\end{array}$ & Shield & Magnets & $\begin{array}{l}\text { Energy } \\
\text { Storage } \\
\text { Unit } \\
\end{array}$ & $\begin{array}{l}\text { Therma } 1 \\
\text { Fly- } \\
\text { Wheel } \\
\text { Tanks } \\
\end{array}$ & $\begin{array}{c}\text { Liner } \\
+ \\
\text { Rev. } \\
\text { Door } \\
\end{array}$ & \\
\hline $\mathrm{Cr}$ & 9 & 8 & 13 & 3 & 23 & 3 & 6 & 12 & 23 \\
\hline $\mathrm{Nb}$ & - & - & - & - & 72 & 28 & - & - & - \\
\hline $\mathrm{Mn}$ & 7 & 6 & 10 & 2 & 17 & 2 & 4 & 8 & 44 \\
\hline $\mathrm{Ni}$ & 10 & 9 & 15 & 3 & 25 & 2 & 5 & 11 & 20 \\
\hline
\end{tabular}

* As compared to a Liquid metal cooled fission reactor. 
TABLE 4.12. Materials Required for Construction of PPPL Tokamak Fusion Reactor and Reactor Building(20)

\begin{tabular}{|c|c|c|}
\hline Structure or Component & Material & Metric Tons \\
\hline Radiation Shield Wall & PE-16 & 31 \\
\hline Vacuum Wall & PE-16 & 94 \\
\hline Blanket Structure and Tubes & $P E-16$ & 965 \\
\hline Divertor Vessel and Tubes & $P E-16$ & 62 \\
\hline Divertor Vacuum Manifold & $316-5 S$ & 38 \\
\hline Main Support Structure & $316-S S$ & 4,100 \\
\hline Helium Ducts to S.G.'s & $316-S S$ & 3,922 \\
\hline Containment Lining & Carbon Steel & 3,682 \\
\hline Concrete Reinforcing Bars & Carbon Stee 1 & 3,900 \\
\hline Flibe & Flibe & 6,800 \\
\hline Superconductors & $\mathrm{Nb}_{3} \mathrm{Sn} / \mathrm{Cu} / \mathrm{SS}$ & 6,800 \\
\hline Concrete & Concrete & 32,000 \\
\hline Hel ium-Cryogenic & $\mathrm{He}$ & 81.3 \\
\hline Hel ium-Reactor Cool ing & $\mathrm{He}$ & 35.7 \\
\hline
\end{tabular}

Projected replacement requirements similarly define extremes in requirements for a postulated mature industry, e.g., in and beyond the 20th year. Tabulated replacement quantities are predominately for blanket structurals, although consumption of breeding and cooling materials (including burnup) is included where a basis for this is given in reference documentation.

The cited maximum quantities (both construction and replacement) for Mo, $\mathrm{V}$ and $\mathrm{Ta}$ are crude estimates that presume use of these materials in blanket structures for some designs. Such designs have not yet been specified, and the indicated amounts for these refractories are included only to give an idea of the probable order of magnitude. 


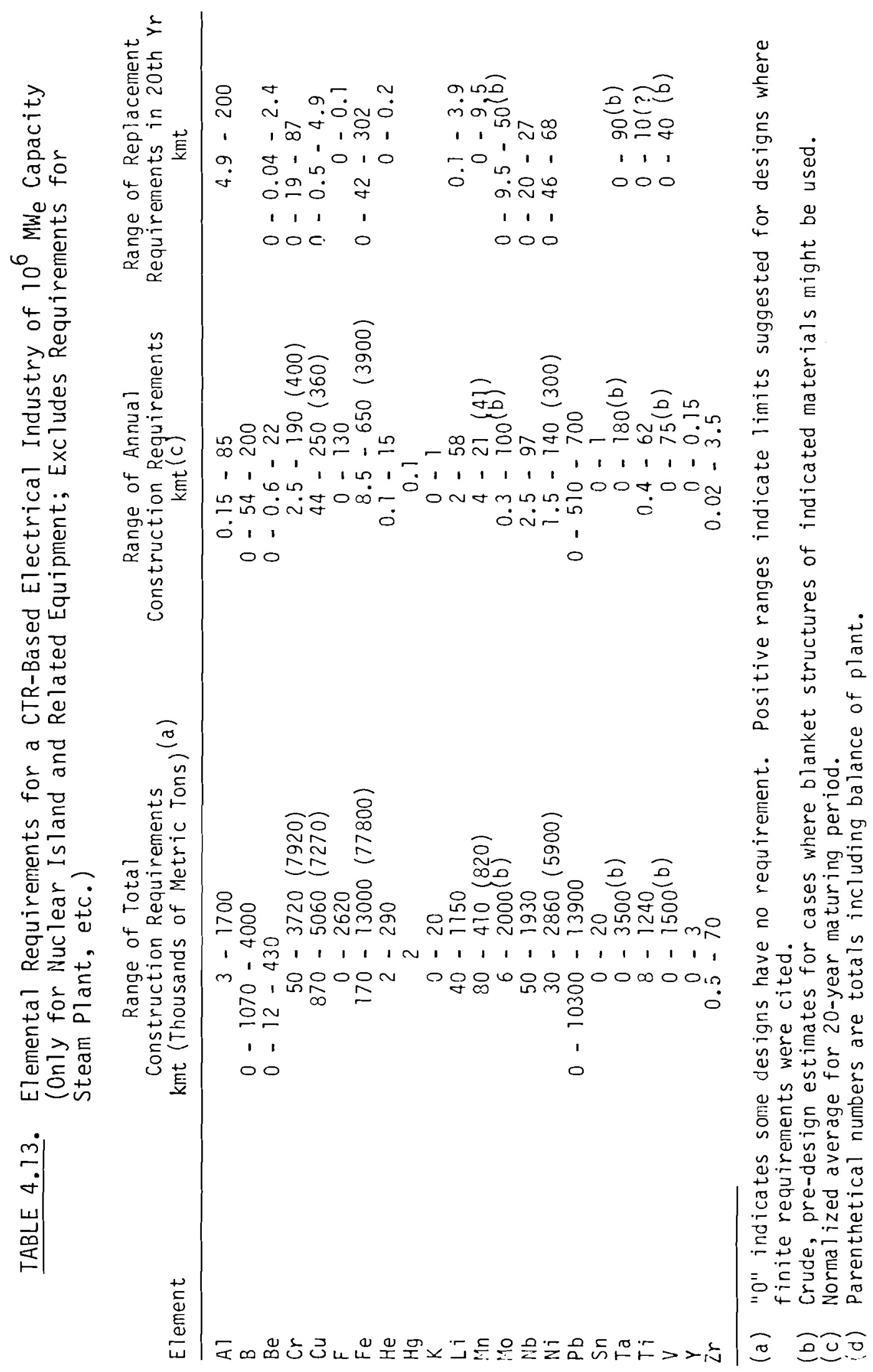




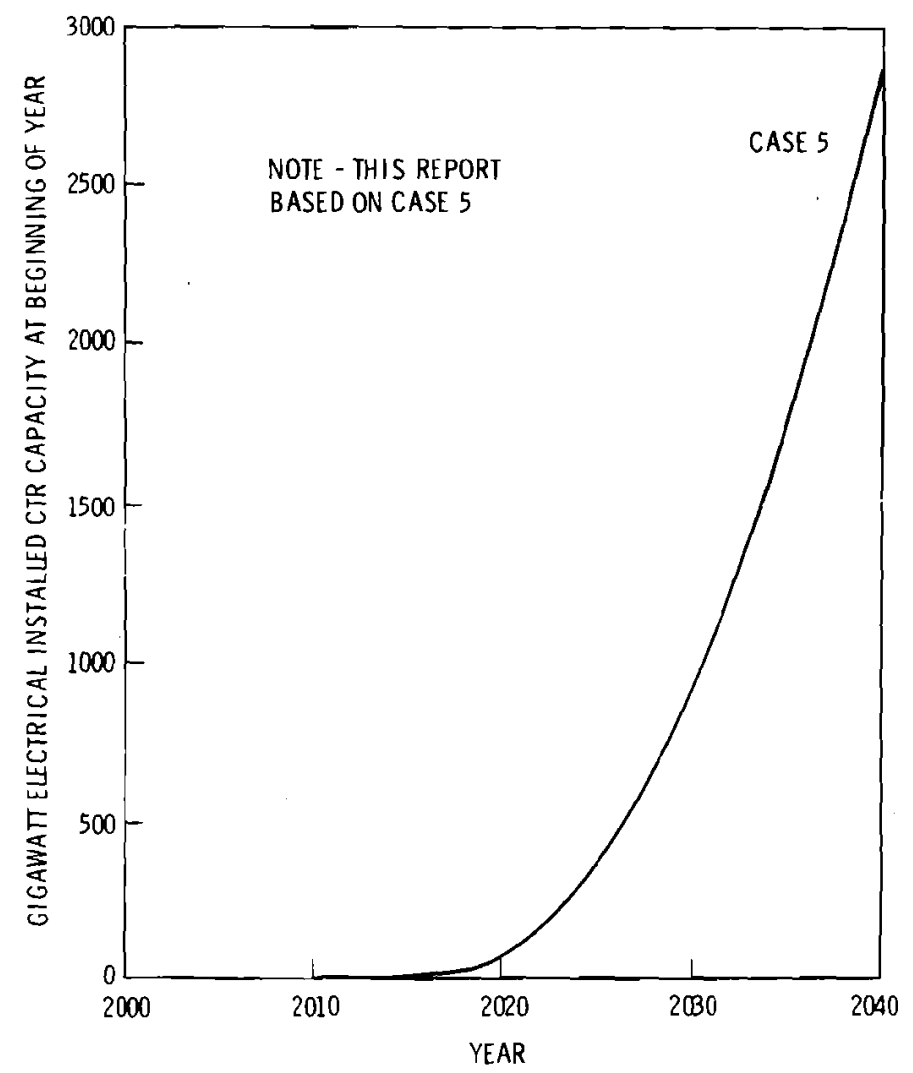

FIGURE 4.7. Potential Fusion Power in the Period 2010-2030

Estimates of total plant requirements (exclusive of turbines, reheaters, control room, cooling towers, and electrical switch gear) have been made by staff at the University of Wisconsin. Major material requirements for balance of plant include carbon and low alloy steels, 300 series stainless steel (mostly 304), copper and aluminum (energy storage unit), and sodium, and concrete. Major impacts upon elemental requirements are shown parenthetical in Table 4.13.

Balance of plant requirements according to UWMAK-I, cail for a six-fold increase in iron, roughly double the chromium, nickel, and manganese, and increase the copper requirement by abaut half relative to nuclear island requirements above. Annual construction requirements for concrete would average about 15,400 metric tons, and for sodium, about 400 metric tons. 
To further estimate the potential nuclear island requirements of a projected CTR-based industry, a model was established whereby one-fifth of the total capacity would be supplied by each of five conceptual designs for which individual commodity requirements were available, at least to a degree. These were UWMAK-I, (21) the PPPL Tokamak, ${ }^{(20)}$ and HNL Tokamak, (22) LASL Reference Theta Pinch Reactor (RTPR), ${ }^{(23,24)}$ and the Brookhaven minimum activation blanket/shield Tokamak design as an option to UWMAK-I. (25) For the Brookhaven design, rough estimates of non-blanket-and-shield materials were based on UWMAK-I reports.

Tables 4.14 through 4.18 list the elemental requirements as used in this model for each of the designs, and Table 4.19 shows the aggregate requirements. The schedule of annual elemental requirements during the assumed 20-year

TABLE 4.14. Elemental Requirements for UWMAK-I Tokamak

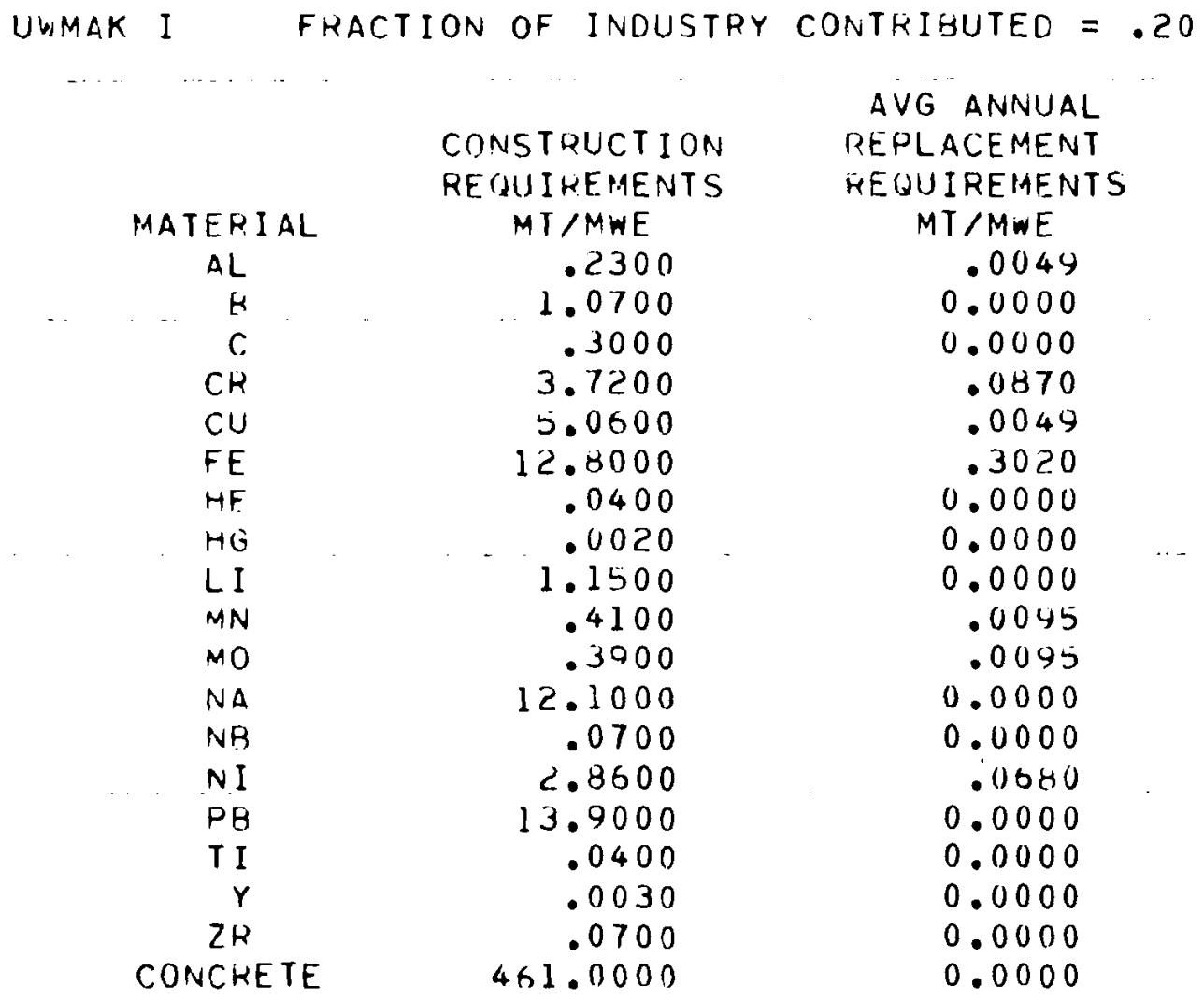




\section{TABLE 4.15. Elemental Requirements for Princeton Tokamak}

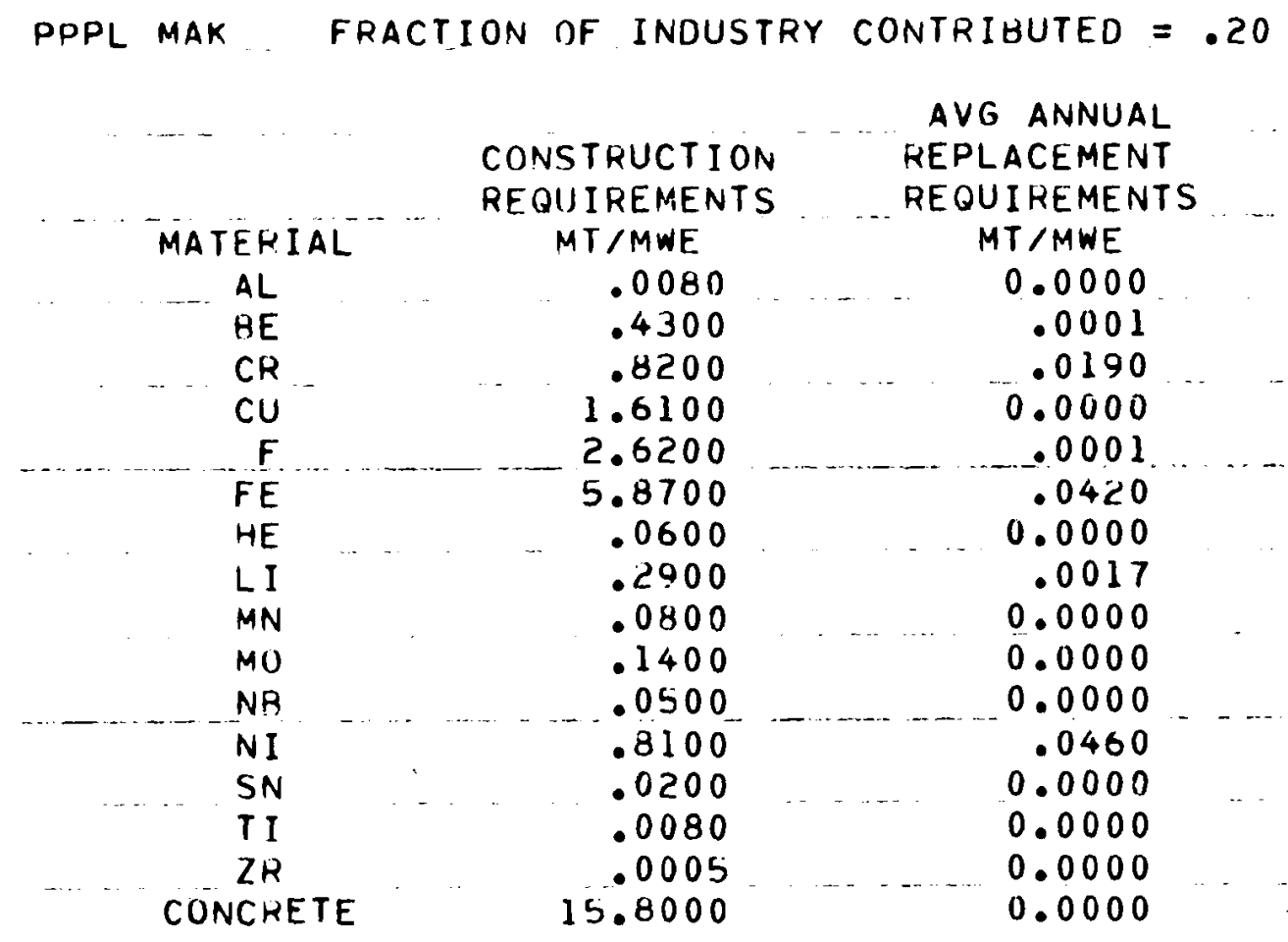

maturation period as defined by Young in Figure 4.7 is presented in Tables 4.20 through 4.22 for construction, replacement, and total elemental requirements, respectively. (Sodium and mercury requirements accrue from UWMAK-I balance of plant estimates. Other requirements are for "nuclear island" facilities only, as defined in the respective references.) Because of differences in definition as well as varying degrees, and preliminary nature of the detail in the references, modeling at this point is not rigorous. Nevertheless, the model analysis is considered to provide somewhat greater realism than the ranges shown in Table 4.13. 
TABLE 4.16. Elemental Requirements for 0ak Ridge Tokamak ORNL MAK FRACTIUN OF INDUSTRY CONTRIBUTED $=.20$

$\begin{array}{ccc} & & \text { AVG ANNUAL } \\ & \text { CONSTRUCTION } & \text { REPLACFMENT } \\ \text { REQUIREMENTS } & \text { REQUIREMENTS } \\ \text { MATERIAL } & \text { MT/MWE } & \text { MT/MWE } \\ \text { C } & 2.1200 & .2120 \\ \text { CR } & .0700 & 0.0000 \\ \text { CU } & .8700 & 0.0000 \\ \text { FE } & 12.4000 & 0.0000 \\ \text { HE } & .0020 & 0.0000 \\ \text { K } & .0200 & 0.0000 \\ \text { LI } & . .4900 & 0.0000 \\ \text { NE } & 1.9300 & .0270 \\ \text { NI } & .0500 & 0.0000 \\ \text { PR } & 10.3000 & 0.0000 \\ \text { TI } & 1.2400 & 0.0000 \\ \text { ZR } & .0020 & .0003 \\ \text { CONCHETE } & 38.6000 & 0.0000\end{array}$

TABLE 4.17. Elemental Requirements for Los Alamos Theta Pinch LASL RTPR FRACTION OF INDUSTRY CONTRIBUTED $=.20$

$\begin{array}{cc} & \text { CONSTHUCTION } \\ \text { MATEKIAL } & \text { REOUIHEMENTS } \\ \text { AL } & \text { MT /MWE } \\ \text { HE } & .0030 \\ C & .0200 \\ \text { CH } & .2600 \\ C U & .0500 \\ \text { FE } & 2.6400 \\ \text { HE } & .1700 \\ \text { LI } & .2900 \\ \text { MO } & .6400 \\ \text { NH } & .0060 \\ \text { NI } & .8900 \\ \text { TI } & .0300 \\ & .0300\end{array}$

AVG ANNUAL
REPLACEMENT
REQUIREMENTS
MT/MWE
0.0000
.0024
0.0000
0.0000
.0005
0.0000
.0002
.0039
0.0000
.0200
0.0000
0.0000


TABLE 4.18. Elemental Requirements for Brookhaven Tokamak Blanket and Shield, Integrated to UWMAK-I Plant

BNL/UWMAK FRACTION OF INDUSTRY CONTRIBUTED $=.20$

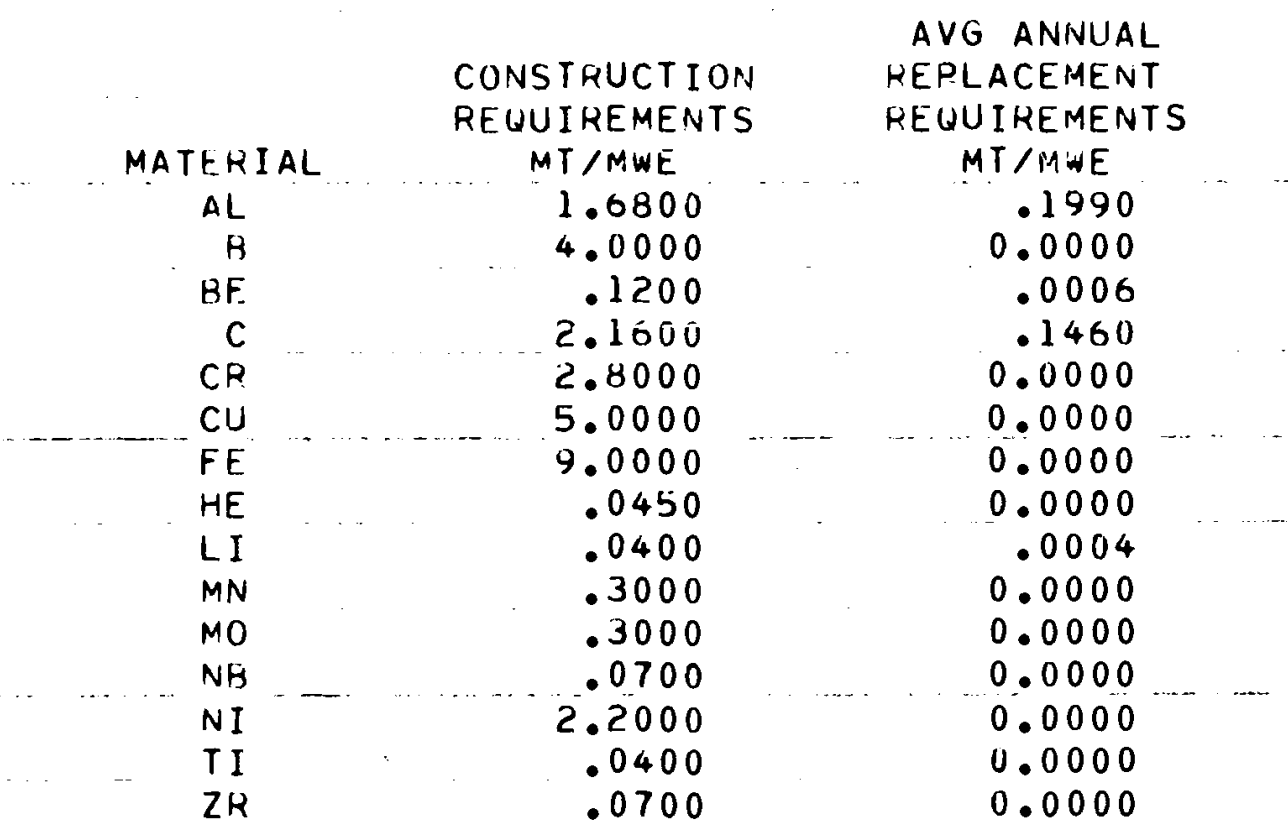


TABLE 4.19. Elemental Requirements for Equal Contributions from Five Designs AGgREgATE OF MATERIAL REQUIREMENTS FOR MIXEO DESIGN LISTEU ABOVE

MATERIAL
$\Delta L$
$H$
$H E$
$C$
$C H$
$C U$
$F$
$F E$
$H E$
$H G$
$K$
$L I$
$M N$
$M O$
$N A$
$N H$
$N I$
$P H$
SN
$T I$
$Y$
$Z K$
CONCHETE

CONSTRUCTION
REQUIREMENTS
MTIMWE
.3842
1.0140
.1140
.9680
1.4920
3.0360
.5240
8.0480
.0374
.0004
.0040
.6020
.1580
.1672
2.4200
.6000
1.1900
4.8400
.0040
.2716
.0006
.0285
103.0800

AVG ANNUAL KEPLACEMENT REQUIREMEINTS

MT / MWE .0408

0.0000

.0006

.0716

.0212

.0011

.0000

.0688

.0000

0.0000

0.0000

.0012

.0019

.0019

0.0000

.0094

.0228

0.0000

0.0000

0.0000

0.0000

.0001

0.0000 


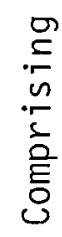

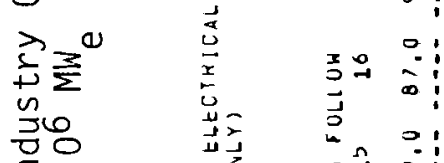

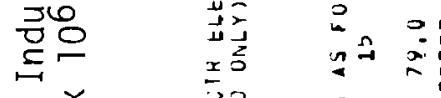

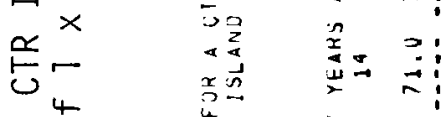

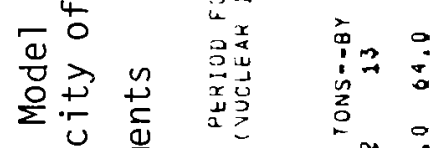

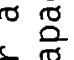

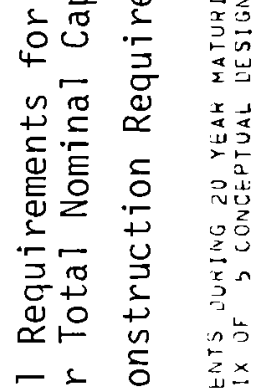

бᄒ

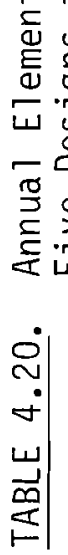

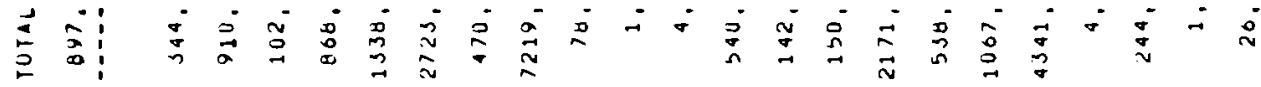

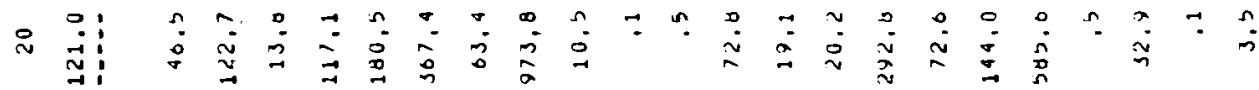

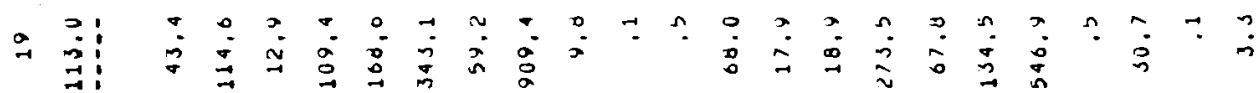

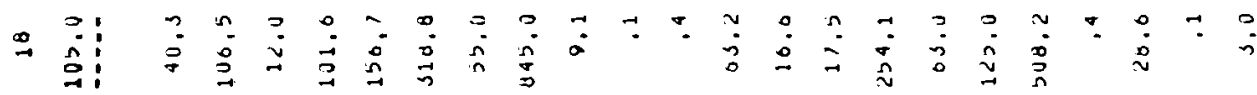

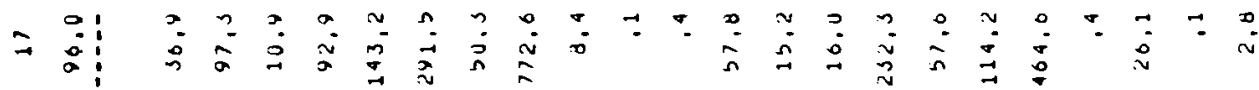

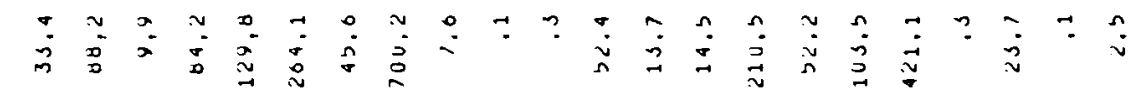

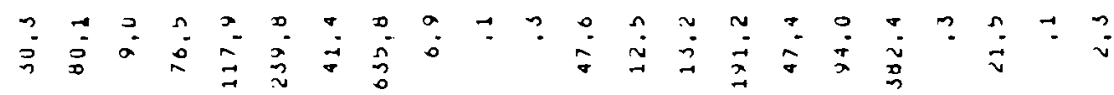

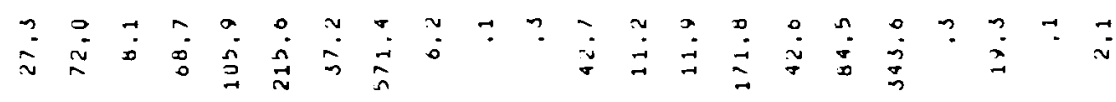

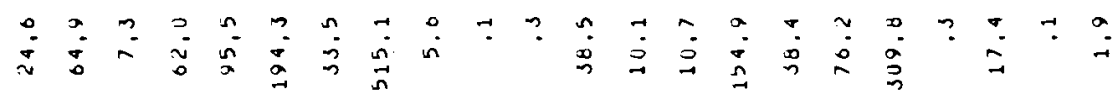

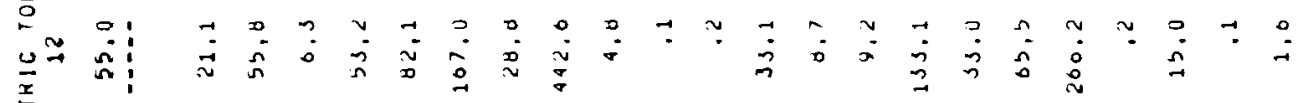

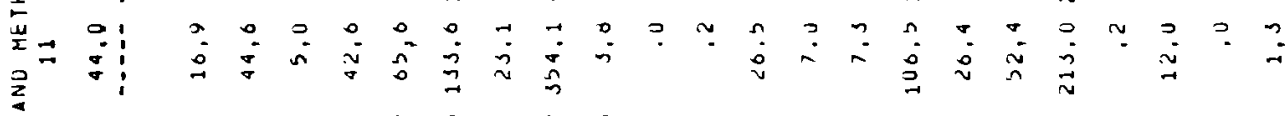

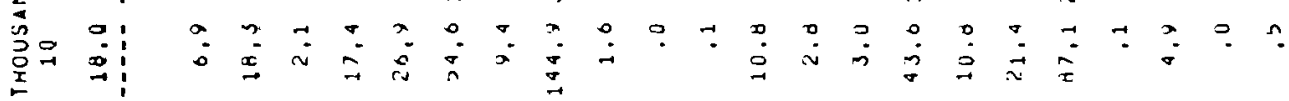

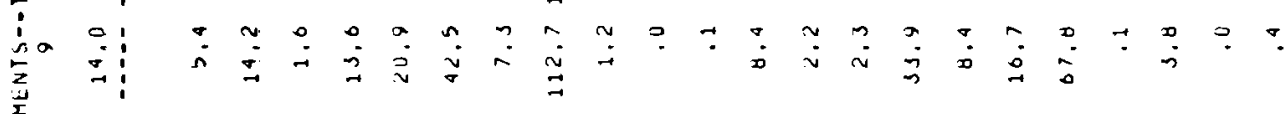
至

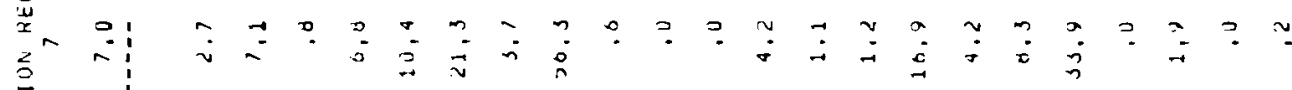
节。

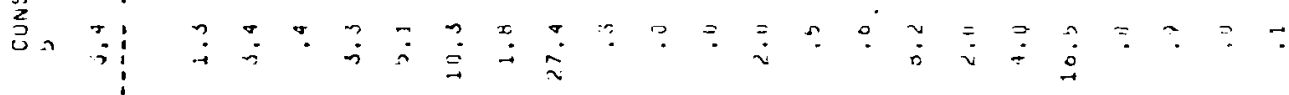

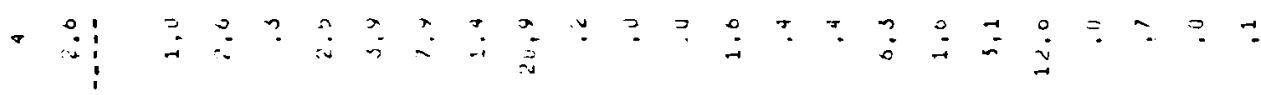

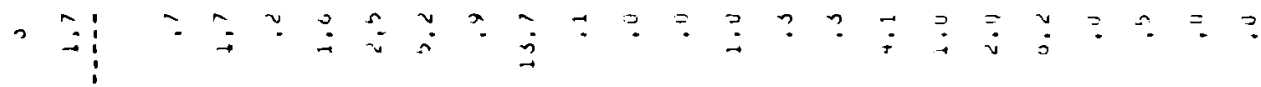

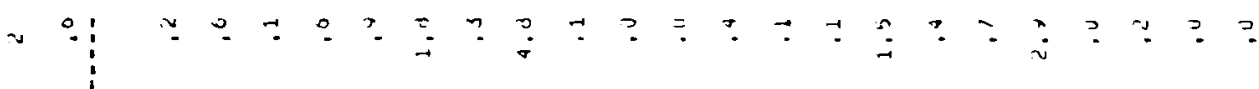

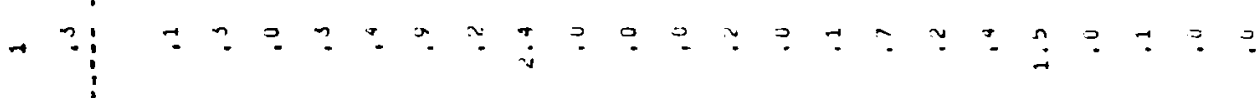
崖黄 
TABLE 4.21. Annual Elemental Requirements for a Model CTR Industry Comprising Five Designs for Total Nominal Capacity of $1 \times 10^{6} \mathrm{MW}_{\mathrm{e}}$

Replacement Requirements

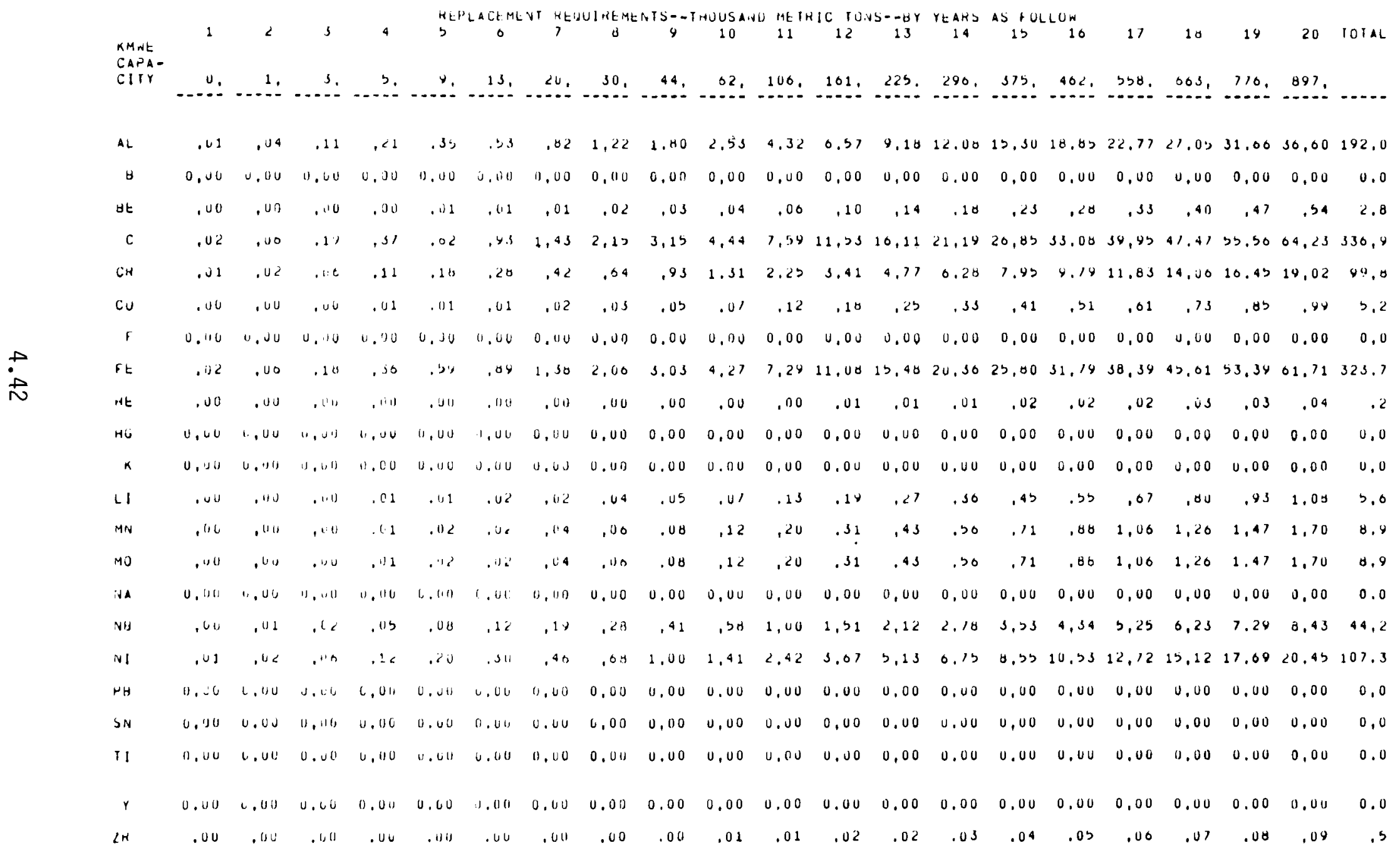




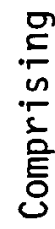

草

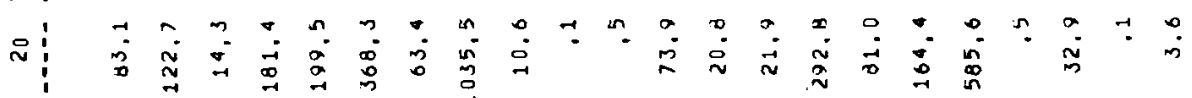

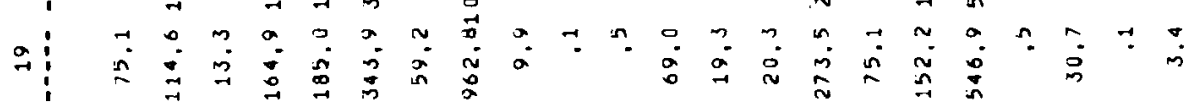

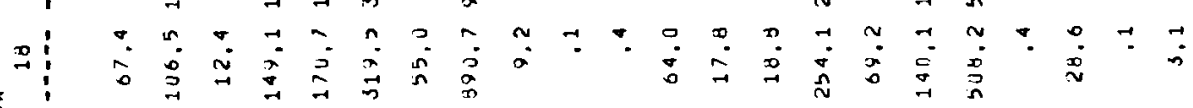

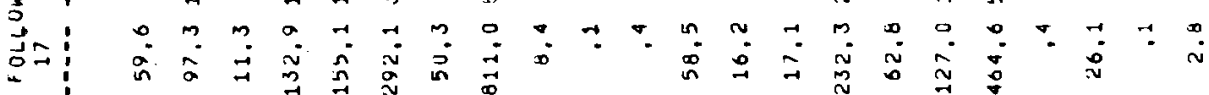

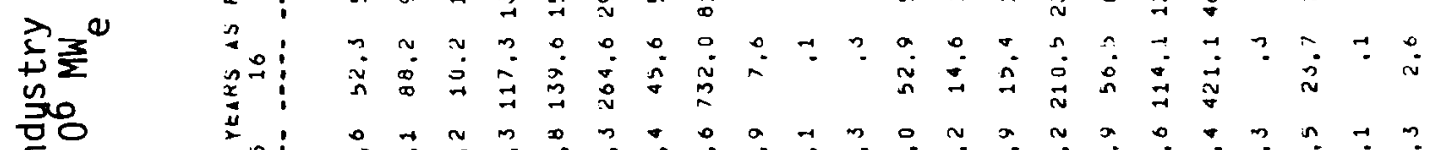
$\stackrel{\Xi}{=}$

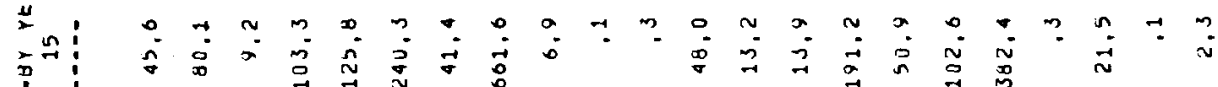

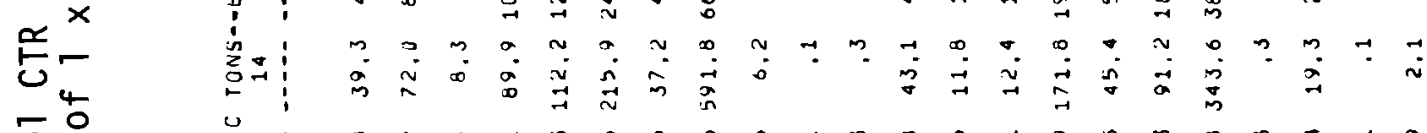

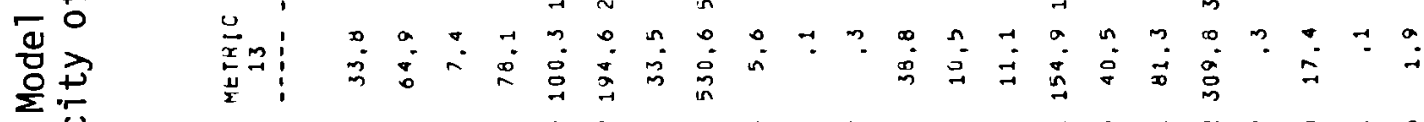

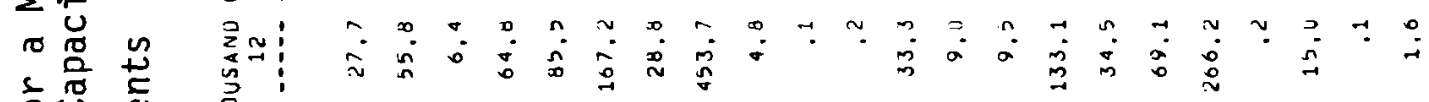
రิષ 西 $-1$

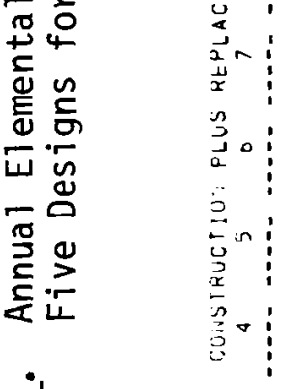

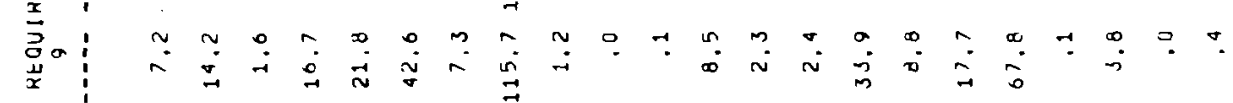

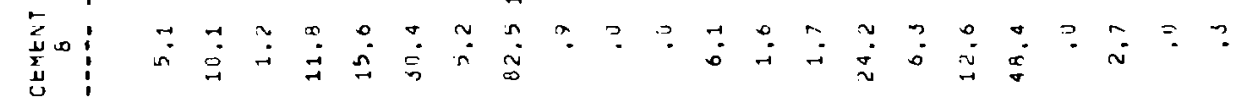

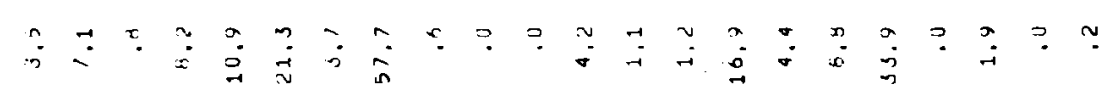

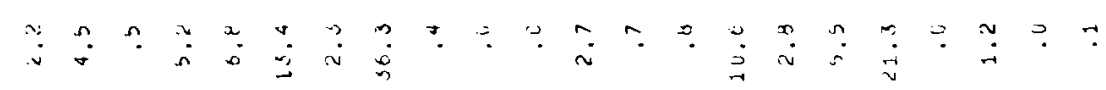

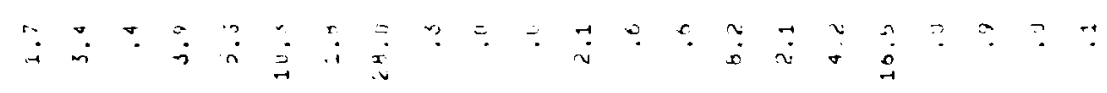

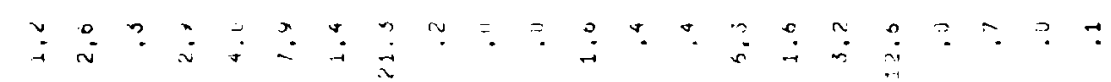

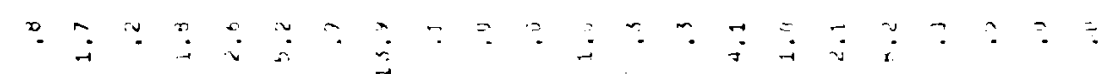

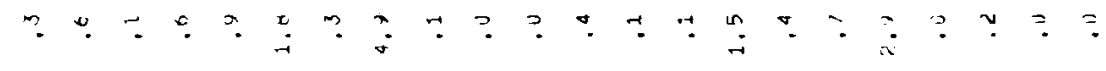

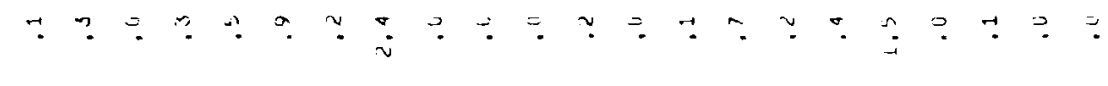

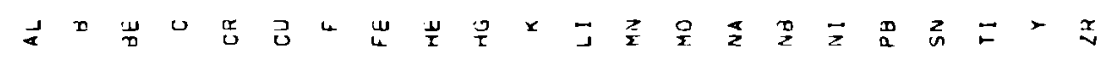




\section{REFERENCES FOR SECTION 4}

1. E. N. Cameron, University of Wisconsin, Preliminary Report on Availability of Metals for the UW Tokomak, June 1974.

2. A. P. Fraas, "Environmental Aspects of Fusion Power Plants," manuscript summarized in Trans. Am. Nucl. Soc., 15:628, 1972.

3. Draft Environmental Statement, Liquid Metal Fast Breeder Reactor Program, WASH-1535, Vo1. III, pp. 5-22, March 1974.

4. Laser-Fusion Semiannual Report - January/June 1973, Lawrence Livermore Laboratory Report, UCRL-50021-73-1.

5. R. L. Hirsch, Fusion Energy Program, Subpanel Report XI Used in Preparing the AEC Chairman's Report to the President, WASH-1281-11, USAEC, October 1973.

6. B. Badger et al., (30 authors), UMWAK-I, A Wisconsin Toroidal Fusion Reactor Design, UWFDM-68, University of Wisconsin, Revised March 1974.

7. A. P. Fraas, Conceptual Design of the Blanket and Shield Region and Related Systems for a Ful1 Scale Toroidal Fusion Reactor, ORNL-TM-3096, May 1973.

8. A Fusion Power Plant, R. G. Mills, Ed., MATT-1050, Princeton Plasma Physics Laboratory, 1974.

9. P. N. Haubenreich and M. Roberts, Eds., ORMAK F/BX A Tokamak Fusion Test Reactor, ORNL-TM-4634, Oak Ridge, TN, June 1974.

10. F. L. Riebe, compiler, Proposed Experiments on Heating, Staging and Stabilization of Theta Pinches, LA-5026-P, Los Alamos Scientific Laboratory, February 1973.

11. An Engineering Design Study of a Reference Theta-Pinch Reactor (RTPR), no author - 26 contributors, LA-5336, ANL-8019, (joint report), December 1973.

12. R. W. Werner, G. A. Carlson, J. Hovingh, J. D. Lee and M. A. Peterson, Progress Report \#2 on the Design Considerations for a Low Power Experimental Mirror Fusion Reactor, UCRL-74054-2, September 1973.

13. W. D. Metz, "Laser Fusion Secrecy Lifted: Microballoons Are the Trick," Science, V. 186, 8 November 1974.

14. L. A. Booth, Ed., Central Station Power Generation by Laser-Driven Fusion, LA-4858-MS, Vol. I. Los Alamos Scientific Laboratory, February 1972. 
15. A. P. Fraas, The Blascon - An Exploding Pellet Fusion Reactor, ORNL-TM-3231, Oak Ridge NationaT Laboratory, Ju1y 1971.

16. J. Hovingh, J. Maniscalco, M. Peterson, and R. W. Werner, "The Preliminary Design of a Suppressed Ablation Laser-Induced Fusion Reactor," CONF-740402-P1, Proceedings of the First Topical Meeting on the Technology of Controlled Thermonuclear Fusion, San Diego, CA, Apri1 16-18, 1974.

17. J. M. Williams, F. T. Finch, T. G. Frank and J. S. Gilbert, "Engineering Design Considerations for Laser Controlled Thermonuclear Reactors," Proceedings of the Fifth Symposium on Engineering Problems of Fusion Research, Princeton, NJ, November 6-9, 1973.

18. T. Frank, D. Freiwald, T. Merson, and J. Devaney, "A Laser Fusion Reactor Concept Utilizing Magnetic Fields for Cavity Wall Protection," CONF-740402-P1, Proceedings of the First Topical Meeting on the Technology of Controlled Nuclear Fusion, San Diego, CA, Apri1 16-18, 1974.

19. F. Bohn, H. Conrads, J. Darvas, S. Forster, "Some Design Aspects of Inertially Confined Fusion Reactors," Proceedings of the Fifth Symposium on Engineering Problems of Fusion Research, Princeton, NJ, November 6-9, 1973.

20. R. G. Mills, Ed.s A Fusion Power Plant. Report MATT-1050, Plasma Physics Laboratory, Princeton University, Princeton, NJ, August 1974.

21. UWMAK-I, A Wisconsin Toroida1 Fusion Reactor Design, Report UWFDM-68, Vo1. 1 (March 15, 1974) and rough draft of Volume II (February 12, 1975) University of Wisconsin Fusion Feasibility Study Group, (including participation by personnel from Westinghouse, Gulf General Atomics, Battelle Northwest, Sargent \& Lundy, Monsanto, Atomics International, and Babcock \& Wilcox, as well as numerous UW staff).

22. A. P. Fraas, Conceptual Design of the Blanket and Shield Region and Related Systems for a Full Scale Toroidal Fusion Reactor, ORNL-TM-3096, May 1973.

23. J. E. Draley, V. A. Maroni, T. A. Coultas, and R. A. Krakowski, "An Environmental Impact Study of a Reference Theta Pinch Reactor (RTPR)," CONF-740402-P1, p. 564, Proceedings of the First Topical Meeting on the Technology of Controlled Nuclear Fusion, San Diego, CA, Apri1 16-18, 1974.

24. J. M. Bunch, F. W. Clinard, D. J. Dudziak, W. V. Green, and R. A. Krakowski, "An Evaluation of Major Materials Problems Anticipated for the Reference Theta Pinch Reactor (RTPR)," paper presented at Materials Science Symposium, Detroit, MI, October 24, 1974.

25. J. R. Powe11, Ed., "Preliminary Reference Design of a Fusion Reactor Exhibiting Very Low Residual Radioactivity," Rough Draft Report, BNL, December 1974. 


\section{PROJECTED MATERIAL/COMMODITY AVAILABILITY}

\subsection{INTRODUCTION}

In considering the projected availability of materials for use in constructing fusion reactor complexes that potentially can provide a major energy source in the future, three basic aspects must be considered. These are:

1) The projected capabilities of manufacturing industries to supply the material requirements for a CTR-based electricity industry

2) The supply of raw materials (we will call these "commodities" in this report) from which articles of manufacture (i.e., "materials") will be made

3) The status of materials fabricating technology as required for the actual construction of CTR-based energy complexes.

Engineering studies at the national laboratories of ERDA related to CTR design concepts, and in particular, the specific conceptual design efforts at the Princeton Plasma Physics Laboratory $(1)$ and the ongoing studies at the University of Wisconsin ${ }^{(2)}$ have considered these aspects in some detail. For example, major considerations in the specification of stainless steel and a nickel-base alloy as nuclear island structurals for initial detailed conceptual design studies at the University of Wisconsin and Princeton, respectively, included the present existence of a manufacturing industry for these materials in quantities sufficient to support at least initial plant constructions, and also a wealth of design and fabrication experience for these materials. Also, in connection with an assessment of material requirements for the UWMAK I (University of Wisconsin Tokamak-conceptual design number 1), a section of Volume 2 of UWFDM-68 dealing with economically-scaled minerai reserves and resources was prepared by Professor E. N. Cameron of the University. Very briefly, Professor Cameron's review included an analys is of reserve availability and resource potential for lithium, chromium, nickel, copper, titanium, aluminum, vanadium, molybdenum, niobium, and beryllium. For lithium, copper, molybdenum, and beryllium, substantial reserves suggest that 
the U.S. will continue to be largely self-sufficient for several decades at anticipated levels of demand. Raw materials to satisfy domestic demands (including possibly CTR demand) for other materials may be expected to continue to come mostly from foreign sources. Specific conclusions by Professor Cameron relative to CTR material demands were:

1) Domestic reserves of 1ithium at present prices may or may not be sufficient to supply CTR requirements. At $3 x$ prices for 1 ithium ores, reserves should be "more than ample."

2) For beryl1ium, "it is clear that the $10^{6} \mathrm{MW}$ e target amount for the Princeton Tokamak is out of all proportion to the size of known U.S. and world reserves." And, "Intensive prospecting with the beryllometer is necessary to discover deposits of the Spor Mountain type. The chances of discovery are unpredictable."

Regarding the Princeton Tokamak design, Dr. R. G. Mills of the Princeton Plasma Physics Laboratory alluded to "questions about the potential supplies of resources such as nickel, helium, and a few others," and stated "The first generation plant described in this report, with its high requirement for beryllium, is clearly not suitable as an ultimate design" (MATT 1050, p. 539). (1) Thus, the economical, industrial, and technological availability of materials and fabrication processes are broadly recognized as potentially pacing or limiting factors in the possible development of a fusion-based energy industry. Some of this concern stems from the anticipated growth of the electricity-generating industry over the next few decades, whatever the fuel source, and some is specific to the needs of fusion reactors as the source of power. It is the intent of this chapter to assess domestic industrial capabilities for meeting probable demands specific to CTR requirements.

\subsection{PROJECTED DOMESTIC DEMAND: 2000-2020 A.D.}

To a first approximation, it is logical to assume that domestic industry that traffics in commodities/materials for which there is demand will continue to adjust its resources and output to meet that demand. This, of 
course, presumes the economic availability of raw materials and the availability of capital for plant growth to meet the demand. It also presumes that societal interactions will be tolerable within the cost/price spectrum which wi11 assist in establishing demand. In the broadest aspect, "demand" defines a sliding scale of consumption versus the price to be paid for the particular commodity or material. The past several years have emphasized the influence that societal concerns, both domestic and international, may have upon prices. Legislated ecological, health, and safety constraints relative to the conduct of the business of manufacturing are exerting appreciable force on the price of items of manufacture. The impact of OPEC action has had significant effects upon prices for virtually all products and services, and directly and indirectly contributed to at least temporary dislocation of consumer demand in many areas. Irksome though it may be to the precepts of a "free" economy, cartelization is very apt to be an international force to which domestic consumption and demand patterns, and economic structure must adapt for some of our needs. In short, relative to the supply of domestic demand by domestic industry in the future, politico-socio-economic policy and directions will become increasingly important. Where the price for domestically-produced goods becomes excessive, domestic demand will either be curtailed or foreign supply will become more significant, and vice versa. Indeed, recent increases in the cost of fossil energy and increased dependence on foreign supply (e.g., $12 \%$ of the domestic demand for crude petroleum was imported in 1970 versus $28 \%$ in 1974, according to C.D.S.) ${ }^{(3)}$ have stimulated interest in alternative sources of energy, such as CTR complexes, as well as decreasing lat least temporarily) the domestic demand for some of these products.

Despite uncertainties associated with relating domestic production capacity to projected demand, available demand projections stiil remain as the principal basis for estimates of future industrial capabilities. The most comprehensive treatment of long-range future demand for a wide variety of commodities is the U.S. Bureau of Mines, Mineral Facts and Problems $(4)$ (M.F. \& P). In this work, "contingency analysis" projections for domestic and "rest-of-world" demands to the year 2000 were presented. The "contingency analysis" methodology includes the incorporation of contingencies 
based on the specialist's understanding of various technological, economic social, environmental, etc., factors upon probable future trends that are expected to impact specific use areas for individual minerals or commodities (see Pp. 9 to 11 of M.F. \& P. for methodology description). (4) In comparison with, for example, historical trend-1ine projections as a predictive methodology, the Bureau of Mines analysis as a rule results in the higher estimates for commodity demand. Other projection methodologies most often are relatively conservative regarding projected consumption to the year 2000, owing in part to the more-recently-obvious impacts of various socio-economic factors. (5)

Demand projections and their implied stimulus to domestic industrial growth may be viewed from three aspects:

1) The influence of projected demand of mine production of raw materials

2) The influence on the primary manufacturing industry that converts raw material (e.g., ore) to the basic article of manufacture for which demand will exist (e.g., metallic or compound form).

3) In the case where a specific physical form (e.g., rolled plate, sheet, rod, wire, section, extrusion, forging, etc.) will be required, the influence upon the primary fabricating industry.

For some commodities/materials, integrated industrial structures indicate that a single, aggregated viewpoint is appropriate. For others, two or three of the viewpoints must be considered independently.

\subsubsection{Domestic Demand Analysis}

For initial assessments of the projected availability of elemental requirements to meet possible CTR demand, Bureau of Mines demand projections for the year $2000^{(4)}$ are indicated in Table 5.1. (Also included in Table 5.1 are estimated demands for the rest of the world, estimated demands for primary metals as appropriate and as available, and estimated cumulative demands for both the U.S. and the rest of the world.) The presumed CTR growth schedule specifies the year 2011 for the initiation of a CTR-based power industry, and a 20-year period through the year 2030 is the considered time to reach maturity. 
TABLE 5.1. Demand for Elements Projected to the Year 2000 A.D.

(Bureau of Mines, Reference 4, Base Year $=1968$ )

\begin{tabular}{|c|c|c|c|c|c|c|c|c|c|}
\hline \multirow[b]{3}{*}{ Element } & \multicolumn{4}{|c|}{ U.S. Demand, kmt } & \multicolumn{4}{|c|}{ Rest of World Demand, kmt } & \multirow{3}{*}{$\begin{array}{l}\text { Total World } \\
\text { Cum. Demand } \\
\text { On Resources } \\
\text { kmt }\end{array}$} \\
\hline & \multirow{2}{*}{\multicolumn{2}{|c|}{$\frac{\text { Year } 2000 \text { Demand }}{\text { Primary }}$}} & \multicolumn{2}{|c|}{$\begin{array}{l}1968-2000 \\
\text { Cumulative Demand }\end{array}$} & Year 200 & Demand & $\begin{array}{r}1968 \\
\text { Cumulat }\end{array}$ & $\begin{array}{l}8-2000 \\
\text { tive Demand }\end{array}$ & \\
\hline & & & Primary & Total & Primary & TotaT & Primary & Total & \\
\hline $\begin{array}{l}\text { Al (metal) } \\
B\end{array}$ & 23,000 & $\begin{array}{r}29,000 \\
280\end{array}$ & 336,000 & 5,100 & & $\begin{array}{r}45,000 \\
570\end{array}$ & & $\begin{array}{r}594,000 \\
9,800\end{array}$ & $\begin{array}{r}930,000 \\
15,000\end{array}$ \\
\hline $\mathrm{Be}$ & 1.4 & 1.5 & & 22 & & 0.8 & & 11 & 33 \\
\hline C & & 44,000 & & 910,000 & & 185,000 & & $4,940,000$ & $5,850,000$ \\
\hline $\mathrm{Cr}$ & 970 & 1,100 & 10000 & 21,000 & & 3,300 & & 69,000 & 90.000 \\
\hline $\begin{array}{l}\mathrm{Cu} \\
\mathrm{F}\end{array}$ & 5,800 & $\begin{array}{r}11,000 \\
2,200\end{array}$ & 100,000 & 38.000 & & $\begin{array}{r}24,000 \\
5,300\end{array}$ & 300,000 & 81.000 & $\begin{array}{l}400,000 \\
120,000\end{array}$ \\
\hline $\mathrm{Fe}$ & 140,000 & 170,000 & $3,400,000$ & & 590,000 & & $14,000,000$ & & $17,000,000$ \\
\hline $\mathrm{He}$ & & 12 & & 230 & & 3 & & 24 & 260 \\
\hline $\mathrm{Hg}$ & 4.4 & 5.2 & 100 & & & 16 & & 340 & 440 \\
\hline$k$ & & 11,000 & & 200,000 & & 45,000 & & 730,000 & 930,000 \\
\hline $\mathrm{Li}$ & & 9.9 & & 170 & & 6.3 & & 110 & 280 \\
\hline Mn & & 1,900 & & 45,000 & & 17,000 & & 340,000 & 390,000 \\
\hline Mo & & 81 & & 1,600 & & 150 & & 2,500 & 4,100 \\
\hline $\mathrm{Na}$ & & 54,000 & & $, 000,000$ & & 170,000 & & $2,700,000$ & $3,700,000$ \\
\hline$N b$ & & 8.7 & & 140 & & 12 & & 310 & 450 \\
\hline $\mathrm{Ni}$ & 420 & 500 & 8,200 & & & 840 & & 25,000 & 33,000 \\
\hline $\mathrm{Pb}$ & 1,900 & 3,000 & 40,000 & & 4,300 & & 100,000 & & 140,000 \\
\hline $\mathrm{Sn}$ & 85 & 120 & 7,400 & & & 290 & 7,500 & & 15,000 \\
\hline & & 1.9 & & 33 & & 1.8 & & 32 & 65 \\
\hline $\mathrm{Ti}$ (meta 1$)$ & 130 & & 4,000 & & & 130 & & 1,300 & 5,300 \\
\hline & & 29 & & 430 & & 31 & & 600 & 1,000 \\
\hline & & 0.1 & & 1.8 & & 0.05 & & 0.7 & 2.5 \\
\hline $\operatorname{Zr}(\operatorname{meta} 1)$ & 24 & 32 & & $340^{\circ}$ & & 22 & & 320 & 660 \\
\hline
\end{tabular}


To allow comparisons relating to the availability of commodities, the Bureau of Mines' contingency analysis estimates were extrapolated to the years 2010 and 2030. Table 5.2 presents these extrapolations, along with arinual growth rates used in the exercise. These projections do not include potential CTR demand. Also presented are "model" CTR material requirements in the years 2011 and 2030 and the highest-case demand for each commodity as defined by selected conceptual designs. The parenthetic values in Table 5.2 relate to total requirements (i.e., nuclear island and balance of plant).

Three comparisons are offered in Table 5.2. These are in the form of the following ratios:

1) CTR demand (per model data of Table 4.22, Section 4) on initiation of CTR industry buildup after demonstration (e.g., year 2011), divided by projected domestic demand in the year 2010 .

2) Maximum CTR model demand in the year 2030, divided by projected domestic demand for that year.

3) Maximum CTR demand in the year 2030 according to the maximum conceptual design requirements by element, divided by projected demand for year 2030. This value for CTR demand was assumed to be $12 \%$ of the maximum construction value stated in Table 4.13, Section 4, plus the maximum replacement amount.

Thus, a ratio of 0.01 indicates that CTR demand would consume only about $1 / 100$ of the projected domestic availability that would normally develop for other demand for that particular element; a ratio of 5.0 indicates that the CTR demand would be five times greater than the "normally" developing industrial capacity to supply other demand for that element, for example.

Where ratios presented in Table 5.2 are 0.01 or less, it is presumed that anticipated CTR requirements would not impact the ability of domestic industry (or commerce) to supply the particular elemental need. It is further presumed that at ratios up to about 0.10 , domestic commerce could readily plan to accommodate CTR demand without undue difficulty. At ratios much greater than 0.10 , the ability of domestic industry to supply anticipated CTR requirements requires review in greater depth. 
TABLE 5.2. CTR Demand Related to Industrial Supply Potential

CTR Requirements, $\mathrm{kmt}$ Model Demand Maximum Design Element

Demand in Year

$\begin{array}{lrrrr}\mathrm{Al} & 0.1 & 83 & 410 & \\ \mathrm{~B} & 0.3 & 123 & 480 & 6.4 \\ \mathrm{Be} & <0.1 & 14 & 55 & 3.9 \\ \mathrm{C} & 0.3 & 187 & 480 & 5.0 \\ \mathrm{Cr} & 0.5 & 200 & 540(1050) & 2.1 \\ \mathrm{Cu} & 0.9 & 368 & 620(890) & 2.8 \\ \mathrm{~F} & 0.2 & 63 & 320 & 4.7 \\ \mathrm{Fe} & 2.4 & 1036 & 1900(9700) & 4.2 \\ \mathrm{He} & <0.1 & 11 & 35 & 0.8 \\ \mathrm{Hg} & <0.1 & 0.1 & 0.2 & 3.5 \\ \mathrm{~K} & <0.1 & 0.5 & 2 & 2.3 \\ \mathrm{Li} & 0.2 & 74 & 140 & 4.0 \\ \mathrm{Mn} & <0.1 & 21 & 60(110) & 4.6 \\ \mathrm{Mo} & 0.1 & 22 & 290 & 2.0 \\ \mathrm{Na} & 0.7 & 293 & 1340 & 3.8 \\ \mathrm{Nb} & 0.2 & 81 & 260 & 4.1 \\ \mathrm{Ni} & 0.4 & 164 & 410(780) & 4.8 \\ \mathrm{~Pb} & 1.5 & 586 & 1700 & 3.4 \\ \mathrm{Sn} & <0.1 & 0.5 & 2 & 2.7 \\ \mathrm{Ta} & - & - & 510 & 1.1 \\ \mathrm{Ti} & 0.1 & 33 & 160 & 2.5 \\ \mathrm{~V} & - & - & 220 & 8.9 \\ \mathrm{Y} & <0.1 & 0.1 & 0.4 & 5.5 \\ \mathrm{Zr} & <0.1 & 3.6 & 9 & 4.4 \\ & & & & 5.7\end{array}$

Ratio of CTR Demand to Total Domestic Demand Model in Year Maximum Design $2011 \quad 2030$ in Year 2030

Domestic Demand kmt G.R. $2010 \quad 2030$

54,000
424
2.4
54,000
1,500
17,000
3,300
184,000
17
6.5
15,000
15.5
2,300
118
80,000
14
700
3,900
130
2.4
510
50
0.2
56

$\begin{array}{ll}< & 0.01 \\ < & 0.01\end{array}$ $6.5<0.04$ 82,000 82,000
2,500 44,000 7,600 216,000 34 10 36,000 3,400

$$
248
$$$$
180,000
$$$$
\begin{array}{r}
36 \\
1,360
\end{array}
$$$$
6,600
$$$$
165
$$$$
\begin{array}{r}
165 \\
4 \\
800
\end{array}
$$

2,800

140
0.4 170

$<0.01$

$<0.01$

$<0.01$

$<0.01$

$<0.01$

$<0.01$

$<0.01$

0.01
0.01

$<<0.01$

$<<0.01$

0.01

$\ll 0.01$

$<0.01$

$<0.01$

$\ll 0.01$

$<0.5$

$<0.01$
$<0.01<0.01$

$2.2-0.53$

$<0.01<0.01<0.01$

0.08

0.21

0.01

$0.01<0.01(0.05)$

0.32

0.01
1.0

$0.01 \quad 0.02$

$<0.01<0.01$

$<0.01 \quad 0.02(0.03)$

0.09

1.2

$<0.01<0.01$

$\begin{array}{ll}2.3 & 7.2 \\ 0.12 & 0.30\end{array}$

$0.09 \quad 0.26$

$<0.01 \quad 0.01$

0.01

127

0.06

- 1.6

$\begin{array}{ll}0.25 & 1.0 \\ 0.02 & 0.05\end{array}$ $\begin{array}{ll}1.9 & 3.7\end{array}$ 
From Table 5.2, it is accordingly judged that, based on presently available CTR conceptual design information and industrial/commerce growth to meet ex-CTR demand, aluminum, carbon, copper, fluorine, iron, mercury, potassium, manganese, sodium, tin, zirconium, and probably titanium will normally be available in amounts necessary to meet CTR demand. [An exception occurs for sintered aluminum product (SAP) as called for in a blanket design developed by BNL staff; ${ }^{(7)}$ SAP is discussed in more detail in Section 6.] of these elements, the U.S. is almost totally dependent upon foreign ore supply for manganese, mercury, and tin, and is heavily dependent upon foreign supply for aluminum (bauxite), fluorine (fluorspar), titanium (rutile) and zirconium (zircon). Potential domestic resources for aluminum, titanium, and zirconium are large, and technical/economic issues potentially could make U.S. industry independent of foreign supply. Sea-nodule technology (and politics) development could easily result in a manganese glut.

Of these noncritical elements, aluminum, carbon, copper, fluorine, iron, mercury, manganese, and tin would be used in forms that are readily compatible with present manufacturing industries; and industrial plant types, capacities, and manufacturing technologies are expected to be no problem. Present and projected markets for potassium and sodium are almost entirely based on use of these elements in salt or compound forms, rather than metallic form as required by CTR designs. Metallic sodium, for example, comprises only about $1 \%$ of the total sodium market. However, fused salt electrolys is processes for the manufacture of these metallics are well established, and capitalization required to meet the anticipated CTR markets would be modest. No "fabrication" would be required, as these metals would be used in bulk form as liquid metal heat transfer media.

Similarly, titanium and zirconium in metallic forms represent a small fraction ( 5 to $10 \%$ ) of the market. However, values cited in the preceding tables are for the metallic portions of market projections. These specialty metals industries have capabilities to supply materials in the forms required for anticipated CTR usage. Much of the CTR requirement for titanium and zirconium is as alloying ingredients in Nb alloys (super-conductive magnetic 
and first-wall and blanket structures), and the more critical consideration will be from the standpoint of the Nb alloy manufacturing industry.

The remaining elements in Table 5.2 for which potential CTR demand is significantly greater than $10 \%$ of the projected, normally developing status of domestic industry and/or commerce include:

1) Structural material requirements

- Stainless steel and nickel base alloy

- Nicke1

- Chromium

- Molybdenum

- Niobium

- Molybdenum, tantalum, vanadium (not yet cited in specific designs)

2) Magnet materials

- Stainless steel

- Nickel

- Chromium

- Molybdenum

- Niobium

- Vanadium (possibly)

3) "Bulk" materials and chemicals

- Boron

- Beryllium

- Helium

- Lithium

- Lead

- Yttrium

These elements and materials are discussed in greater detail in Section 6.

\subsubsection{Capacity for Structural Material Manufacture}

Major structural materials, as distinct from "elemental" requirements, specified by the various CTR conceptual designs include the following: 
Austenitic Stainless Steels

- Type 304

- Type 316

PE-16

Carbon and Alloy Steels

Aluminum and Alloys

Concrete

Table 5.3 presents a summary of estimated maximum annual structural material requirements for a model industry equally comprising UWMAK I, PPPL, ORMAK, RTPR, and BNL/UWMAK designs. "Balance of plant" requirements have been aggregated by arbitrarily assigning some of the UWMAK I balance of plant estimates as representing other types of plants as wel1. This is no doubt invalid, but does serve to pinpoint some potential supply problems. Also included in Table 5.3 are estimated requirements for some specific nonstructural items of manufacture $\left(\mathrm{B}_{4} \mathrm{C}\right.$, superconductors, $\left.\mathrm{flibe}\right)$. These are discussed in Section 6 . Brief reviews of projected capabilities of domestic industry to meet potential CTR structural material requirements are presented in the following paragraphs.

TABLE 5.3. Approximate Maximum Annual CTR Requirements (Year 2030) for Selected Materials of Manufacture, Model Industry, Equal Participation by Five Designs, $10^{6} \mathrm{MW}_{\mathrm{e}}$ Capacity

Construction Ruclear Balance of

$\frac{\text { Mater }}{316 \mathrm{SS}}$

304 SS

PE-16

$C$ and

Alloy Steel

$\mathrm{B}_{4} \mathrm{C}$

$\mathrm{Nb}-\mathrm{Ti}$

$\mathrm{Nb}_{3} \mathrm{Sn}$

FLIBE

SAP

Concrete Island

970

53

12

360

150

62

1.6

75

67

1,200
Plant

93

$$
2,700
$$

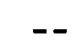

5,400
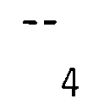

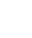

Replacement Requirements, $\mathrm{kmt}$

25

--

15
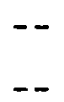

$-$

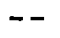

$-$

$--$

28
Total

Requirements, kmt Nuclear Total Island Plant $1,000 \quad 1,090$ 532,800

12 27

$\begin{array}{rr}360 & 5,800 \\ 150 & 150 \\ 62 & 66 \\ 2 & 2 \\ 75 & 75 \\ 67 & 95\end{array}$




\section{Stainless Steel}

The stainless steel industry is a specialized segment of the steel industry. Most steel plants have ample capacity, and technical capability for the manufacture of most grades of stainless steel, but production for this specialty market is concentrated in only a relatively few steel mills. Equipment and capability for manufacture exists to meet possible demand for stainless steel that is several times greater than current demand.

The market for 316 and 304 stainless steel supplied by domestic production was $770 \mathrm{kmt}$ in 1973 and $930 \mathrm{kmt}$ in 1974 according to W. Kaestner of the U.S. Department of Commerce. This represented roughly $0.8 \%$ of domestic demand for steel mill products. Long-range projections of demand and domestic production for the steel industry in general have been made by the Bureau of

Mines ${ }^{(4)}$ and other organizations. ${ }^{(8,9)}$ Demand estimates for the year 2000 A.D. range from roughly $170 \mathrm{Mmt}$ (million metric tons) to $240 \mathrm{Mmt}$, with an average of perhaps $200 \mathrm{Mmt}$. Projected to the year 2030 A.D., using the Bureau of Mines annual growth rate, "average" demand would be about 280 Mnt.

Long-range projections for stainless steel products, or more specifically, 304 and 316 grades, are not available. However, the demand for stainless steels relative to total steel industry is expected to grow substantially. If one assumes that in the year 2030, demand for 304 and 316 products would comprise $1.5 \%$ of the total steel demand, then domestic demand for 304 and 316 in 2030 would be about 4-1/4 Mt. This assumed demand for these popular grades of stainless steel describes an annual compounded growth rate of $3 \%$. This incidentally, matches very closely the median growth rate projected by the Bureau of Mines for nickel, a distinctive consumable descriptor of the industry producing 300-series stainless steels. It thus appears not unreasonable to expect an ex-CTR demand for 304 and 316 of between 4.0 and 4.5 Mmt in the year 2030.

From Table 5.3, the maximum annual CTR demand for types 304 and 316 stainless steels is estimated to be roughly $1 \mathrm{Mmt}$ for the nuclear island alone, but about 4 mt for total plant requirements. Thus, nuclear island 
needs in years of maximum growth would demand 20 to $25 \%$ of the capacity of the projected stainless steel industry, or conversely would require a 20 to $25 \%$ expansion of that industry's output. As the necessity for this expansion would become apparent within the first few years of maturation, management of the required growth should be routine.

The greater balance-of-plant requirements for austenitic stainless steels are more apt to constrain growth of a CTR-based energy industry. The extent to which non-CTR-based energy plants would require similar amounts of these materials has not been assessed, but it is likely that the anticipated development of the post-2000 A.D. electrical industry would face similar constraints-if not for stainless steels, then for other heat-and-corrosion resistant materials. CTR balance-of-plant requirements for austenitic stainless steels would approach the total industry output. However, even at a $2 x$ output requirement, adequate time for planning of expansion, if needed, would be available.

Thus, the domestic aspects of supply of stainless steel to meet CTR requirements in years of maximum demand is viewed as a problem that would be overcome with normal planning, and probably would not comprise a major constraint to growth of a CTR-based industry.

\section{Nickel-Base Alloy}

The Wiggin Alloy PE-16 requirement specified by the PPPL design is projected to require a maximum of $27 \mathrm{kmt}$ per year in the balanced model industry. (A $10^{6} \mathrm{ME}_{\mathrm{e}}$ industry based on the PPPL design alone would require about $150 \mathrm{kmt}$ in the year 2030.)

Long-range demand projections for high nickel alloys, such as PE-16 are not available. However, roughly $30 \%$ of primary nickel consumed domestically is converted to nickel-base alloy (and superalloy) products by the specialized nickel alloy "rolling mi11" industry. Assuming that this ratio is valid for long-range projections, the demand for primary nickel in high-nickel alloys would be about $130 \mathrm{kmt}$ in the year 2000, and roughly $340 \mathrm{kmt}$ in 2030, using the Bureau of Mines projected median annual growth rate. If one further assumes that home and prompt scrap will acount for 20 to $30 \%$ of production, 
the indicated capacity of the nickel alloy industry (which would supply PE-16) would be between 400 and $450 \mathrm{kmt}$ in the year 2030. Demand for a balanced model CTR industry would be roughly $6 \%$ of this projected industry capacity.

Trend-line analysis of "rolling mill" deliveries from International Nickel Company cited for 1962 through $1970^{(10)}$ were projected to the year 2030 as an indication of what might be expected from a major producer of mill products. This projection suggested that "normal growth" of the Inco Mills (Huntington Alloy's and Henry Wiggin) might be expected to result in production levels (for all products) on the order of $90 \mathrm{kmt}$ and $125 \mathrm{kmt}$ in the years 2010 and 2030, respectively. A total industry capacity of about twice these levels seems respectably conservative. Nickel alloy supply appears to be no real problem for this "model" approach.

Carbon and Alloy Steels

Most of the steel requirements relate to balance of plant needs. Total estimated CTR-based industry needs in the year 2020 are slightly in excess of $5 \mathrm{Mmt}$. Compared to the projected steel industry capacity of $200 \mathrm{Mmt}$ in 2020 A.D., CTR requirements for steel products wouid scarceiy inipact thie steel industry to a serious degree.

\section{Aluminum Alloys (SAP)}

The requirement of substance for aluminum alloys in CTR deisgn is encountered in the Brookhaven minimum activation blanket and shield design for which material needs are summarized in Table 4.18, Section 4. For the "model" industry to which the BNL design is assumed to contribute $200 \mathrm{KMW}_{\mathrm{e}}$ capacity, aluminum alloy requirements for this design would be about $70 \% \mathrm{kmt}$ in 2030 , the postulated year of maximum demand. As indicated in Table 5.2, this demand plus lesser demands for other designs in that year would be 1ess than $1 \%$ of the projected domestic aluminum industry production in the year 2030.

However, early BNL designs specified that sintered aluminum product (SAP) would be the material from which the shield and blanket modules would be fabricated. At present, SAP production by domestic industry is negligible. When SAP was being produced, maximum annual production was only about $45 \mathrm{mt}$ according 
to $K$. Buchavecky of the Alcoa Technical Center. As a powder metallurgy product, the manufacturing technology for SAP varies appreciably from that exercised in the manufacture of more conventional structural aluminum alloys.

In discussion with $K$. Buchavecky (Alcoa), recent improvements in technology based on exploratory production of high strength powder metallurgy alloys and upon developments in pigment production indicated that improved SAP in larger-sized ingots (such as would be required by the BNL CTR design) could now be made in quantity with about 2 years' lead time. The quantities required should pose no problems, presuming adequate commercial incentive (profit) and not too stringent purity requirements. Very high purity requirements would introduce problems with metal supply.

Potential purity requirements appear important to the minimum activation concept. Thus, whether SAP ${ }^{(7)}$ or a special high-purity, conventional wrought alloy of the 6000 , or perhaps 5000 series would be used, (11) supply of lowimpurity grades of a aluminum might be a problem. Alcoa Technical Center's A. Craig is investigating means of producing aluminum with a maximum of $10 \mathrm{ppm}$ impurities. If this proves successful, metal supply should be no problem.

\section{Concrete}

Al though not aggregated in Table 4.22 , Section 4 , the estimated maximum annual requirement for concrete indicated by the model industry nuclear is land aggregation of Table 4.19 , Section 4 , is $12.5 \mathrm{Mmt}$. Total plant requirements might approach $50 \mathrm{Mmt}$. This demand is projected to occur in the year 2030.

In 1973, cement production was $82 \mathrm{Mmt}$, and crushed stone, sand and gravel consumption ( $95 \%$ of which went to the construction industry with a significant fraction dedicated to the mixing of concrete) was $1850 \mathrm{Mmt}$. (12) The estimated ready-mix concrete industry capacity in 1974 was $1.5 \times 10^{8} \mathrm{~m}^{3}\left(2 \times 10^{8}\right.$ in $\left.y d\right)$, which is roughly equivalent to $350 \mathrm{Mmt}$. Short-range growth projections (e.g., 10-year forecasts) for concrete are most commonly cited as between 2 and $4 \%$ per year. If this rate (e.g., $3 \%$ ) is used to project capacity to the year 2030, an indicated capacity of 1800 Mmt results. On this basis, CTR 
concrete requirements for the nuclear island would be 1 ess than $1 \%$ of capacity in the year of maximum CTR demand. For total requirements of about $50 \mathrm{Mmt}$, CTR requirements would be less than $3 \%$ of capacity for concrete. Future industrial capability to supply concrete to meet CTR demand is not considered a potential problem.

\subsubsection{Foreign Supply of Selected Commodities}

Boron, beryllium, chromium, helium, lithium, molybdenum, niobium, nickel, lead, tantalum, vanadium, and yttrium are comriocities for which detailed considerations are presented in Section 6. For the other elemental CTR requirements, this section will discuss the dependence of domestic demand upon foreign supply.

\section{Aluminum}

Domestic production of bauxite, the raw material from which aluminum is won, amounts to only 10 to $15 \%$ of domestic bauxite consumption, and even this smal1 fraction has been waning in recent years. (3) Imports of alumina, as well as bauxite, have increased substantially in the past 5 years. Major sources utilized by U.S. indusiry for bauxite are Jamaica, Surinam, Dominican Republic, and Guyana, and for alumina, Australia, Jamaica, and Surinam. These "friendly" sources are considered stable, but the possibility of cartelization could prove economically disruptive. Given sufficient economic incentive and an adequate energy base, abundant low-grade U.S. resources such as the Georgia kaolins could be brought into production.

Domestic production of primary and secondary aluminum typically accounts for greater than $90 \%$ of annual domestic consumption of aluminum. For practical purposes, the U.S. is self-sufficient regarding aluminum manufacture. The majority of a? uminum imported comes from Canada. Domestic primary aluminum capacity is estimated to be $32 \%$ of total world capacity, and the U.S. in 1972-1974 accounted for 34-35\% of estimated world production.

With the possible exception of technological advances brought about by short-term dislocations resulting from cartel action in the supply of foreign bauxite/aluminum, no changes in the supply pattern for aluminum are envisioned. CTR demand wi11 be adequately met by the industry. 


\section{Copper}

The domestic copper industry (mines, smelters, refineries) is by design marginally adequate relative to domestic demand. The impetus for this industrial strategy is to avoid overcapitalization in an industry where large periodic price fluctuations historically occur. Thus, the U.S. is a net importer of copper in ore, blister, and refined forms. By design, domestic mine production slightly lags smelter capacity, which in turn slightly lags refinery capacity, which in turn slightly lags domestic demand. Nevertheless, the domestic refining industry typically supplies $90 \%$ or more of domestic demand, domestic mines typically supply about $75 \%$ of demand, ${ }^{(3)}$ and except for economic conservatism in the industry, the U.S. may be considered selfsufficient in a 11 regards. About $20 \%$ of domestic demand is supplied by the domestic secondary copper industry. The industry relies upon principally Canada, Peru, and Chile for imports. In 1972-1974, domestic mines accounted for 20 to $22 \%$ of world mine production for copper.

This industry structure and approach toward supply of the domestic demand is considered stable for the foreseeable future. The supply of copper to meet CTR requirements should pose no problems.

\section{Fluorine}

The demand for fluorine in the manufacture of industrial chemicals (into which category flibe would fit) comprises about one-third of the total market for the primary raw material, fluorspar. ${ }^{(3)}$ Although flibe is not now a significant product of manufacture, its manufacture would very conveniently fit chemical plant operations according to $S$. Roboff of Kawecki Berylco Industries and N. Bass and S. Zenczak of Brush-Wellman, Inc. (Beryllium fluoride is an intermediate product in the manufacture of beryllium metal, and lithium fluoride is widely used as a flux. Thus, fluorine use is directly related to the beryllium and lithium industries discussed in Section 6. )

From 1970 to 1974, domestic production of fluorspar decreased from about 20 to $15 \%$ of domestic demand. ${ }^{(3)}$ Domestic industry is thus increasingly heavily dependent upon imports, principally from Mexico, but with notable 
imports also from Spain and Italy. These sources of supply presently appear stable, but cartel action is a possible economic threat. Fluorine production as a byproduct from phosphate processing is a domestic source of supply fostered by environmental regulations. Continued regulatory pressures coupled with economic incentive deriving from depletion of the highest quality fluorspar deposits could allow by-product fluorine from phosphate rock treatment to totally meet domestic demand for fluorine by 2000 A.D.

Presuming the continued stability of economic foreign supply of fluorspar, fluorine availability and use is not considered to be a pacing factor in the development of a CTR-based electrical industry.

Iron

Economic competition is and will continue to be the principal factor in establishing the balance between domestic production and imports in meeting domestic demand for iron and stee1. Currently, imports (chiefly from Canada and Venezuela) account for roughly one-third of the iron ore consumed by the domestic iron and steel industry. ${ }^{(3)}$ The U.S. is also a net importer of iron and steel products, with imports exceeding exports bj about 3 to 5 times in 1970-1974. Shipments from domestic mills supplied about $92 \%$ of apparent domestic demand in 1973-1974, up from about $85 \%$ in 1971-1972.

The maintenance of a viable iron and steel industry is vital to the growth of any industrial society, and the continued 1ong-range health of the domestic iron and steel industry must be presumed. The capability of the domestic industry to supply CTR demands for general construction and alloy steels is accordingly taken for granted for the purposes of this study.

\section{Mercury}

The CTR demand for mercury in vacuum pumps is smal1 relative to the projected domestic demand for other uses of mercury. However, environmental pressures have recently forestalled growth in domestic mercury consumption, and annual consumption through the early 1970s remained between 50 and 60 thousand flasks, down from the 75 to 100 thousand flasks per year level of the mid and late 1960s. Nevertheless, worldwide mercury consumption is 
presently projected to grow at a compound annual rate of $2.2 \%$ through the end of this century. (13) Growth in domestic demand will probably lag this rate. (3)

Domestic primary production of mercury in the past 5 years has decreased markedly in the face of falling prices for mercury since the late 1960s. In 1970, domestic primary and secondary production accounted for 44 and $13 \%$ of domestic consumption; in 1974 domestic primary production supplied a mere $3 \%$ of demand, and secondary production 15\%. (3) Despite the announced plans by one company to bring a primary plant capable of meeting about one-third of current demand on stream in 1975, the U.S. will continue to be heavily dependent upon foreign supply barring a large upturn in price or proof of newplant technical economics. Canada is the major supplier of mercury to the U.S., and Algeria, Mexico, and Spain are also suppliers of significance. Attempted cartelization in 1974 was unsuccessful.

Despite present U.S. dependence upon foreign supply for mercury, the future availability of mercury to meet modest CTR demands is not considered to be a problem.

\section{Potassium and Sodium}

Metallic sodium and potassium are very minor segments of industry that traffics in common salt and potash, respectively. Metallic sodium is won commercially from sodium chloride by electrolysis of the molten salt. In 1969, industrial capacity for sodium production was estimated as $170 \mathrm{kmt}$, and short-range growth projections estimated an annual growth rate of $3 \%$ per year. (14) As most sodium is used in the manufacture of tetraethyl lead and tetramethyl lead, the future growth in demand for sodium is more tenuous than it was a few years ago. A forecast made in 1972 (15) projected a decrease of $7 \%$ in demand through 1976 . Recent production, however, has remained high (146, 160, and $157 \mathrm{kmt}$ in 1972, 1973, and 1974, respectively).

In a 5 year period from 1961 to 1966, production was increased by more than 50\% in response to demand. A similar increase in capacity, if required, to meet CTR demand as it develops in the time frame from 2011 to 2030 A.D. (see Table 4.22, Section 4) appears well within the capabilities of the industry. 
Consumption of salt in the manufacture of metallic sodium presently comprises less than $1 \%$ of salt consumption for other purposes. Imports of salt for consumption are between 5 and 10\% of the supply. CTR demand would scarcely affect this raw material market.

Most potash is produced as the chloride (KCl) from which metallic potassium may be made by reaction of the molten chloride with sodium, and distilling potassium from the resulting molten sodium-potassium alloy. Potash consumption (mostly as fertilizerj grew from 4.3 Mt in 1970 to $5.5 \mathrm{Mmt}$ in 1974: (3) and continued short-range growth at $4 \%$ per annum is expected. Domestic production during this period was steady at about 2.4 Mmt. Imports (almost a 11 from Canada) accordingly increased. Reversal of the oversupply situation in potash in 1973 is stimulating interest in increased exploitation of domestic resources.

The sma11 CTR-related potential demand for metallic potassium will be of no concern.

\section{Manganese}

As with steel. CTR requirements for manganese are small relative to the size of demand (in steel) for ex-CTR use in the 2010-2030 projections. The U.S. steel industry is totally dependent upon foreign supply of manganese ore provided by Brazil, Gabon, South Africa, and Zaire. Imports of ferromanganese (South Africa, France, India) have been steadily increasing in proportion to domestic production of ferromanganese from imported ore. ${ }^{(3)}$ As manganese is essential to the domestic steel industry, in assuming continued viability of the steel industry, one must also assume continued supply of manganese. Manganese apart from steel requirements does not figure in CTR requirements.

A strong political deterrant to the development of deep-sea nodule resources is the adverse economic impact the resulting manganese glut could have on nations to which manganese revenues are critical.

$\underline{\text { Tin }}$

Domestic mine production of tin is miniscule, and domestic smelters of principally imported ore supply less than $10 \%$ of domestic consumption. The 
domestic secondary industry supplies roughly one-fourth of domestic demand. The U.S. is for practical purposes, totally dependent upon imports to meet demand for new tin. Malaysia and Thailand are the major sources of tin for the U.S. (3) The development of substitutes for tin in several applications has resulted in virtual stagnation of domestic tin demand for several years. By virtue of control exercised by the International Tin Council, supplies of tin at a reasonable economy appear assured.

The small amount of tin indicated as a CTR requirement by the model approach is no cause for concern.

\section{Titanium and Zirconium}

Both titanium and zirconium metals represent small fractions of total ore consumption. In the case of titanium metal, the U.S. is practically totally dependent upon imports of rutile (Australia), the ore from which titanium is made. Ilmenite, a potential titanium ore, is produced domestically to a level to meet 70 to $80 \%$ of domestic demand, however. The U.S. is also a net importer of titanium metal (sponge), relying on Japan, the Soviet Union, and the United Kingdom. The present structure is dictated largely by economic factors. Sponge imports typically supply about one-fourth of domestic demand. Domestic industry supplies virtually all domestic demand for mill products. (13)

Roughly half of domestic demand for zircon is supplied by Australia, with the balance apparently produced domestically. The U.S. is a net exporter of zirconium metal, and is totally self-sufficient in all aspects of zirconium metal.

Domestic industrial production of both metals is projected with a high rate of growth. Reliance on foreign ore supply will probably continue for the foreseeable future. In crisis situation, the U.S. could be selfsufficient in all aspects relative to these two metals. No major impacts are foreseen to result from CTR demands for these metals. 


\subsection{RESERVES/RESOURCES}

The term "reserves" is applied to the earth's mineral resources that are presently economically extractable and are known to exist in specific deposits. Reserves may be classified as "proved," "inferred," "probable," "possible," etc.

"Resources" may be "identified" or "undiscovered." Identified resources are often interpreted to include reserves, but additionally include known or inferred mineralization that cannot be economically extracted. Such resources are frequently quantified according to their estimated availability at $1.5,3$, or 10 times the cost of current mining and extraction technology.

Introductory chapters in USGS $820^{(16)}$ provide some excellent discussion on the classification of resources, as well as a comprehensive treatise on mineral resources and reserves. This source, Commodity Data Summaries ${ }^{(3)}$ by the Bureau of Mines, and the previously-mentioned survey of selected material resources by Professor Cameron ${ }^{(2)}$ were briefly examined to assess the ability of domestic and world mineral resources to meet CTR material requirements.

Any methodology of assessing adequacy of distant-future supply upon currently-defined reserves (whether "proved," "inferred," "probabie," etc.) is fraught with risk. Reserves are usually proved up by developers only to the extent necessary to justify reasonable near-term economic exploitation of a resource. To do otherwise would entail unnecessary economic penalty. As a consequence, estimates of reserves, particularly proved reserves, are traditionally conservative. Nevertheless, estimates of reserves are used in the present analysis to infer where cases of short-fall might be expected for elements required by the "model" CTR-based industry as it might be currently envisioned.

Table 5.4 lists an order-of-magnitude concensus of reserves and adaitional probable resources from the above-cited sources for most of the elemental requirements for a 20-year-maturing CTR industry. For first-order assessments of reserve adequacy in light of demand, cumulative demands through the year 2000 (from Reference 4) for consumption other than CTR purposes, and also the cumulative, 20-year requirements for the "model" nuclear island of a CTR-based industry (the last column from Tabie 4.22) are 1 isted. 
TABLE 5.4. Adequacy of Reserves for Elements by "Model" CTR

\begin{tabular}{|c|c|c|c|c|c|c|c|c|c|}
\hline \multirow[b]{2}{*}{ Element } & \multicolumn{2}{|c|}{$\begin{array}{c}\text { Approximate } \\
\text { Reserves, } \\
\text { Pint }\end{array}$} & \multicolumn{2}{|c|}{$\begin{array}{l}\text { Estimated } \\
\text { Approx. Added } \\
\text { Resources, Mmt }\end{array}$} & \multicolumn{2}{|c|}{$\begin{array}{l}\text { Cumulative Ex-CTR } \\
\text { Demand to }(4) \\
2000, \mathrm{Mmt}^{4}\end{array}$} & \multirow{2}{*}{$\begin{array}{c}\text { Cumulative } \\
\text { (20 Yr) CTR } \\
\text { Model Demand, } \\
\text { Mmt, Table } \\
4.22\end{array}$} & \multirow{2}{*}{$\begin{array}{l}\text { EX CTR Cum } \\
\text { World Demand/ } \\
\text { World Reserve } \\
\text { (Ratio) }\end{array}$} & \multirow{2}{*}{$\begin{array}{l}\text { Cum. CTR } \\
\text { Model } \\
\text { Demand / } \\
\text { World Res. } \\
\text { (Ratio) }\end{array}$} \\
\hline & $t \quad$ U.S & World & U.S. & World & U.S. & Wor $1 \mathrm{~d}$ & & & \\
\hline $\begin{array}{l}\text { Al } \\
\mathrm{Be}\end{array}$ & $\begin{array}{l}10 \\
0.03\end{array}$ & $\begin{array}{r}3,000 \\
0.05\end{array}$ & $\begin{array}{r}1,000 \\
0.05\end{array}$ & $\begin{array}{l}3,000 \\
0.7(?\end{array}$ & $\begin{array}{r}340 \\
\quad 0.02\end{array}$ & $\begin{array}{l}900 \\
0.03\end{array}$ & $\begin{array}{l}0.5 \\
0.1\end{array}$ & $\begin{array}{l}0.3 \\
0.6\end{array}$ & ${ }_{2} .01$ \\
\hline $\begin{array}{l}\mathrm{B} \\
\mathrm{Cr} \\
\mathrm{Cu} \\
\mathrm{F} \\
\mathrm{Fe} \\
\mathrm{He} \\
\mathrm{Hg} \\
\mathrm{K} \\
\mathrm{Li} \\
\mathrm{Mn}\end{array}$ & $\begin{array}{c}28 \\
0 \\
70 \\
3 \\
1,800 \\
0.8 \\
0.01 \\
0.2 \\
0.6 \\
0\end{array}$ & $\begin{array}{r}77 \\
400 \\
350 \\
40 \\
88,000 \\
-- \\
0.2 \\
67 \\
2 \\
1,800\end{array}$ & $\begin{array}{c}100(?) \\
1 \\
100 \\
7 \\
18,000 \\
3.2 \\
0.02 \\
\text { inexhau } \\
4 \\
65\end{array}$ & $\begin{array}{c}? \\
1,000 \\
500 \\
90 \\
180,000 \\
-- \\
\text { stible } \\
-- \\
\text { large }\end{array}$ & $\begin{array}{c}5.1 \\
21 \\
100 \\
38 \\
3,400 \\
0.2 \\
0.1 \\
200 \\
0.2 \\
45\end{array}$ & $\begin{array}{c}15 \\
90 \\
400 \\
120 \\
17,000 \\
0.3 \\
0.4 \\
900 \\
0.3 \\
400\end{array}$ & $\begin{array}{l}0.9 \\
1.4 \\
2.7 \\
0.5 \\
7.5 \\
0.08 \\
0.001 \\
0.004 \\
0.5 \\
0.2\end{array}$ & $\begin{array}{c}0.2 \\
0.2 \\
1.1 \\
3.0 \\
0.2 \\
0.4 \\
2.0 \\
13 . \\
0.2 \\
0.2\end{array}$ & $\begin{array}{c}<.01 \\
<.01 \\
<.01 \\
0.01 \\
<<.01 \\
0.1 \\
<.01 \\
<<.01 \\
0.3 \\
<<.01\end{array}$ \\
\hline $\begin{array}{l}\mathrm{YO} \\
\mathrm{Na} \\
\mathrm{Nb} \\
\mathrm{Ni} \\
\mathrm{Pb} \\
\mathrm{Sn} \\
\mathrm{Ta} \\
\mathrm{Ti} \\
\mathrm{V} \\
\mathrm{Y} \\
\mathrm{Zr}\end{array}$ & $\begin{array}{c}4 \\
---. \\
0.01 \\
0.2 \\
40 \\
0.04 \\
0 \\
30 \\
0.1 \\
n i 1 \\
5\end{array}$ & $\begin{array}{c}8 \\
-\quad \text { inexhaus } \\
8 \\
30 \\
140 \\
10 \\
0.05 \\
140 \\
10 \\
0.03 \\
15\end{array}$ & $\begin{array}{c}100(?) \\
\text { stible }-- \\
0.1 \\
14 \\
- \\
0.2 \\
-- \\
120 \\
2 \\
\text { large } \\
\text { large }\end{array}$ & $\begin{array}{c}1,000(?) \\
---- \\
\text { large } \\
70 \\
1,500 \\
27 \\
? \\
1,000 \\
v . \text { large } \\
\text { large } \\
\text { large }\end{array}$ & $\begin{array}{c}1,2 \\
1,000 \\
0.15 \\
8 \\
40 \\
3 \\
0.03 \\
4 \\
0.4 \\
0.002 \\
0.3\end{array}$ & $\begin{array}{c}4 \\
4,000 \\
0.3 \\
24 \\
140 \\
8 \\
0.06 \\
5 \\
1 \\
0.003 \\
0.7\end{array}$ & $\begin{array}{l}0.2(2.5)^{\mathrm{a}} \\
2.1 \\
0.6(2.2)^{\mathrm{a}} \\
1.2 \\
4.3 \\
0.004 \\
(4.4)^{\mathrm{a}} \\
0.2 \\
(1.9)^{\mathrm{a}} \\
0.001 \\
0.03\end{array}$ & $\begin{array}{l}0.5 \\
0 \\
0.04 \\
1.2 \\
1.0 \\
0.8 \\
1.2 \\
0.04 \\
0.1 \\
0.1 \\
0.05\end{array}$ & $\begin{array}{l}0.03(0.3)^{\mathrm{a}} \\
0 \\
0.1(0.3)^{\mathrm{a}} \\
0.04 \\
0.03 \\
<.01 \\
(38)^{\mathrm{a}} \\
<.01 \\
(0.19)^{\mathrm{a}} \\
0.03 \\
<.01\end{array}$ \\
\hline
\end{tabular}

a. Values in parentheses presume maximum design demands for cases where all CTR machines would use the indicated refractory metal in design for maturation of a $106 \mathrm{MW}$ industry. 
(Nuclear island, rather than "total plant" requirements would be used with the presumption that balance-of-plant requirements would be redundant with non-CTR sources of electric power.) Assessments are made in the form of ratios of 1) cumulative world demand, other than CTR, divided by world reserves, and 2) cumulative model CTR requirements divided by world reserves.

From the assessment in Table 5.4, reserves of raw materials for aluminum, boron, chromium, iron, manganese, sodium, titanium, zirconium, and probably yttrium appear ample for well into the next century (ex-CTR demand/reserves $\leq 0.5)$, and demands upon reserves by a developing CTR industry are negligible (CTR demand/reserves generally 50.01 ). For helium (a special topic, as reserves are wasting without utility--see Section 6), lithium, Mo, Nb, and V, general demand is also small ( $\leq 0.5 \times$ reserves $)$, but CTR demand over the 20-year maturation period is somewhat more significant, and could well become pacing with continued CTR growth beyond the initial 20-year period.

The group of elemental requirements that includes copper, fluorine, mercury, potassium, nickel, lead, and tin comprises materials whose reserves as defined by present technology and economics may be less than adequate to meet general world demand through the remainder of this century (ex-CTR ratio approaching or exceeding 1), but CTR demand per se would not aggravate this situation appreciably. For these elements, the following "situation statements" are offered.

Copper - Identified lower grade resources presently considered conditional or submarginal will be used to meet demands well into the next century. Commercialization of seanodule resources could add greatly to reserves.

Fluorine - Even considering "hypothetical reserves" of conventional nature, fluorspar from which most fluorine is derived, will be in a potential short-fall situation about the time CTR commercialization comes about. Fluorine contained $(\sim 3 \%)$ in marine phosphate rock may become a major source of supply by the year 2000. Billions of tons of fluorine are contained in this submarginal resource. 
Mercury - Reserves and particularly resources for mercury are probably conservative. $(3,16)$ In addition, economic and environmentally-driven curtailment of mercury demand in recent years suggests that supply in and beyond the year 2000 will not be critical.

Potassium - Reserves are developed as needed. Resources in identified deposits are huge. All sources reviewed indicate no cause for alarm by the high ratio of demand/reserves cited in Table 5.4.

Nickel - Identified resources, which include large laterite deposits, will be developed to meet demand.

Lead - Identified resources will, with a high degree of certainty, add to reserves to meet demand as needed.

Tin - Available information places definite limits on suspected, unidentified tin resources. (16) However, these resources when added to reserves will probably be sufficient to sustain demand well into the next century. (3) Recent trends in tin consumption suggest that cited cumulative demand through 2000 may be high. Increasing use of alternate materials may reduce the general demand/reserves ratio to 0.5 or less.

The final category of CTR elemental requirements includes those elements for which cumulative model CTR requirements are large relative to other projected cumulative requirements. These include beryllium, lithium, and refractory metals for the cases where major design utilization for them is inferred. It is clear that any major use of Ta as a CTR blanket structural could not be supported by the severely 1 imited reserves, nor even speculative resources. Likewise, beryllium requirements as estimated by the CTR model (which includes the PPPL design) could not be supported by known reserves, although speculative world resources, if realized, could support such use. Large CTR use of $\mathrm{Mo}, \mathrm{Nb}$, and $V$ could most likely be supported by presently-defined reserves. 
In the case of Mo, general demand coupled with the widespread use of this material as a CTR structural would require development of additional mineral resources as the CTR industry matures.

\subsection{SINTERED ALUMINUM PRODUCT}

Sintered aluminum powder (SAP) is strengthened by the presence of a finely divided dispersion of aluminum oxide formed from an oxide surface scale intentionally developed on the powder prior to processing. It shows excellent retention of strength up to the melting point of aluminum $\left(600^{\circ} \mathrm{C}\right)$, but is not competitive with conventionally strengthened alloys below about $250^{\circ} \mathrm{C}$. Applications for SAP to date have been quite limited.

SAP products are normally produced in a semifinished form by extrusion, a process which acts to improve the bonding between aluminum particles and to form the oxide dispersion. Subsequent processing can then be accomplished by conventional forming methods such as forging, rolling, drawing, machining, etc. Although the ability to produce a uniform billet by powder processing methods limits the maximum quantity of material which can be processed, recent advances in processing methods made during the development of high strength aluminum powder metallurgy alloys have permitted the processing of billets weighing as much as $1400 \mathrm{~kg}$ according to $\mathrm{K}$. Buchavecky of Alcoa. Thus, it is likely that SAP products for the manufacture of blanket modules of the dimensions proposed in current BNL designs $(7,11)$ could be produced without difficulty. However, it is important to note that such products are not now available and would require advances in present SAP state-of-the-art.

In order to obtain the desired low activation behavior, it is probable that a new SAP product, perhaps based upon super purity (99.999\%) aluminum, would have to be developed. Except for increased cost, it is not anticipated that such a product would provide any problems.

Since the strength of SAP is dependent upon the dispersed oxide phase, conventional fusion welding processes cannot be used in joining. When SAP is melted, the oxide agglomerates and segregates within the fusion zone, drastically reducing properties. Brazing is also of limited usefulness, due 
to a tendency for excessive gas contents in SAP and partly due to the inherent limitations as applied to aluminum alloys. Vacuum processing, as developed in recent years for aluminum powder metallurgy products, can be expected to reduce gas problems says K. Buchavecky (Alcoa), but brazing can probably not be considered a useful process for joining aluminum components for high temperature service. Joining processes such as cold pressure welding, eutectic welding, and flash welding have been used successfully in the past to join SAP components. Whether such processes could be applied successfully to the more massive components envisioned in current blanket module designs is questionable. Joining appears likely to prove a major deterrent to the use of SAP in the construction of blanket modules.

The use of conventional wrought alloys, water cooled to reduce the maximum service temperature, has been proposed in more recent BNL minimum activation blanket module designs. (11) Aluminum alloys in either the 6000 series (Al-Mg-Si) or 5000 series $(\mathrm{Al}-\mathrm{Mg}$ ) can be considered for this application if the service temperature is reduced to about $200^{\circ} \mathrm{C}$. Joining problems with either type of alloy would be reduced and considerable experience with both types of materials in pressure vessel construction is available. In this case also, high purity alloys would have to be developed to maintain a low activation level. Such products, because of the importance of minor alloy additions on alloy behavior (e.g., grain size control and property control during fabrication and service), might prove more difficult to achieve than high purity SAP products.

\subsection{RESUME OF FORECAST MATERIAL/COMMODITY STATUS}

Table 5.5 summarizes the preliminary findings as discussed in this chapter. For each of the major elemental and material requirements, the projected industrial status relative to supply of a growing CTR industry demands is coded as to 1 ) adequate, or 2) inadequate (with helium as a special case). For those elements/materials for which the forecast industry output will be sufficient, comments relative to potential short-fall in raw material resources and domestic dependence on world reserves have already been addressed in this 
chapter. These include carbon and alloy steels, aluminum (including SAP), concrete, copper, fluorine, mercury, potassium, sodium, tin, titanium, and zirconium.

Materials and elements for which there is question regarding projected industrial capacity sufficient to meet CTR requirements include stainless steels, nickel-base alloys, boron, beryllium, chromium, helium, lithium, molybdenum, niobium, lead, tantalum, vanadium, and yttrium. Additional, more-detailed investigations of the likely status of future commerce in these materials were conducted, and are reported in Section 6 . 
TABLE 5.5. Summary of Material Supply Capability in Response to Probable CTR Requirements (See next page for coding remarks)

\begin{tabular}{|c|c|c|c|c|}
\hline El ement & $\begin{array}{l}\text { Projected } \\
\text { Industrial } \\
\text { Manufacturing } \\
\text { Capacity } \\
\text { Status } \\
\end{array}$ & $\begin{array}{c}\text { Manufacturing } \\
\text { Technology } \\
\text { Readiness } \\
\end{array}$ & $\begin{array}{l}\text { Projected } \\
\text { Adequacy } \\
\text { of Reserve }\end{array}$ & $\begin{array}{c}\text { Source of } \\
\text { Raw Material } \\
\text { Supply } \\
\end{array}$ \\
\hline $\mathrm{Al}$ & 1 & 1 & 1 & 3 \\
\hline B & 2 & 1 & 1 & 1 \\
\hline $\mathrm{Be}$ & 2 & 1 & 4 & 2 \\
\hline $\mathrm{Cr}$ & 2 & 1 & 1 & 4 \\
\hline $\mathrm{Cu}$ & 1 & 1 & 3 & 2 \\
\hline $\mathrm{F}$ & 1 & 1 & 3 & 3 \\
\hline $\mathrm{He}$ & 5 & 5 & 5 & 5 \\
\hline $\mathrm{Fe}$ & 1 & 1 & 1 & 2 \\
\hline $\mathrm{Hg}$ & 1 & 1 & 2 & 3 \\
\hline K & 1 & 1 & 1 & 3 \\
\hline $\mathrm{Li}$ & 2 & 1 & 3 & 1 \\
\hline$M n$ & 1 & 1 & 1 & 4 \\
\hline Mo & 2 & 2 & 2 & 1 \\
\hline $\mathrm{Na}$ & 1 & 1 & 1 & 1 \\
\hline $\mathrm{Nb}$ & 2 & 1 & 2 & 4 \\
\hline $\mathrm{Ni}$ & 2 & 1 & 2 & 3 \\
\hline $\mathrm{Pb}$ & 2 & 1 & 2 & 2 \\
\hline Sn & 1 & 1 & 2 & 4 \\
\hline $\mathrm{Ta}$ & 2 & 1 & 4 & 4 \\
\hline $\mathrm{Ti}$ & 1 & 1 & 1 & 3 \\
\hline v & 2 & 2 & 2 & 3 \\
\hline Y & 2 & 1 & 1 & 1 \\
\hline $\mathrm{Zr}$ & 1 & 1 & 1 & 2 \\
\hline \multicolumn{5}{|l|}{ Material } \\
\hline Stainless Steel & 2 & 1 & & \\
\hline Ni-Base Alloy & 2 & 1 & & \\
\hline C \& Alloy Steel & 1 & 1 & & \\
\hline Al Alloys & 1 & 1 & & \\
\hline Concrete & 1 & 1 & & \\
\hline
\end{tabular}


Rank Schedule for Table:

Domestic Industrial Supply Capacity

1) No Problems Envisioned

2) CTR Demands Warrant Study

5) Special Case

Manufacturing/Fabrication Technology

1) Present Technology = CTR Requirements

2) Manufacturing Development Needed

5) Special Case

Reserve/Resource Adequacy

1) Reserves Adequate

2) Reserves Probably Adequate; Necessary Resource Development Probable

3) Resources Adequate; Higher Prices Likely

4) Reserves Inadequate; Resources Undefined or Inadequate

5) Special Case

Source of Supply of Raw Materials

1) Total Domestic Self-Sufficiency

2) Some Foreign Dependency Based on Economics

3) Primary Dependent on Foreign Supply; Self-Sufficiency will Depend on Technico/Economic Situation in Future

4) U.S. Will Continue to be Dependent on Foreign Supply 


\section{REFERENCES FOR SECTION 5}

1. A Fusion Power Plant, R. G. Mi11s, Ed., Report MATT-1050, August 1974, Plasma Physics Laboratory, Princeton University, Princeton, NJ.

2. UWMAK-I, A Wisconsin Toroidal Fusion Reactor Design, Report UWFDM-68, Vo1. I (March 15, 1974) and rough draft of Volume II (February 12, 1975) University of Wisconsin Fusion Feasibility Study Group, (including participation by personnel from Westinghouse, Gulf General Atomics, Battelle-Northwest, Sargent \& Lundy, Monsanto, Atomics International, and Babcock \& Wilcox, as well as numerous UW staff).

3. Conmodity Data Summaries-1975. Bureau of Mines (Resource information by Geological Survey), U.S. Department of the Interior.

4. Mineral Facts and Problems, 1970 Edition, Bureau of Mines Bulletin 650, by staff, Bureau of Mines, U.S. Government Printing Office, 1970.

5. D. B. Brooks and P. W. Andrews, "Mineral Resources, Economic Growth, and World Population," Science, Vol. 185, No. 4145, pp. 13-19, July 1974.

6. G. L. Kulcinski, Potential CTR Requirements for Helium up to Year 2020, UWFDM-83, Apri 1 , 1974.

7. J. R. Powell, F. T. Miles, A. Arovson, and W. E. Winsche, Studies of Fusion Reactor Blankets with Minimum Radioactive Inventory and with Tritium Breeding in Solid Lithium Compounds: A Preliminary Report June 1973, BNL-18236, Brookhaven National Laboratory, Upton, NY. (See also BNL-18439, and CONF-740402-P1, pp. 533-547.)

8. Material Needs and the Environment - Today and Tomorrow, Final Report of the National Commission on Materials Policy, June 1973, pp. 2-9.

9. H. N. Landsberg, L. L. Fischmann, and J. L. Fisher, Resources in America's Future, The John Hopkins Press, Baltimore, MD, 1963.

10. Metal Statistics, 1974, Fairchild Publications, Inc., NY, p. 193.

11. J. R. Powe11, Ed., "Preliminary Reference Design of a Fusion Reactor Exhibiting Very Low Residual Radioactivity," Rough draft report, BNL, December 1974.

12. "Rock Products Forecast," Sidney Levine, Rock Products, Vo1. 77, No. 12, December 1974, p. 43.

13. Engineering and Mining Journa1, March 1975. 
14. "Sodium and Compounds," K. L. Lindsay, The Encyclopedia of Chemistry, Hampe1 and Lawley, etc., Van Nostrand Reinhold Company, NY.

15. Chemical Market Reporter, June 5, 1972, p. 9.

16. United States Mineral Resources, Brobst and Pratt, eds., USDI Geological Survey Professional Paper 820, U.S. Printing Office, 1973. 


\section{DETAILED EVALUATION OF SELECTED MATERIALS/COMMODITIES}

Initial screening of material requirements associated with the potential buildup of a fusion-based electrical power generating industry as presented in previous sections has identified a number of elemental or material-ofmanufacture requirements for which there may be supply problems from aspects of technological or commercial readiness, potential industrial capacity limitations, and/or potential short-fall of raw materials. For these materials/ commodities, additional investigations were instituted, and for several, representatives of the pertinent industries were contacted for additional information and discussions.

In general summary, the industry contacts displayed much interest, as would be expected when dealing with a potentially sizeable future market for their product(s). In all cases, the response of industry management was positive. Some comments were to the effect that CTR requirements, although large, would be managed totally by industry, but lead times of 10 to 20 years might be required for planned capitalization and expansion of industry capacity. Other comments (more usual) were to the effect that CTR requirements could be readily accommodated by industry with but minor plant expansions.

Specific discussions of the more-detailed treatments are presented in the following paragraphs.

\subsection{STRUCTURAL MATERIALS}

\subsubsection{Stainless Steel and Nickel Alloy}

The UWMAK-I design, based upon a 316 stainless steel blanket and shield design, the PPPL design, based upon the use of PE-16 (a nickel-iron-chromium alloy) as the blanket structural material, the use of austenitic stainless steel in magnet structures and cryogenic dewars for magnetic confinement machines, and in various piping, ducting, and manifolds would demand large quantities of these nickel- and chromium-bearing materials. Maximum utilization of such materials is called for by the UWMAK-I design. If the total industry (e.g., $10^{6} \mathrm{MW}_{\mathrm{e}}$ ) were to comprise this design, a total of about 
$24 \mathrm{Mmt}$ (million metric tons) of austenitic stainless steel would be required for the nuclear island over the 20-year span of maturation, with a like amount for balance-of-plant requirements. Total requirements could thus be as great as about $50 \mathrm{Mmt}$ of $316+304$, or as great as about $5 \mathrm{Mmt}$ in the year of greatest consumption. ("Model" requirements would be somewhat less than this.) At this "maximum" requirement (the PPPL design uses the high nickel alloy, PE-16, but in lesser amounts, so nickel, chromium, and Mo demand is less), elemental requirements of potentially critical nature are:

\begin{tabular}{|c|c|c|}
\hline Element & $\begin{array}{c}\text { Total Demand, } \\
\text { Mmt } \\
\end{array}$ & $\begin{array}{l}\text { Maximum } \\
\text { Annual Demand, } \\
\text { Mmt } \\
\end{array}$ \\
\hline Chromium & 9 & 0.9 \\
\hline Nickel & 7 & 0.7 \\
\hline Molybdenum & 1 & 0.1 \\
\hline
\end{tabular}

The projected expected capability of the steel industry to meet CTR demands during maturation was discussed briefly in Section 5.2.2 of this report, with the general conclusion that total demands would require some long-range ( 10 years) planning, but probably would not be limiting. A more detailed review of steel industry statistics ${ }^{(1)}$ reinforces the conclusion, as follows.

From 1950 to the present, the domestic steel industry has grown at a compound annual rate of $1.5 \%$, whereas the stainless portion of the steel industry has grown at a rate of $3.2 \%$ (based on net shipments). In 1950, stainless and heat-resisting steels (407 kmt shipped) comprised $0.6 \%$ of the net tonnage of steel shipped; in 1974 the corresponding level was $1.2 \%$ (1220 kmt shipped). Years in between have shown a quite regular and continuous gain in importance of stainless steels. Both 1973 and 1974 were record years for shipments of stainless steel, recording successive $220 \%$ growths over best prior years. This attests the stainless industry's ability to rapidly adapt to specialty product market demands. 
Specific examination of 304 and 316 shows that from 1950 to 1954 , these grades amounted to 18\% of stainless production. In 1955-1959 these grades accounted for $23 \%$ of stainless production, and by $1973-1974$, $45 \%$ of stainless production was in these two austenitic grades.

Projecting shipments of stainless and heat-resisting steels from the domestic industry at the annual growth rate shown in the 1 ast 25 years of $3.2 \%$ results in the following estimates for shipment.

\begin{tabular}{ccc} 
Year & \multicolumn{2}{c}{$\begin{array}{c}\text { Projected Shipments of Stainless } \\
\text { and Heat-Resisting }\end{array}$} \\
\cline { 2 - 3 } 2010 & $\begin{array}{c}\text { Average of 1970- } \\
\text { 1974 as Basis }\end{array}$ & $\begin{array}{c}1974 \text { Shipments } \\
\text { as Basis }\end{array}$ \\
2030 & 3.2 & 4.2 \\
\cline { 2 - 3 } & 5.9 & 7.9
\end{tabular}

Thus, in the year 2010, projected domestic shipments to meet demand would be at least $3.2 \mathrm{Mmt}$, and might well be as high as $4.2 \mathrm{Mmt}$. Should the trend in shipments shown for the past 10 years continue (average annual compound growth of 4.3 + percent), shipments in 2010 A.D. could be 6.2 Mit. Assuming 1) an estimate of $4 \mathrm{Mmt}$ to be realistic, 2) continued growth for ex-CTR demand to proceed at an annual rate of $3.2 \%$, and 3) growth of a CTR industry as postulated by Hartley, ${ }^{(2)}$ the maximum CTR demand for stainless steel to supply an industry based on the UWMAK-I total plant design could be met if shipments of stainless steel increased at a compound annual rate of 5.9 beginning in 2011 A.D., or slightly less than double the projected "normal" growth rate. (To satisfy nuclear island demand only, the rate of growth in annual shipments would need to be $4.8 \%$.) Based on the "mode1" design using estimated requirements for austenitic stainless steels for five different conceptual designs, CTR demand for nuclear island construction and operations would be met at a rate of growth of shipments of $3.9 \%$ per year and total plant requirements would be met at a growth rate of about $5.4 \%$.

These rates of growth are not large, and should be able to be met by the steel industry with a minimum of difficulty. With these growth rates, stainless steel shipments in the year 2030 project to: 
Model Approach for CTR

Total Shipments

11.3 Mmt

Ex-CTR Demand

$7.5 \mathrm{Mmt}$

Nuclear Island Demand

$1.0 \mathrm{Mmt}$

Balance of Plant Demand

$2.8 \mathrm{Mmt}$

Maximum Design Approach (UWMAK I)

Total Shipments

12.6 Mmt

Ex-CTR Demand

$7.5 \mathrm{Mmt}$

Nuclear Island Demand

$2.6 \mathrm{Mmt}$

Balance of Plant Demand

$2.6 \mathrm{Mmt}$

Demand similar to "balance of plant" would probably be required if HTGR- and LMFBR-based industries develop rather than CTR machines.

Stainless steels are predominately melted in either electric arc or induction furnaces. Growth in use of electric furnaces in the steel industry has been rapid in recent years. Barring serious limitations in the availability of electric power (which may well occur), continued rapid growth in electric steelmaking capacity (hence, stainless capacity) is expected. Stainless steel can also be (but most often is not) manufactured by the BoF process in conjunction with vacuum degassing. Normal growth, coupled with developing technological changes in the steel industry are compatible with the achievement of ample melting capacity for stainless steel such as projected for even the high requirements of the most demanding CTR conceptual design.

Primary fabrication of stainless steel to mill product forms is well established for all shapes and forms including plate, sheet, strip, bar, rod, wire, tubing, pipe, forgings, fasteners, flanges, and fittings. These products are commonly purchased under appropriate AISI, SAE, AMS, or ASTM specifications which require standards of chemical, physical, and mechanical quality. Because of differences in primary fabrication processes between stainless steels and the larger tonnage carbon steels, the production of stainless steel is commonly done at steel mills that specialize in the manufacture of stainless and alloy steels. In addition to the major producers of 
stainless steel, many smaller specialty alloy manufacturers also produce stainless steel products and forms according to their specialty lines (e.g., tubing, wire, strip, etc.).

No technological difficulties are envisioned regarding the supply of stainless steels in the forms and quantities that would be required by a developing CTR industry as presently envisioned.

The nickel alloy PE-16 used as a design basis by PPPL would be required in much less amounts than required for austenitic stainless steels. If onefifth of the projected $1 \times 10^{6} \mathrm{MW}$ capacity were to use PE-16 as a blanket structure, total requirements during the 20-year maturation period would be less than $0.15 \mathrm{Mmt}$, and maximum annual requirement would be $0.03 \mathrm{Mmt}$. Measured against a projected industry annual production capacity of 10 to 15 times this amount in the year of maximum requirement, the normally-growing nickel alloy manufacturing industry could meet requirements. In the event that the total CTR base were to require nickel alloy blanket structure according to the PPPL design, annual demand could swell one-third to one-half of the projected industry's annual capacity, and programmed industrial growth to match this demand would be required. Instead of a projected industrial annual growth rate of $3.3 \%$ for nickel alloy mi11s, a growth rate of about $5 \%$ per year beginning in the year 2010 would be required. Planning for and financing this slight increase in annual capacity growth rate should provide no unusual problems.

$\mathrm{PE}-16$, with a nominal composition of $43 \% \mathrm{Ni}, 35 \% \mathrm{Fe}, 17 \% \mathrm{Cr}, 3 \% \mathrm{Mo}, 1 \% \mathrm{Ti}$, $1 \% \mathrm{Al}$, is an age-hardenable material. In the annealed condition it is readily cold fabricable, and is weldable. Solution-treatment plus aging is required to develop optimum properties upon which its design use in the PPPL machine is based. As a consequence, facilities for heat treating fabricated assemblies are called for in the PPPL plan. (3) Final assembly welds would be made on annealed material, and the design provides for such welds to be in lower fluence regions away from the plasma.

The presumed complex blanket segment assemblies coupled with the need for "air cooling" following solution treatment of PE-16 prior to aging 
suggests that elaborate fixturing for heat-treatment may be required. Ingenuity in the design of heat treatment processes and equipment will probably be required. Until details of component fabrication and heat treatment have been "finalized" difficulties in maintaining uniformity of properties cannot be assessed for designs utilizing heat-treatable blanket structures.

\section{Chromium Supply}

Chromium, nickel, and Mo demand associated with the use of stainless steels and PE-16 according to the 5 -design model would require a maximum of $8 \%, 12 \%$, and $9 \%$, respectively, of the projected annual domestic demand for these elements. Presuming adequate mineral reserves, increasing the mine and refinery or ferroalloy capacity by an additional 10\% or so over a 20 -year period would cause no problem at all. The forms in which these elements would be used would be fully compatible with present and projected industry technology, and no new technology would be required.

Demand for these elements that would arise from maximum design considerations (i.e., $10^{6} \mathrm{MW}_{\mathrm{e}}$ with UWMAK-I for chromium and nickel demand, and UWMAK-III for Mo--UWMAK-III conceptual design information and Mo demand was not available when this analysis was made) would intensify somewhat the demand on mineral resources. For the UWMAK-I case, nuclear island demands relative to ex-CTR demand in the year 2030 would be 19, 30, and 31\% for chromium, nickel, and Mo, respectively, and for total plant demand, the respective percentages would be 42,60, and 88 . Even with these relatively high demands, supplies of raw materials to the stainless steel industry would require only about $2 \%$ additional supply annually to keep pace with the "maximum" CTR demand during maturation. The presumed case for UWMAK-III (Mo blanket) is discussed in a later section.

The U.S. has no chromium reserves, and submarginal resources (which have been exploited in war years) are negligible except possibly at $10 \mathrm{x}$ prices. (4) Cameron has indexed world chromium reserves on the basis of Thayer's publication in USGS-820, (5) and estimated about 340 Mmt of contained chromium available at $1 \times$ prices, about 810 Mmt available at $3 \times$ prices, with additional 
hypothetical resources estimated at about $1100 \mathrm{Mmt}$ (the latter includes principally the deep, unexplored resources estimated for the Bushveld Complex). The largest world reserves are associated with the Bushveld Complex of South Africa and the Great Dyke of Rhodesia. $(4,6)$

As a consequence, the U.S. imports 211 of its requirements for new chromium. Major sources for chromite are the U.S.S.R. (31\%), South Africa (29\%), Turkey (18\%), Phillipines (15\%), and for ferrochromium, South Africa (36\%), Rhodesia (16\%), Japan (13\%), and other nations. The poriticaleconomic tenor at present leads to some uncertainly relative to the future domestic supply/demand situation. According to U.S. Department of Commerce's W. Kaestner, specialists there believe that chromium will always be available to the U.S.; the principal question is, at what price? He also speculated that in the long range, South African Nations may become a dominent world force in the supply of primary stainless steel ingot as they have become in ferrochromium.

As indicated previously, (Table 5.1), CTR "model" demand for chromium in less than $1 \%$ of present $(1 X)$ reserves. The maximum cumulative demand for chromium estimated from the UWMAK-I total plant requirements for stainless steels during maturation, and including scheduled blanket replacements, would be about 9 Mmt. This would represent between 2 and $3 \%$ of $1 \times$ reserves, but less than $1 \%$ of presently estimated $3 \times$ reserves. Forecast demand, updated from the 1968 Bureau of Mines contingency analysis projections, * through 2000 (63 Mmt) would consume oniy some $15 \%$ of present reserves. There is no need to develop additional chromium resources to satisfy the 20-year growth requirements for a CTR industry (as limited domestic and North American resources are not economicaily viabie). Whiat is needed is the development of a national policy with respect to chromium that will assure its continued supply from abroad, at acceptable prices.

* In projections for commodities considered in this chapter, the rates of growth cited by Bureau of Mines in M.F. \& P. 1970, based upon pre-1969 demand was used to extend projections to the year 2030 based upon 1974 estimated production. 


\section{Nickel Supply}

Domestic nickel reserves are very small ( $180 \mathrm{kmt}$ contained nickel). The largest domestic resource is the Duluth Gabbro, estimated to contain 12 to 13 Mmt of nicke1. This is low grade averaging $0.21 \%$ nickel, but also contains about $0.64 \%$ copper, which makes it attractive. Cameron estimates that this resource might be exploited at $3 \times$ prices; ${ }^{(4)}$ however, formidable environmental problems are apparent and may block such development. Current world reserves are more than sufficient to supply the projected cumulative world demand (revised to $218 \mathrm{Mmt}$ ) through 2030. Presently identified resources may be developed to supply nickel (at $\sim 3 \times$ prices, according to Cameron) through the 21 st century.

The development of economic processes "to extract the $0.2-0.4 \%$ of nickel universally disseminated through peridotites and serprentines would result in vast amounts of nickel" becoming available (Cornwal1, p. 442, Reference 5). Seafloor nodules contain several hundred Mmt of nickel, and pending resolution of political and technological difficulties could supply large amounts of coproduct nickel, copper, cobalt, and a gross oversupply of manganese.

CTR cumulative demand for nickel in stainless steel is not large relative to world reserves, for the "model" case. For the "maximum design" case (UWMAK-I), CTR requirements would be about $25 \%$ of current world reserves, and about $10 \%$ of conventional resources. Good possibilities exist for new, significant reserves based on geological understanding arising from the Thompson reserve in Canada. (5)

The maximum potential CTR demand for nickel in stainless steel is sufficient to cause mild concern about the availability of nickel to meet this demand. The potential problem is not considered critical at this time, however. The stainless steel requirements of the UWMAK-I design for other than blanket and shield needs are appreciably greater than those required for the case of the nuclear island. This raises the question, do similar needs exist for stainless in auxiliary and support facilities and in the electrical generating plants associated with the concepts which have not yet been detailed to the extent that UWMAK-I has? Flibe storage tanks, energy storage structures, 
gas processing equipment, and tritium trapping systems, etc., are examples of support facilities that appear not to have been analyzed in compiling stainless steel (or other material) requirements for several designs, some of which were used in the model approach. Thus, nickel requirements may more closely apporach the "maximum" than the "model" requirements.

As conceptual designs continue to be developed, nickel requirements in stainless steel or nickel-base alloys that would be used in large quantities should be tallied. In the interim between the present and the actual beginning of growth of a CTR-based electrical power industry, the rate of depletion of reserves and the development of new nickel reserves should be monitored.

Molybdenum Supply

This discussion pertains only to Mo requirements associated with the use of Mo as an alloying addition in stainless and alloy steels (UWMAK-I) or PE-16 (PPPL). Maximum Mo cumulative needs (UWMAK-I exclusively) for a $10^{6} \mathrm{MW}_{\mathrm{e}}$ industry, maturing over 20 years, would be about $1 \mathrm{Mmt}$. The five-design model would require about $0.2 \mathrm{Mmt}$.

Domestic reserves of Mo are conservatively estimated at 4 to $5 \mathrm{Mmt}$, principally as sulfides in Colorado properties, but with a substantial amount to be produced as by-product from Cu-Mo porphyry deposits. Identified world reserves comprise a similar amount. Identified resources are several times this amount, and speculative reserves based upon geological understanding are very large.

Cumulative world demand for Mo through the year 2000 is estimated at about $4 \mathrm{Mnt}$, or about one-half of present reserves. With continued growth at an annual rate of $3.7 \%$ (Bureau of Mines projection through 2000 ), world consumption ex-CTR by the year 2020 would deplete present reserves. Maximum CTR cumulative demand for the 2010-2030 period would require the development of 10-15\% additional reserves from the large resource estimates. This is not expected to be a problem, as the continuing development of Mo reserves may be expected to keep pace with the consumption of present reserves.

The U.S. is totally self-sufficient in Mo, and domestic sources supply most of the world demand for Mo. The development of either "model" or 
"maximum" (stainless stee1) demand for Mo in CTR use would add less than 5\% to the projected domestic demand for Mo in the year 2030. This level of increase could be routinely accommodated by the domestic Mo industry.

\subsubsection{Refractory Metals}

The fabrication of CTR components from refractory metal alloys was recognized as a potentially critical area requiring special attention in this task. Accordingly, a specific study by the McDonnell Douglas Corporation of the status of this subject was undertaken, and is in a separate report, BNWL-2053. This section addresses the subject of the potential supply of mill products by domestic industry to meet possible CTR demands for refractory metal alloys.

\section{Niobium}

Niobium or Nb-1Zr are specified as first-wall and blanket structural materials in several conceptual CTR designs, including the Los Alamos Theta Pinch and the Oak Ridge Tokamak machines for which the quantities needed have been estimated. $(7,8)$ These designs are included in the "model" estimates presented in Section 4 of this report. Conceptual designs for mirror and laser machines have also specified $\mathrm{Nb}$ as a structural material, but design quantities have not yet been defined.

In addition to requirements for $\mathrm{Nb}$ as a structure, all types of CTR machines, except laser imploders, require the use of superconducting magnets or energy storage units. Niobium alloys ( $\mathrm{Nb}-\mathrm{Ti}, \mathrm{Nb}_{3} \mathrm{Sn}$, or others) may be required, and indeed are specified for most conceptual designs. These requirements, al though not structural, are included in considerations in this section.

Concepts comprising the five-design model (Section 4) include two designs that specify $\mathrm{Nb}$ (or $\mathrm{Nb}-1 \mathrm{Zr}$ ) as blanket structural materials. All require either $\mathrm{Nb}-\mathrm{Ti}$ or $\mathrm{Nb}_{3} \mathrm{Sn}$ as a superconductor material. Cumulative requirements for $\mathrm{Nb}$ for this model are about $580 \mathrm{kmt}$, of which about $270 \mathrm{kmt}$ is as $\mathrm{Nb}$ blanket structure (including replacements), and $310 \mathrm{kmt}$ is in $\mathrm{Nb}-\mathrm{Ti}$ superconductor material. In 2030, the projected requirements would be:

$$
\begin{array}{ll}
\mathrm{Nb} \text { structural material } & -40.4 \mathrm{kmt} \\
\mathrm{Nb}-\mathrm{Ti} \text { alloy (assume 33\% } \mathrm{Ti} \text { ) } & -59.4 \mathrm{kmt} \\
\mathrm{Nb}_{3} \mathrm{Sn} & -1.5 \mathrm{kmt} .
\end{array}
$$


In the event that the total industry were to be based upon the use of $\mathrm{Nb}$ as the blanket structural material, cumulative demand for the structure would increase to an estimated $725 \mathrm{kmt}$, and overall cumulative demand for contained $\mathrm{Nb}$ (structural and superconductor) would be about $1.0 \mathrm{Mmt}$. (Presumably the superconductor requirements would not change.) In 2030 structural requirements (construction and replacements) would rise to about $102 \mathrm{kmt}$.

If $\mathrm{Nb}_{3} \mathrm{Sn}$ (or other $\mathrm{A} 15$ superconductors) were to be used rather than $\mathrm{Nb}-\mathrm{Ti}$ alloy for superconducting magnetic and energy storage machines, the requirement for wrought $\mathrm{Nb}-\mathrm{Ti}$ alloy would not exist. This would reduce significantly the total demand for $\mathrm{Nb}$ as well as the demand for $\mathrm{Nb}$ wrought product.

The domestic industry that manufactures $\mathrm{Nb}$ alloys is relatively small and specialized. At present, there are only three companies that actively produce and fabricate primary Nb alloy mill products. When substantial potential aerospace markets for $\mathrm{Nb}$ alloys failed to materialize as had been hoped for in the 1960s, a number of organizations that had been in the business retrenched. However, a substantial technology base for the manufacturing of Nb alloy mill products exists, and is maintained by the present commercial organizations. Sheet, strip, plate, tubing, bar, rod, and wire are routinely manufactured.

It should be recognized that the range of products offered on a routine basis by this specialty industry is appreciably more limited than for the stainless steel industry, for example. In the event that emerging designs for CTR plants might require the routine production of $2-\mathrm{cm}$ thick $\mathrm{Nb}$ alloy plate in sizes of $200 \times 300 \mathrm{~cm}$ (as a hypothetical example), moderate efforts in the development of processing operations by the industry would be required. An example of current product availability as extracted from one producer's recent product data manual is cited below:

Product Availability

1) $E B$ melted and machined ingots $0.18 \mathrm{~m}-0.25 \mathrm{~m}$ diam $\times 1.83 \mathrm{~m}$

( 7 in. -10 in. diam $\times 72$ in.) Tength

2) Arc melted and machined ingot $0.13 \mathrm{~m}-0.41 \mathrm{~m}$ diam $\times 0.30 \mathrm{~m}-1.83 \mathrm{~m}$ (5 in. -16 in. diam $\times 12$ in. -72 in.) length 
3) Extruded and conditioned round $0.15 \mathrm{~m}$ ( 6 in.) diam $\times 1$ ength or approx. or sheet bar

$0.06 \mathrm{~m} \times 0.18 \mathrm{~m}-0.20 \mathrm{~m}$

$(2-1 / 4$ in. $\times 7$ in. -8 in. $) \times$ length

4) Forgings and rolled rings

Available upon request

5) Plate

$0.005 \mathrm{~m}-0.020 \mathrm{~m} \times 0.41 \mathrm{~m}$

(3/16 in. $-3 / 4$ in. $\times 16$ in.) $\times$ length

$0.003 \mathrm{~m} \times 0.91 \mathrm{~m}$

(1/8 in. $x 36$ in.) $\max . \times 0.91 \mathrm{~m}(36$ in.) $\max$.

6) Sheet

$0.0003 \mathrm{~m}-0.0016 \mathrm{~m} \times 0.47 \mathrm{~m}$

$(0.011$ in -0.062 in. $x 18-1 / 2$ in. $) \times$ coil

$0.00038 \mathrm{~m}-0.0016 \mathrm{~m} \times 1.52 \mathrm{~m} \times 3.05 \mathrm{~m}$

$(0.015$ in. -0.062 in. $x 60$ in.) $\times 120$ in.

$0.0016 \mathrm{~m}-0.003 \mathrm{~m} \times 1.27 \mathrm{~m} \times 1.27 \mathrm{~m}$

(0.062 in. -0.125 in. $x 50$ in. $x 50$ in.)

7) Foil

$0.000025 \mathrm{~m}-0.000125 \mathrm{~m} \times 0.30 \mathrm{~m}$

$(0.001$ in. -0.005 in. $x 12$ in. $) \times$ coil

$0.000125 \mathrm{~m}-0.00025 \mathrm{~m} \times 0.61 \mathrm{~m}$

$(0.005$ in. -0.010 in. $x 24$ in. $)$ maximum

8) Rod and round bar

$0.003 \mathrm{~m}-0.14 \mathrm{~m}$

(1/8 in. $-5-1 / 2$ in.) diam $\times$ length

9) Wire

$0.00025 \mathrm{~m}-0.0016 \mathrm{~m}$

(0.010 in.-0.06? in.) diam $\times$ coil

10) Tubing

Seamless as small as $0.002 \mathrm{~m}$ (0.080 in.)

$0 . D . \times 0.00025 \mathrm{~m}(0.010$ in. $)$ wa11 $\mathrm{x}$

$2.44 \mathrm{~m}-3.05 \mathrm{~m}(8-10 \mathrm{ft})$ made. Large 0.D. over $0.025 \mathrm{~m}(1.00 \mathrm{in.})$ and thin wall $0.00025 \mathrm{~m}-0.00076 \mathrm{~m}$ (0.010 in. -0.030 in.) welded tubing can also be supplied.

The largest present demand for $\mathrm{Nb}$ alloy is $\mathrm{Nb}-1 \mathrm{Zr}$ tubing required by some fission reactors. Relatively small amounts of a variety of $\mathrm{Nb}$ base alloys are produced in response to miscellaneous demands.

By far the majority of $\mathrm{Nb}$ consumed is as ferroniobium used in the manufacture of HSLA steels. Smaller amounts of $\mathrm{Nb}$ metal are used as alloying additions to some superalloys. The consumption of $\mathrm{Nb}$ in the manufacture of $\mathrm{Nb}$ alloy mill products is a small fraction of the 1 to $1.5 \mathrm{kmt}$ of $\mathrm{Nb}$ consumed annually in the U.S.

Based on recent statistics, the 1968 Bureau of Mines projections for the demand for $\mathrm{Nb}$ in the year 2000 appear quite high. However, in the opinion of 
Molycorp's J. Cannon, the demand for Nb in HSLA steels is expected to grow rapidly between now and the year 2000, and annual domestic consumption of 15 to $20 \mathrm{kmt}$ in that year might result. If this occurs, cumulative consumption by 2000 would be on the order of 200 and perhaps $600 \mathrm{kmt}$ for domestic and world use respectively, by that time.

In discussions with representatives of the Nb alloy manufacturing industry, all indications were that this industry could easily, and would be delighted to be given the opportunity to meet the demands of a CTR industry for structural forms (including $\mathrm{Nb}-\mathrm{Ti}$ wire or $\mathrm{Nb}_{3} \mathrm{Sn}$-containing product). One integrated producer (concentrate treatment through mill product forms) indicated that to meet the model demand for Nb structural alloy in the year 2030 (about $81 \mathrm{kmt}$ ), the major requirement would be for additional pentoxide production equipment (1iquid extraction boxes and digesters). Mi11, and probably melting capacity presently available (and underutilized), would probably be adequate to meet this demand now according to K. R. Garrity of Fansteel. Kawecki Berylco Industries' S. Roboff reports that they are installing a $1200 \mathrm{~kW}$ electron-beam melting furnace for melting $\mathrm{Nb}$ and Ta materials. From these discussions, it is apparent that existing industrial capacity for iNb alloy requirements at likely maximum annual rates is either adequate or could be rapidly (e.g., 1 year lead) expanded to satisfy CTR demand. Given a 20-year maturation time, any capacity expansion requirements would be readily accommodated by the industry.

U.S. reserves of $\mathrm{Nb}$ are negligible, as are resources. Most imports are from Brazil's extensive Araxa pyrochlor deposit. World reserves, dominated by Brazil and Canada, and including pegmatites in Zaire and Nigeria, are an estimated $8 \mathrm{Mmt}$. At present rates of consumption, reserves are sufficient for thousands of years. CTR machines based upon the use of Ni al ioy blanket structures and magnets could deplete these reserves in about a century presuming growth beyond the maturation period. Niobium resources estimates are simply "large," as there is no incentive for further exploration and discovery beyond the findings resulting from intensive effort mounted in the late 1950s and early 1960s. 
No problems associated with Nb supply to meet potential CTR requirements are foreseen.

Molybdenum

Demand for Mo associated with CTR designs based on use of Mo alloy as a nuclear island structural material is not yet delineated. Based on preliminary design studies on UWMAK-III, which will use Mo in the blanket, a crude estimate from present thinking is that in the year of maximum consumption (e.g., 2030) a total industry based on UWMAK-III might require on the order of 100-150 kmt of Mo. (This information furnished by G. Kulcinski, University of Wisconsin.) Assuming a normalized Mo requirement of $0.5 \mathrm{mt} / \mathrm{MW}_{\mathrm{e}}$ * for construction and $0.05 \mathrm{mt} / \mathrm{MW}_{\mathrm{e}}$ for annual replacement, and further assuming the maturation rate postulated by Young (see Figure 4.11, Section 4) an industry based exclusively upon a Mo structure blanket design would require growth in Mo supply as follows:

\begin{tabular}{ccc} 
Year & $\begin{array}{c}\text { Estimated } \\
\text { Maximum Design } \\
\text { Requirement, kmt }\end{array}$ & $\begin{array}{c}\text { "Mode1" } \\
\text { Requirenent, kmt }\end{array}$ \\
\cline { 2 - 2 } & 0.15 & 0.1 \\
2015 & 2.2 & 0.6 \\
2020 & 12.1 & 3.1 \\
2025 & 58.3 & 13.9 \\
2030 & 105.4 & 21.9
\end{tabular}

Cumulative demand for Mo mill products (predominantly sheet, plate and tubing) would be about $700 \mathrm{kmt}$. If, as is more probable, the growing CTR industry were based on, say five designs, only one of which called for a Mo blanket

* Recent discussions (J. Davis, McDonnell Douglas Aircraft Company) relating to UWMAK III--an emerging conceptual design calling for the use of Mo-indicate that this would require an estimated $0.27 \mathrm{mt} / \mathrm{MWe}$ for construction of the nuclear island, and an additional $1.26 \mathrm{mt} / \mathrm{MWe}$ for balance-of-plant needs, such as heat exchangers, piping, pumps, dump tanks, and thermal flywhee 1. These construction requirements are appreciably greater than the rough estimates available in the early stages of this design exercise. In addition, the required forms will include plate up to perhaps $12 \mathrm{~mm}(1 / 2 \mathrm{in}$.) in thickness, as opposed to sheet gages that were initially considered to be most predominant. 
structure, requirements would be reduced to about one fifth of the above amounts, or a maximum annual requirement of 20-25 kmt, and a cumulative demand of about $160 \mathrm{kmt}$.

As with Nb, the steel industry is by far the largest consumer of Mo. The following information on Mo was confirmed by C. Clark and W. Craig of Climax Molybdenum Company, and by R. Gilbert and G. R. Couch of Amax Specialty Metals Company. Only 4 to $5 \%$ of Mo mine production (about $52 \mathrm{kmt}$ of contained Mo, domestic, and $80 \mathrm{kmi}$ for total Western World) is divertad to Mo metal products; demand for wrought mill products (sheet, strip, rod, wire, tube, etc.) consumes only about half of this. In 1973-1974, the annual demand for mill product forms of Mo was about $2 \mathrm{kmt}$. An industrial projection of growth in demand for Mo metal products (annual growth rate for the next 12 years of $6.5 \%$ ) leads to an expected demand of 16 to $17 \mathrm{kmt}$ by the year 2000, with a demand of perhaps 8 to $10 \mathrm{kmt}$ for Mo mill products. The Mo industry expansion plans are based on this projection. Continuing this projection to the year 2030 leads to the following analysis for mill product supply.

\begin{tabular}{|c|c|c|c|}
\hline Year & $\begin{array}{c}\text { Ex-CTR } \\
\text { Demand, kmt }\end{array}$ & $\begin{array}{l}\text { "Mode1" CTR } \\
\text { Demand, kmt }\end{array}$ & $\begin{array}{l}\text { "Max Design": } \\
\text { CTR Demand, kmt }\end{array}$ \\
\hline 2011 & 20 & $0.1(20.1)^{(a)}$ & $0.2(20.2)^{(a)}$ \\
\hline 2015 & 25 & $0.6 \quad(26)$ & (27) \\
\hline 2020 & 35 & $3.1 \quad(38)$ & 12.1 \\
\hline 2025 & 48 & $13.9 \quad(62)$ & $58.3 \quad(106)$ \\
\hline 2030 & 66 & $21.9 \quad(88)$ & $105.4 \quad(171)$ \\
\hline
\end{tabular}

$(a)=$ Required industrial supply to meet all demand.

To meet mede? demand, an annual rate of growth in industry capacity of about $7 \%$ (rather than the presumed $6.5 \%$ rate) would be required for the first 10 years, and about 9\% for the "final" 10 years of CTR maturation. The 1ess probable case of single CTR design requirements would mandate annual growth rates of about $8 \%$ for the first 5 years of CTR buildup, building to about $18 \%$ during the start of the second decade. Presuming 1ong-range accuracy of relatively short-range industry forecasts of Mo metal product demand (i.e., 
assuming that industrial capacity for Mo mill products attains roughly $20 \mathrm{kmt}$ by the year 2010 to meet ex-CTR demand) a planned increase in the rate of growth to meet "model" CTR requirements would probably be readily accommodated by industry. The higher rates of growth required for several years for the less-likely, single "Mo machine" CTR base would involve appreciably greater capital risk which might be difficult for industry to justify, as the Mo mill product industry would become dominated by the market for CTR demand after about 10 years. In a11 probability some type of market guarantee would be necessary to induce the industry to accept a capitalization program needed to expand mill product facilities.

The manufacturing technology relating to Mo alloy mill product manufacture has emphasized relatively thin-gage products, such as sheet, tubing, and wire, in response to potential and actual needs of aerospace and electronics industries. The basis for present technology stems largely from information generated during the Refractory Metal Sheet Rolling Program conducted at the request of the Department of Defense in the 1960s. In particular for Mo alloys, optimum strength and toughness properties (the latter expressed in terms of a ductile-to-brittle transition temperature) are achieved by using thickness reductions subsequent to the last full (recrystallization) anneal of $80 \%$ or greater, with a substantial fraction of this reduction achieved by cross rolling to better approach isotropy in sheet properties.

In current practice, are cast melts of Mo or its principal alloy, Mo-TZM; destined for flat products are hot extruded to sheet blanks of 5 to $6 \mathrm{~cm}$ thickness of 18 to $20 \mathrm{~cm}$ width. These are flat-rolled in a direction normal to the prior extrusion direction and then turned 90 degrees and rolled to final gage (with appropriate intermediate anneals). In this manner, sheet and thin plate (up to roughly $0.6 \mathrm{~cm}$ in thickness) can be fabricated with properties that are roughly characteristic of those represented by the thinner sheet evaluated during the manufacturing development programs of the $1960 \mathrm{~s}$ (according to M. Semchyshen and R. Burman of Climax Molybdenum Company).

The latest information concerning a conceptual CTR design calling for Mo TZM alloy as a principal constructional material (according to J. Davis of McDonne 11 Douglas Astronautics Company - East), gages up to perhaps 
0.6 to $0.65 \mathrm{~cm}$, would be required for various applications for the nuclear island. Balance-of-plant requirements would require the use of plate in thicknesses up to perhaps $1.3 \mathrm{~cm}$. With large extrusion equipment now coming on line (according to M. Semchyshen and R. Burman of Climax Molybdenum Company), it might be possible to approach "optimum" properties in plate gages up to about $1.3 \mathrm{~cm}$ by extruding to sheet bar thicknesses perhaps as great as $10 \mathrm{~cm}$. So long as plate dimensions constrained by current melting (35.5 cm diameter ingots) and extrusion equipment capabilities are acceptable, scale-up and "optimization" programs would represent an effort that probably could be conducted by industry, providing sufficient market incentive existed, and providing that designs called for properties within the capabilities of size-limited process equipment.

At present, the maximum widths available on flat-rolled Mo products are limited to about $60 \mathrm{~cm}$ because of rolling mill limitations. Because of its high modulus and high hot hardness, Mo-TZM requires specially designed rolling mills. A wide mill facility, including in-line furnacing, would require appreciable capitalization (perhaps in the range of $\$ 10$ to 25 million according to M. Semchyshen and R. Burman of Climax Molybdenum Company), which is totally outside the realm of support by present markets. If the design and fabrication scenario associated with UWMAK-III calls for sheet and plate widths in excess of $60 \mathrm{~cm}$, the market assurance required would have to be sufficiently firm to justify at least this degree of capitalization by the Mo industry. If sheet and plate dimensions or product quality aspects were to mandate larger melting and extrusion facilities, an even greater level of market assurance would be required.

At the present time, these propositions remain academic, as the report on UWMAK-III has not been released in final form and, aside from technical considerations, economics for the concept will be most important. If the future reveals a Mo-based CTR design to be technically and economically viable, and serious consideration is to be given to prototype construction, this should be preceded by a detailed study of the impact upon, and constraints imposed by, the Mo mil1 products industry. 
Domestic Mo reserves approach 4 Mmt, and rest-of-world reserves about equal this amount. (4) These reserve estimates are considered conservative; domestic reserves inferred in identified deposits may run to 9 or $10 \mathrm{Mmt} .(4,5)$ Identified world resources, which include reserves, approach $30 \mathrm{Mmt},{ }^{(5)}$ and hypothetical resources based on geological knowledge are estimated to be measurable in the Gmt range. Present reserves are adequate to meet demand wel1 into the 21 st century. Cumulative world demand by 2000 may consume about half of the present conservatively-cited reserves. Demand of a model CTR industry that would include $20 \%$ of a Mo-blanket design would about double the CTR demand for Mo (in 316 stainless steel), and requirements for Mo would consume about 5\% of current reserves during the 20-year maturation period. Considering an "all Mo" CTR industry, the drawdown would be between 10 and $15 \%$ of current reserves.

As discussed previously, future development of Mo reserves is expected to keep pace with consumption.

$\underline{\text { Vanadium }}$

Vanadium has not yet been considered for structural application in CTR nuclear islands to the extent necessary to define potential material requirements. Argonne is believed to be developing a conceptual CTR machine based on a $V$ alloy blanket structure, however, Vanadium alloys are not capable of the higher operating temperature potential of either Nb or Mo but their potential exceeds those of austenitic stainless steels, and probably at least some of the readily-fabricated nickel-base materials. Vanadium is especially attractive from the standpoint of low activation in the CTR environment.

For want of quantitative definition, amounts of $V$ required in a hypothetical CTR design are assumed to be one-half of the quantities assumed for Mo, based on lower density for $V$. Thus, "model" requirements for $V$ alloys in hypothetical designs comprising one-fifth of a developing CTR industry are: 


$\begin{array}{lc}\frac{\text { Year }}{2011} & \begin{array}{c}\text { Vanadium A1loy } \\ \text { Requirement, kmt }\end{array} \\ 2015 & 0.05 \\ 2020 & 0.3 \\ 2025 & 1.6 \\ 2030 & 7.0 \\ \text { Cumulative } & 11.0\end{array}$

Limited studies to develop $V$ alioys for potential aerospace and fission reactor use were carried out in the 1960s. $(9,10)$ Westinghouse and Argonne developed and produced pilot quantities (principally tubing), of "Vanstar" and $V$, titanium, and chromium alloys, which was the closest approach to the development of a $V$ alloy mill product industry. $(11,12,13,14)$ This work, along with studies at IITRI (then Armour Research Foundation), were important in demonstrating that the establishment of a $V$ alloy industry is technically viable.

Vanadium produced commercially by thermal reduction of the pentoxide with aluminum, calcium, or carbon may not be sufficiently pure for conventional fabrication to mill products. J. DeVan of ORNL reports that the "Vanstar" pilot program was successful because of the supply of $V$ of high purity from a Bureau of Mines pilot fused salt electrolysis operation, which has since been discontinued.

Because there is no present market for $\mathrm{V}$ alloy mill products, there is no $V$ alloy mill product industry as such. The technology, however, exists, and plant facilities used in the production of Ta and Nb alloys is probably amenable also to the fabrication of $V$ alloys. Should markets develop to warrant the establishing of a $V$ alloy mill product industry, such an industry would certainly come into existence according to R. Gottschalk, UCC, Mining and Metals Division.

A deterring technological aspect might be the relatively limited state of knowledge relating to $V$ alloy properties as a function of alloy content and over a broad spectrum of environmental conditions. Most $V$ alloy 
development studies were directed towards specific targets, and comprehension of alloy properties is considerably more restricted for $V$ than for $\mathrm{Nb}$, Mo, or $\mathrm{Ta}$, for example. If $\mathrm{V}$ alloys are to be seriously considered as an important CTR material of construction, specific alloy and manufacturing process development efforts directed towards specific CTR needs should be initiated within the next few years to insure the optimum design and use of $V$ alloys in CTR machines.

More than $90 \%$ of vanadium consumption is in the form of ferroalloys used by the steel industry (about $40 \%$ of this is consumed in HSLA stee1s). The balance is used as a metallic addition in the manufacture of titanium alloys (e.g., Ti-6A1-4V) or for chemical and catalytic uses. In 1973, industry statistics indicate the following consumption patterns:

$\begin{array}{ll}\text { U.S. and Canada } & -6.5 \mathrm{kmt} \\ \text { EEC Nations } & -5.3 \mathrm{kmt} \\ \text { Rest of Europe } & -1.7 \mathrm{kmt}\end{array}$

For 1974:

U.S. $\quad-6.6 \mathrm{kmt}$

Rest of free world - $10.3 \mathrm{kmt}$ (including $1 \mathrm{kmt}$ shipped to Iron Curtain countries).

These data, supplied by Union Carbide's R. Gottschalk, indicate that Bureau of Mines data are somewhat low.

Present production capacity for $V$ exceeds demand by roughly $20 \%$. Shortrange projections of growth in western world demand for $V$ anticipates annual growth at $4.5 \%$ to a total of about $24 \mathrm{kmt}$ in 1980 . Western world production capacity in 1980 is expected to grow to nearly $33 \mathrm{kmt} .{ }^{(15)}$ Longer range projections of demand for $V$ by Union Carbide's R. Gottschalk, presuming growth in the use of $V$ bearing HSLA steels by the automotive industry, suggest a domestic demand for $V$ in the year 2000 of about $20 \mathrm{kmt}$. This is somewhat lower than the 1970 Bureau of Mines projection for domestic demand. The restof-world demand is conservatively estimated at $36 \mathrm{kmt}$, appreciably greater than 1970 Bureau of Mines forecast. Considering emerging industrial strength 
in nations such as China, Brazil, and India, rest-of-world demand for $V$ in the year 2000 could be 20 to $30 \%$ greater.

Continuing projected growth in demand for $V$, domestic demand in 2030 would be about $85 \mathrm{kmt}$ for ex-CTR use. CTR "model" demand would add $11 \mathrm{kmt}$ to this. Over the 20-year buildup to this CTR demand, V supply to meet CTR requirements could be met by an added $0.6 \%$ annual growth. Even in the event that all CTR machines would require blanket structures of $V$ alloy, with a hypothetical demand in the year 2030 of about $40 \mathrm{kmt}$, added growth in production capacity of only $2 \%$ per year would be required. In neither case would requirements demand more than routine planning by the industry that supplies $V$. In the event that ex-CTR demand in the year 2000 were to fall far short of the forecast level, measurable effort in terms of expanded domestic production facilities would be required, but with reasonable market assurance and capital availability, domestic industry would certainly reply favorably, even for the maximum demand case according to Union Carbide's R. Gottschalk.

Presuming long-range growth in $V$ demand of $5 \%$ compounded annually, cumulative world demand of roughly 1 Mmt by 2000, and 4.4 Mnt by 2030 would be expected. "Model" CTR use (e.g., growth for V-structure-based machines to $0.2 \mathrm{MMW}_{\mathrm{e}}$ by 2030) would comprise 2 to $3 \%$ of this demand, and maximum $V$ demand were al1 CTR machines to have $V$ structures in building to $1 \mathrm{MMW}_{\mathrm{e}}$ would require 10 to $15 \%$ of this supply. World reserves of $V$ in conventional deposits are conservatively cited as about $10 \mathrm{Mmt}$. Cameron estimated reserves to be closer to $24 \mathrm{Mmt}$, principally in South African and Soviet deposits. (4) Known resources that are poorly defined are "large." Vanadium is being recovered from fily ash from petroleum products. Large quantities of $V$ as by-product from Venezuelan crude oils are expected to be marketed in 10 to 15 years, and from the processing of titaniferrous magnetites in 20 to 30 years, according to Union Carbide's R. Gottschalk. The long-range supply of $V$ will not be a problem confronting potential CTR demand.

Domestic reserves of $V$ in the current market are sma11, estimated at about $0.1 \mathrm{Mmt}$. At $3 \times$ prices, they could become more significant (e.g., 21 Mmt, according to Cameron). (4) Although the U.S. could be self-sufficient 
in $V$, economics will probably dictate that the U.S. continue to be a net importer of $V$ for the foreseeable future.

\section{$\underline{\text { Tantalum }}$}

Certain characteristics of Ta suggest its attractiveness as a structural material for CTR nuclear islands. However, as summarized in Table 5.1, current reserves of $50 \mathrm{kmt}$ are about sufficient to meet projected cumulative world demand to the year 2000, and are totally inadequate to supply any significant (e.g., one-fifth of CTR industry based on Ta structures) CTR usage. Although the discovery of new types of Ta deposits as extensive as the pyrochlor deposits of Nb would possibly permit consideration of Ta for CTR structural use, there is no indication that such discoveries will occur. For this reason, it is improbable that calling for use designs of $\mathrm{Ta}$ as a major CTR structural material will ever be realistic.

\subsection{OTHER BLANKET AND SHIELD MATERIALS}

\subsubsection{Boron}

Boron is required by three conceptual designs as a neutron absorber in the shield. In two cases, it would be used as the carbide, $B_{4} C$ (UWMAKs and BNL design), and in a third it is used as an addition to concrete (PPPL). Its use in the "model" CTR scheme presented in Section 4 would result in an annual demand rising to about $123 \mathrm{kmt}$ in the year 2030, and cumulative demand for the 20-year maturation period would be about $0.9 \mathrm{Mmt}$.

Current domestic mine production of boron minerals and compounds is in an amount equivalent to nearly $200 \mathrm{kmt}$ of contained boron annually, more than half of which is exported. (16) of the world's reported mine production, U.S. production comprises about one-half. Turkey and the U.S.S.R. are also major suppliers of boron materials.

Major uses of boron compound (borax, boric acid and the anhydride, sodium perborate, etc.) are in glassmaking, soaps, cleaners, detergents, and cleansing pharmaceuticals (toothpase, mouthwash, eyewash, etc.). 
Boron carbide is manufactured by several domestic concerns, and is used principally as an abrasive grain or powder. The amount of boron consumed in this application is a small fraction of total domestic consumption of boron. S. Roboff of Kawecki Berylco Industries indicated there would be no problem in expanding capacity for the manufacture of $\mathrm{B}_{4} \mathrm{C}$ to meet requirements for $a$ developing CTR industry, providing the market were reasonably assured.

The forecast domestic demand for boron contained in various compounds in the year 2000, based on the Bureau of Mines contingency analysis of 1970 is about $280 \mathrm{kmt}$, with total world consumption of three times this amount. Extrapolating to the year 2030 indicates domestic consumption of $930 \mathrm{kmt}$, and world consumption of $2700 \mathrm{kmt}$. Cumulative world demand through the year 2030 would be on the order of 90-95 Mmt. In comparison, model CTR demand for boron in the year 2030 would be about 13\% of projected domestic demand, with cumulative demand during maturation of about $1 \mathrm{Mmt}$. It is apparent that major use of $\mathrm{B}_{4} \mathrm{C}$ (or boron in another form) for shielding in CTR machines would result in a rather significant new use for boron. However, an increase in the rate of growth projected for the domestic supply of boron of less than $1 \%$ would suffice in meeting CTR demand during the period from 2011 to 2030 .

Domestic reserves of boron are estimated to be $28 \mathrm{Mmt}$, and world reserves are greater than $70 \mathrm{Mnt}$. Bureau of Mines' K. P. Wang believes that domestic reserves may be somewhat overestimated, but that large Turkish reserves will prove to be much greater than current estimates. Domestic resources that have been identified are estimated by U.S.G.S. as sufficient to afford supply at current rates of domestic consumption for 300 years, and "hypothetical and speculative" domestic resources may be expected to extend this self-sufficiency for 1000 years. (5) Based upon their vast and growing reserves, Turkey is moving towards a position of dominance in world trade in boron minerals that has been enjoyed by the U.S. for decades. Domestic and/or foreign sources will be able to supply CTR demands for boron-rich materials.

\subsubsection{Beryllium}

Beryllium will be most useful in CTR-machines as a neutron multiplier to enhance tritium breeding. For example, the philosophy underlying the 
design by the University of Wisconsin of LIWMAK-II was to minimize the tritium inventory by increasing the tritium concentration to facilitate recovery. This was accomplished by specifying a decrease in the amount of lithium (versus LWMAK-I) and utilizing helium cooling of the blanket. To exceed parity in tritium breeding, it was necessary to specify beryllium for neutron moderating and multiplication. (17) This design called for a requirement of about $0.24 \mathrm{mt} / \mathrm{MW}_{e}$ of beryllium in the form of metal microspheres. 0ther designs specifying beryllium are the PPPL machine $(0.43 \mathrm{mt} / \mathrm{MW}$ as flibe), LASL-RTPR (0.02 mt/MW e construction, $0.0024 \mathrm{mt} / \mathrm{MW}_{\mathrm{e}}$ annual replacement), and the BNL minimum-activation blanket $\left(0.12 \mathrm{mt} / \mathrm{MW}_{\mathrm{e}}\right.$ construction, $0.0006 \mathrm{mt} / \mathrm{MW}_{\mathrm{e}}$ annual replacement). The latter three designs were included in the "model" assessment in Section 4. Some designs do not require beryllium. For those that do, requirements vary by more than one order of magnitude.

Early in the development of a CTR industry, short doubling times for tritium will be required for the startup of new reactors where tritium supply will have to come from relatively few reactors. As the industry matures, and less net tritium production per reactor is required, the industry may comprise both net tritium breeders and net tritium burners. (18) The use of beryllium will give added flexibility in balancing such industry requirements. Based on current conceptual CTR designs, beryllium use may range from zero to as much as $0.43 \mathrm{mt} / \mathrm{MW}_{\mathrm{e}}$ (e.g., $430 \mathrm{mt}$ per $1000 \mathrm{MW}_{\mathrm{e}}$ machine). Where beryllium is used, annual replacement resulting from burnup will be smal1 $\left(<0.1 \mathrm{~kg} / \mathrm{MW}_{\mathrm{e}}\right)$.

The model described in Section 4 would require cumulative consumption of $125 \mathrm{kmt}$ of beryllium during the 20-year maturing period, with $13 \mathrm{kmt}$ required in the 20th year. This assumes that the same mix of reactor designs would come on stream in the later years as in the earlier years, which, as inferred above, is not likely.

Two U.S. Companies are the principal suppliers of domestic beryllium needs. Domestic demand for beryllium for the past 5 years has averaged about $325 \mathrm{mt}$ per year. Typically, 60 to $65 \%$ of this demand is supplied to meet requirements for beryllium copper, about $30 \%$ is in the form of beryllium metal (hot pressed and wrought-product forms), and the balance is used in 
oxide form. U.S. demand for beryllium is considerably greater than half of the total world demand, and demand projections indicate that domestic consumption will continue to dominate world consumption in the future.

The U.S. is a net importer of beryllium minerals (beryl, predominantly from Brazil, but African beryl imports are also significant), but with the recent development and commercialization of the Spor Mountain, Utah, bertrandite deposit, the U.S. his demonstated a capability for self-sufficiency. In 1973-1974, imports apparent1y supplied less than $20 \%$ of domestic demand. Foreign production of beryl is a hand-cobbing operation, and at production rates greater than about 5 to $6 \mathrm{kmt}$ of beryl ( $600 \mathrm{mt}$ of contained beryllium), the price begins to increase says $S$. Roboff of Kawecki Berylco Industries.

Bureau of Mines contingency analysis projections in the 1970 MF\&P estimated domestic and world demands for beryllium in 2000 as 1.5 and $2.3 \mathrm{kmt}$ respectively, but more recent estimates would reduce these levels by about $30 \%$, according to Bureau of Mines' B. Petkov. Trend 1 ines based on recent demand suggest still lower rates of growth (barring significant new uses for beryllium), and on this basis, annual domestic demand for beryllium may not rise to much above $500 \mathrm{mt}$ by the year 2000. At rates of consumption suggested by trendline projections, cumulative world consumption by 2000 would be between 15 and $20 \mathrm{kmt}$, and by 2030 , between 50 and $55 \mathrm{kmt}$. At the higher rate of growth in demand by recent Bureau of Mines projections, cumulative domestic demand through 2000 would be about $16 \mathrm{kmt}$, for example.

Domestic reserves of beryllium are estimated by the Bureau of Mines to be $25 \mathrm{kmt}$ of beryllium. (16) Other estimates go beyond known reserves and place domestic reserves as high as $54 \mathrm{kmt}$. (5) Although industry holds reserve information proprietary, the comment was offered by $N$. Bass and S. Zenczak of Brush Wellman that the Bureau of Mines estimate is conservative. Published resource information cites low-grade fine-grained beryl in pegmatites of the Carolinas as the major domestic resource, but "even at $10 \mathrm{X}$ prices, the feasibility of recovering beryllium from such deposits is dubious" (Cameron, Reference 4). Also according to Cameron, "Beryllium minerals, particularly if fine-grained, are very difficult to recognize. Intensive prospecting with 
the beryllometer is necessary to discover deposits of the Spor Mountain type. The chances of discovery are unpredictable.... There are no real data on world reserves of beryllium." At present rates of consumption of beryllium, there is no incentive for exploration, as domestic and likely world reserves are adequate to meet demand for the better part of a century.

As discussed in earlier paragraphs, the "model" approach in Section 4 which included the PPPL, LASL, and BNL designs, all of which specify beryllium as a blanket material, may not be a realistic model from the standpoint of effective beryllium utilization. The cumulative demand for beryllium is about double the most optimistic current estiamte of (inferred) beryllium reserves without considering other, interim demand upon those reserves. Eliminating the most consumptive PPPL design from the model results in bery1lium requirements for the RTPR and BNL concepts of less than $40 \mathrm{kmt}$, which is more in line with reserve estimates (still presuming full beryllium requirements throughout maturation). It is thus apparent that beryllium reserves wi11 support appreciable requirements by CTR machines, but not to the extent that would be required by the construction of large numbers of machines of the PPPL or UWMAK-II designs, for example.

Another deterrent to designs requiring hundreds of tons of beryllium per machine is economics. Even considering possible economics of scale in increased beryllium production as outlined by $N$. Bass and S. Zenczak of Brush Wellman, the cost of beryllium required by the PPPL design would approach $\$ 100$ million per machine, and for UWMAK-II, the cost would be nearly $\$ 50$ million. These costs equate to about $\$ 50$ and $\$ 30 / \mathrm{kW}_{e}$ capacity, and would represent an appreciable percentage of the initial capitalization for only beryllium supply. For the BNL design, requirements would cost $\$ 10$ to $\$ 15 / \mathrm{kW}_{\mathrm{e}}$, which although high, might be acceptable.

If beryllium is required to enhance breeding for tritium supply of the growing industry, maximum demand may occur in the tenth or eleventh year according to the model, and might taper off as the industry matures and industry tritium production would have to back off to near parity. According to the five-design model in Section 4, the CTR annual demand for beryllium might 
peak at about $5 \mathrm{kmt}$. If this presumed peak demand were short-lived, inventory buildup prior to demand might be the best way to cushion peak-year demand. Brush Wellman's N. Bass and S. Zenczak say this probably could be accomplished without major expansion of the beryllium industry, for which current capacity is about double production. If peak demand would extend over more than a year or two, the beryllium industry would have ample time for expansion. In discussions with industry representatives, CTR annual demand levels of 10-15 kmt were referenced. This was conceded to represent major expansion, and such a program would probably require on the order of 10 to 20 years to develop, and would have to be accompanied by 1) assurance of market, 2) avai1ability of capital, and 3 ) development of mineral resources according to S. Roboff (Kawecki Berylco Industries) and N. Bass/S. Zenczak (Brush Wellman). Even at these large demands relative to current and projected future production levels, both companies agreed that, with the above assumptions, CTR demand for beryllium could be met.

In summary, the analysis indicates that beryllium use in CTR machines will have to be tempered by 1) reserves and future definition and development of resources, 2) economics, and 3) definition of the required technicai need for beryllium and scheduling of demand for its consumption in CTR applications. Reserves and normal growth of industrial capacity could supply a few machines with beryllium demands as great as called for PPPL or UWMAK-II designs, and could meet requirements for machines that call for more moderate amounts of beryllium, such as might be the case of the hypothetical four-design model. Larger demands for beryllium, such as dictated by as much as $20 \%$ of CTR plants in a mature industry requiring hundreds of tons of beryllium per plant, would require significant definition and development of new resources to treble or quadruple current reserves. Given these reserves, the beryllium industry could and would expand with the development of a CTR-based electrical power industry.

It is recommended that additional study be given to the design mix of a developing CTR industry to better establish what realistic and supportable requirements for beryllium might be, and to establish a better estimate of the requirements schedule. 


\subsubsection{He1 ium}

Helium use in CTR machines is required for blanket and/or shield cooling, and in cryostats to maintain the superconducting state for magnets and energy storage devices. In some designs, 1iquid-metal-cooled blankets have been specified, minimizing the demand for helium as a working fluid. For machines other than laser designs, large quantities of helium will be required for superconducting equipment. (Laboratory investigations have revealed some superconducting species that may develop capabilities for satisfactory operation at liquid hydrogen temperature. If this technology comes to economic commercial fruition, CTR demand for helium could be greatly reduced, but other problems attendant with the use of hydrogen would emerge.) Helium production in the plasma of DT or DD machines, and in blankets of CTR machines via transmutation of blanket materials seriously degrades the blanket material, but it has one redeeming feature--sufficient helium may be produced and recovered to supply the operating needs of the machines. (3)

["Helium sold as a compressed gas is measured at one atmosphere at $70^{\circ} \mathrm{F}$. The unit of measure is $28.3 \mathrm{~m}^{3}\left(1000 \mathrm{ft}^{3}\right)$. Helium sold as liquid is measured by the liter or pound. A liter of liquid is equivalent to $0.75 \mathrm{~m}^{3}\left(26.68 \mathrm{ft}^{3}\right)$ of gas. A pound of 1 iquid is equivalent to $2.74 \mathrm{~m}^{3}\left(96.72 \mathrm{ft}^{3}\right)$ of gas." (19) Statistical data are cited in terms of millions of cubic feet, but CTR requirements have been referenced in metric tons. One $\mathrm{kg}$ is equivalent to $6.04 \mathrm{~m}^{3}\left(213.2 \mathrm{ft}^{3}\right)$ of gas, $1 \mathrm{mt}$ is equivalent to $6,031 \mathrm{~m}^{3}(0.213 \mathrm{mil}-$ lion $\left.\mathrm{ft}^{3}\right)$ of gas, and $28,316 \mathrm{~m}^{3}\left(1 \mathrm{mi} 11\right.$ ion $\left.\mathrm{ft}^{3}\right)$ of gas is equivalent to $4.69 \mathrm{mt}$. ]

Normalized helium requirements for the five designs comprising the CTR industry model described in Section 4 are $0.002,0.04,0.045,0.06$, and $0.29 \mathrm{mt} / \mathrm{MW}_{\mathrm{e}}$. Kulcinski listed normalized helium demands for five designs as ranging from 292 to $1640 \mathrm{~m}^{3} / \mathrm{MW}_{\mathrm{e}}\left(10.3\right.$ to 57.9 thousand $\left.\mathrm{ft}^{3} / \mathrm{MW}_{\mathrm{e}}\right)$, or 0.048 to $0.272 \mathrm{mt} / \mathrm{MW}_{\mathrm{e}} \cdot{ }^{(18)}$ The model requirement for a $10^{6} \mathrm{MW}$ industry maturing in 20 years is $78 \mathrm{kmt}$ of helium, with a maximum annual demand of $10.6 \mathrm{kmt}$ in the 20th year. A four-design model based upon Kulcinski's analys is (18) would require $152 \mathrm{kmt}$ cumulative helium supply, with $17 \mathrm{kmt}$ required in the 20 th year. 
The helium production and reserve situation has been adequately reviewed by others, $(5,6,18)$ and Kulcinski $(18)$ in particular has discussed the significance of long-range supply of helium in the context of probable CTR demand. The present analysis will only highlight important aspects.

Helium is separated from natural gas. A helium content in natural gas of at least $0.3 \%$ is required for economic domestic production of helium. Proved gas reserves containing $0.3 \%$ helium will probably be consumed prior to the year $2000,(18,19)$ leaving lowergrade resources from which helium could probably be extracted at 5 to $6 \times$ current costs.

Helium present in the atmosphere ( $25 \mathrm{ppm}$, calculated to total $3.4 \mathrm{Gmt}$ ) might be extracted from exhaust streams of liquid oxygen plants at prices that would be at least competitive with those for extraction from low-helium content $(20.7 \%$ He) natural gas. Based upon the 1970 Bureau of Mines contingency analysis forecast for oxygen demand, perhaps $1.5 \mathrm{kmt}$ and $6.5 \mathrm{kmt}$ of helium by-product might be available by 2000 and 2030 A.D., respectively. This would fall considerably short of the CTR requirements, without considering other demand for helium. The cost of extracting helium from the atmosphere without demand for oxygen or nitrogen has been estimated to be from $\$ 1$ to $\$ 3$ per cubic foot $(0.2$ to 0.6 million dollars per mt, about $100 \times$ current prices), and would be extremely energy intensive.

From 1960 through 1973, helium was extracted from rich natural gas and stored by and under contract to the Bureau of Mines in the helium conservation program established under P.L. 86-777. This program has been discontinued, and helium from the rich natural gas reserves is being lost to the atmosphere at a rate estimated to be between 35 and $40 \mathrm{kmt}$ per year. An estimated $178 \mathrm{kmt}$ of helium are in storage in the Cliffside gas reservoir in Texas, according to Dr. E. T. Hayes, Materials Consultant, Washington, D.C. With the cancellation of government purchase contracts for conservation, helium production has decreased from about $22 \mathrm{kmt}$ per year to about $4 \mathrm{kmt}$ per year, and production plants are now idie. Helium produced for sale in 1974 amounted to about $3 \mathrm{kmt}$, of which one-fourth was exported. Domestic demand has averaged about $2.4 \mathrm{kmt}$ per year for the last 5 years (down from a maximum of about $4.5 \mathrm{kmt}$ in the mid $60 \mathrm{~s}$ to meet space program requirements). 
No. of

Copies

J. Moteff

University of Cincinnati

Department of Materials

Sciences and Metallurgical

Engineering

Location 12

Cincinnati, $\mathrm{OH} 45221$

R. A. Gross

Columbia University

Plasma Physics Laboratory

New York, NY 10027

R. J. Tien

Columbia University

Plasma Physics Laboratory

New York, NY 10027

C. Y. Li

Cornell University

Ithaca, NY 14850

Program Manager for Fusion

Power

Electric Power Research

Institute

3412 Hillview Avenue

Palo Alto, CA 94304

2 Assistant Director for Materials Sciences Program, DPR

Energy Research and Development Administration

Washington, DC 20545

Assistant Director for

Technology, RRD

Energy Research and Development Administration Washington, DC 20545

Chief, Fuel Systems Branch, RRD

Energy Research and Development Administration Washington, DC 20545
No. of

Copies

Chief, Materials and

Chemistry Branch, Office

of Technology, RDD

Energy Research and

Development Administration

Washington, DC 20545

Assistant Director, D\&T, DCTR

Energy Research and Development Administration

Washington, DC 20545

Chief, Systems Studies and Applications Branch, D\&T, CTR

Energy Research and Development Administration

Washington, DC 20545

4 Chief, Materials and Radiation Effects Branch, CTR

Energy Research and Development Administration

Washington, DC 20545

Assistant Director for Confinement Systems, CTR

Energy Research and Development Administration

Washington, DC 20545

Assistant Director for Plasma Physics, CTR

Energy Research and Development Administration

Washington, DC 20545

Assistant Director for Technical Projects

Energy Research and Development Administration

Washington, DC 20545

Manager, Fusion Engineering Department

General Atomics Company

P.0. Box 81608

San Diego, CA 92138 
No. of

Copies

G. R. Hopkins

Genera1 Atomics Company

P. 0. Box 81608

San Diego, CA 92138

L. Rovner

Genera1 Atomics Company

P. 0. Box 81608

San Diego, CA 92138

Chief, Materials and Process Department

Grumman Aerospace Corporation

Materials and Process Department

Bethpage, NY 11714

Chief, Nuclear Physics

Research Department

Grumman Aerospace Corporation

Materials and Process

Department

Bethpage, NY 11714

Manager, Materials Engineering

Hanford Engineering Development Laboratory

P. 0. Box 1970

Richland, WA 99352

D. Doran

Hanford Engineering Development Laboratory

P. 0. Box 1970

Richland, WA 99352

J. J. Holmes

Hanford Engineering Development Laboratory

P. 0. Box 1970

Richland, WA 99352

J. E. Irvin

Hanford Engineering Development Laboratory

P. 0. Box 1970

Richland, WA 99352
No. of

Copies

J. L. Straalsund

Hanford Engineering Development Laboratory

P. 0. Box 1970

Richland, WA 99352

H. K. Forsen

Jersey Nuclear Company

777 106th Avenue N.E.

Bellevue, WA 98004

Division Leader, CTR Division

Los Alamos Scientific Laboratory University of California

P. 0. Box 1663

Los Alamos, NM 87554

Division Leader, CMB Division

Los Alamos Scientific Laboratory University of California

P.0. Box 1663

Los Alamos, NM 87544

Division Leader, $P$ Division

Los Alamos Scientific Laboratory University of California

P. 0. Box 1663

Los Alamos, NM 87544

F. W. Clinard

Los Alamos Scientific Laboratory University of California

P. 0. Box 1663

Los Alamos, NM 87544

C. R. Emigh

Los Alamos Scientific Laboratory University of California

P. 0. Box 1663

Los Alamos, NM 87544

W. Green

Los Alamos Scientific Laboratory University of California

P. 0. Box 1663

Los Alamos, NM 87544 
No. of

Copies

Director, CTR Division

Lawrence Livermore Laboratory University of California

P. 0. Box 808

Livermore, CA 94550

Director, E. Division

Lawrence Livermore Laboratory

University of California

P. 0. Box 808

Livermore, CA 94550

2 Program Manager for CTR, Chemistry and Materials Sciences Department

Lawrence Livermore Laboratory University of California

P. 0. Box 808

Livermore, CA 94550

$R$. Vankonyenburg

Lawrence Livermore Laboratory University of California

P. 0. Box 808

Livermore, CA 94550

50

D. Kummer

McDonne11-Douglas Astronautics

P. 0. Box 516

St. Louis, M0 63166

L. Lidsky, Department of Nuclear Engineering

Massachusetts Institute of Technology

Cambridge, MA 02139

K. Russel1, Department of Materials Science

Massachusetts Institute of Technology

Cambridge, MA 02139

T. Kammash

University of Michigan

Nuclear Engineering Department

College of Engineering

Ann Arbor, MI 48105
No. of

Copies

Manager, Technology Applica-

tions and Development

Mound Laboratory

P. 0. Box 32

Miamisburg, $\mathrm{OH} \quad 45342$

Director, Center for Radiation Research

National Bureau of Standards

Room C-225

Washington, DC 20234

Head, Thermo Structural Materials Branch

Naval Research Laboratory

Metaliurgy Division, Code 6390

Washington, DC 20200

F. Smidt

Nava 1 Research Laboratory

Metallurgy Division, Code 6390

Washington, DC 20200

T. S. Elleman

North Carolina State University

Department of Nuclear

Engineering

Raleigh, NC 26707

Director, Thermonuciear

Division, Building 9201-2

0ak Ridge National Laboratory

P. 0. Box Y

Oak Ridge, TN 37830

Director, Metals and Ceramics Division

Oak Ridge National Laboratory

P. 0. Box Y

Oak Ridge, TN 37830

Program Manager, Fusion Reactor Technology Program Building 9204-1

Oak Ridge National Laboratory

P. 0. Box Y

Oak Ridge, TN 37830 
No. of

Copies

Manager, Controlled Thermonuclear Reactor Materials, Metals and Ceramics Division, Building 4500s

Oak Ridge National Laboratory P.0. Box $Y$

Oak Ridge, TN 37830

B. R. Appletori

Oak Ridge National Laboratory P. 0. Box $Y$

Oak Ridge, TN 37830

E. E. Bloom

Oak Ridge National Laboratory

P. 0. Box Y

Oak Ridge, TN 37830

C. R. Brinkman

Oak Ridge National Laboratory

P. 0. Box $Y$

Oak Ridge, TN 37830

R. J. Colchin

Building 9201-2

Oak Ridge National Laboratory

P. 0. Box $Y$

Oak Ridge, TN 37830

J. H. Devan

Building $4500 \mathrm{~S}$

Oak Ridge National Laboratory

P. 0. Box $Y$

Oak Ridge, TN 37830

A. P. Fraas

Oak Ridge Nationa 1 Laboratory

P. 0. Box $Y$

Oak Ridge, TN 37830

J. A. Horak

Building 4500s

Oak Ridge National Laboratory

P. 0. Box $Y$

Oak Ridge, TN 37830
No. of

Copies

W. R. Martin

Building 4500s

Oak Ridge National Laboratory

P. 0. Box $Y$

Oak Ridge, TN 37830

M. Roberts

Building 9204-1

Oak Ridge National Laboratory

P. 0. Box $Y$

Oak Ridge, TN 37830

F. W. Wiffen

Building 4500 s

Oak Ridge National Laboratory

P.0. Box Y

Oak Ridge, TN 37830

Director, Plasma Physics Laboratory

Plasma Physics Laboratory

Princeton University

Forrestal Campus

Box 451

Princeton, NJ 08540

Project Manager, TFTR

Plasma Physics Laboratory

Princeton University

Forrestal Campus

Box 451

Princeton, NJ 08540

S. Cohen

Plasma Physics Laboratory

Princeton University

Forrestal Campus

Box 451

Princeton, NJ 08540

C. Osgood

Plasma Physics Laboratory

Princeton University

Forrestal Campus

Box 451

Princeton, NJ 08540 
No. of

Copies

K. Wakefiled

Plasma Physics Laboratory

Princeton University

Forrestal Campus

Box 451

Princeton, NJ 08540

R. G. Mills

Plasma Physics Laboratory

Princeton University

Forrestal Campus

Box 451

Princeton, NJ 08540

2 W. Bauer

Sandia Laboratories

Livermore, CA 94550

2 F. L. Vook

Sandia Laboratories

Albuquerque, NM 87115

H. G. F. Wilsdorf

University of Virginia

Department of Materials Science

Research Labs for Engineering Sciences

Charlottesville, VA 22901

Manager, Fusion Power Systems

Department

Westinghouse Electric Company

Nuclear Center

P.0. Box 355

Pittsburgh, PA 15230

R. Gold

Westinghouse Electric Corporation

Research and Development Center

Beulah Road

Pittsburgh, PA 15234

J. R. Holland

Westinghouse Electric Corporation

Research and Development Center

Beulah Road

Pittsburgh, PA 15234
No. of

Copies

G. L. Kulcinski

University of Wisconsin-Madison

Department of Nuclear Engineering

Madison, WI 53706

Cameron

University of Wisconsin-Madison

Department of Nuclear Engineering

Madison, WI 53706

C. W. Maynard

University of Wisconsin-Madison

Department of Nuclear Engineering

Madison, WI 53706

D. Lichtmann

University of Wisconsin-Milwaukee Department of Physics

Milwaukee, WI 53201

R. Couch, President

AMAX Specialty Metals Corporation

American Metal Climax, Inc.

One Greenwich Plaza

Greenwich, CT 06830

E. S. Bartlett

Battelle-Columbus

505 King Avenue

Columbus, $\mathrm{OH} 43201$

Dr. S. Zenczak, Vice President Marketing

Brush-Wellman

17876 St. Clair Avenue

Cleveland, $\mathrm{OH} \quad 44110$

E. Romagnoli

Department of Commerce

Washington, DC

W. Kaestner

Department of Commerce

Washington, DC

W. Ames

Department of Commerce

Washington, DC 
No. of

Copies

K. P. Wang

Department of the Interior Bureau of Mines

Nonferrous Metals Division

Washington, DC

B. Petkov

Department of the Interior Bureau of Mines

Nonferrous Metals Division

Washington, DC

J. Jol1y

Department of the Interior

Bureau of Mines

Nonferrous Metals Division

Washington, DC

K. R. Garrity, General Manager

Fanstee1, Inc.

1 Tantalun Place

North Chicago, IL 60064

D. W. T. Barrett, President

Foote Mineral Company

Route 100

Exton, PA 19341

S. Roboff, Director of Corporate Development

Kawecki-Berylco Industries

220 E. 42nd Street

New York, NY 10017

J. G. Cannon, Manager

Modern Metals

Molycorp, Inc.

6 Corporate Park Drive

White Plains, NY 10604

R. Gottschalk, Manager

Market Research

Union Carbide Corporation

Mining and Metals Division

270 Park Avenue

New York, NY 10017
No. of

Copies

ONSITE

ERDA Richland Operations Office

Programs Division

P. G. Holsted

41 Battelle-Northwest

G. S. Allison (23)

N. E. Carter

T. D. Chikalla

S. D. Dahlgren

R. L. Dillon

D. A. Dingee

B. F. Gore

A. B. Johnson

R. H. Jones

W. S. Kelly

R. W. Kemper

R. P. Marshal1

R. D. Nelson

L. C. Schmid

D. Styris

Technical Information

Files (3) 